\title{
Watering the St. Katherine Landscape: Exploring the Nexus between Socio-Economic and Hydro-Cultural Change
}

Joshua D. Lohnes

West Virginia University

Follow this and additional works at: https://researchrepository.wvu.edu/etd

\section{Recommended Citation}

Lohnes, Joshua D., "Watering the St. Katherine Landscape: Exploring the Nexus between Socio-Economic and Hydro-Cultural Change" (2013). Graduate Theses, Dissertations, and Problem Reports. 168. https://researchrepository.wvu.edu/etd/168

This Thesis is protected by copyright and/or related rights. It has been brought to you by the The Research Repository @ WVU with permission from the rights-holder(s). You are free to use this Thesis in any way that is permitted by the copyright and related rights legislation that applies to your use. For other uses you must obtain permission from the rights-holder(s) directly, unless additional rights are indicated by a Creative Commons license in the record and/ or on the work itself. This Thesis has been accepted for inclusion in WVU Graduate Theses, Dissertations, and Problem Reports collection by an authorized administrator of The Research Repository @ WVU. For more information, please contact researchrepository@mail.wvu.edu. 
Watering the St. Katherine Landscape:

Exploring the Nexus between Socio-Economic and Hydro-Cultural Change

\author{
by \\ Joshua D. Lohnes
}

Thesis submitted to the Eberly College of Arts and Sciences at West Virginia University in partial fulfillment of the requirements for the degree of
Masters of Arts
in
Geography

Dr. Karen Culcasi, Ph.D., Chair

Dr. Bradley Wilson, Ph.D.

Dr. Trevor Harris, Ph.D.

Department of Geology and Geography

Morgantown, West Virginia

2013

Keywords: Development; Capital; Water; Egypt; South Sinai; Tourism;

Modernity; Landscape; Bedouin; Culture; Mental Maps

Copyright 2013 Joshua D. Lohnes 


\author{
ABSTRACT \\ Watering the St. Katherine Landscape: \\ Exploring the Nexus between Socio-Economic and Hydro-Cultural Change \\ Joshua D. Lohnes
}

The town of St. Katherine is located in the mountainous and most water rich region of Egypt's Sinai Peninsula. This relative water abundance was a critical factor to the historical and cultural landscape that emerged there over the centuries. Past human settlements have left an intricate network of catchments, conduits and wells. Much of this infrastructure is still in use today across the hundreds of orchards that dot valley floors around this growing urban center. A pipeline has recently linked this community to the Nile River hundreds of miles away restructuring water consumption patterns throughout the area and reinforcing a sedentarization process that began forty years ago. This thesis offers a critique of this development placing it squarely within the context of a fix to the overproduction inherent to capitalist based economies. It discusses the effects that increased capital flows from the tourism industry have had on St. Katherine's waterscape. Drawing on a series of interviews and mental mapping exercises, it also challenges the hydro-development discourse in the area by reflecting on some of the ways that new water management schemes are being negotiated among the multiple stakeholders in and around St. Katherine. 


\section{ACKNOWLEDGEMENTS}

I would like to thank all of those who made the completion of this thesis possible. First and foremost I want to recognize my wife Jenna. Thank you for knowing me. Thank you for accommodating your life to my dreams even while these remain so vague.

Karen Culcasi was instrumental in shaping the contours of this work. She helped me to maintain a manageable thesis, tirelessly reviewed my writing and always offered sound advice, even beyond the scope of this project. In combination with her mentorship, I am thankful for the input of my committee members. Bradley Wilson was a constant source of motivation as his interest in St. Katherine always seemed to match my own. Trevor Harris recalibrated my over exuberance with practical methodological and writing guidance.

Thank you to my parents David and Kathryn Lohnes who taught me that relationships are always the best investment. Evie-Louise my daughter, thank you for reorienting my priorities. My pilgrimage with David De Armey led me to the Sinai, and long breakfast conversations with Philip Rizk in Cairo spurred my return to school. I am blessed to have so many other friends who listened and asked questions about this journey. Thank you to Chad Spade, Clinton Davis, Maingi Solomon, Derek Stemple and Ally Sobey, it was a pleasure going through this endeavor with you. Finally, I want to thank my friends in St. Katherine and those I had the opportunity to work with there. You have forever changed the way that I understand our world and my place in it. 


\section{TABLE OF CONTENTS}

Abstract

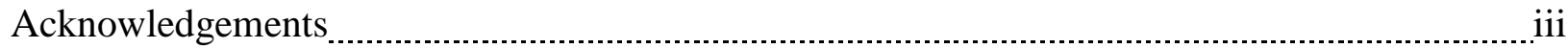

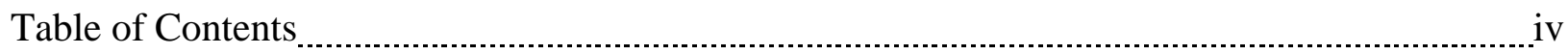

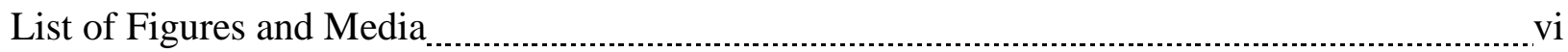

Chapter 1 - Introduction to the Research 1

A. Research Interests

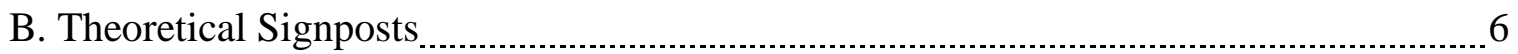

1. Water and Development Discourse $\ldots$

2. Water and the Tourism Economy ........................................................................ 8

3. Modern Water

C. Thesis Outline

Chapter 2 - Methodology $\quad 13$

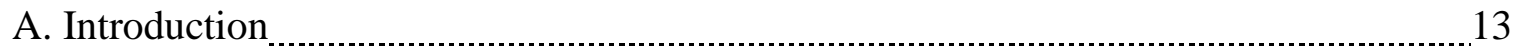

B. Methods

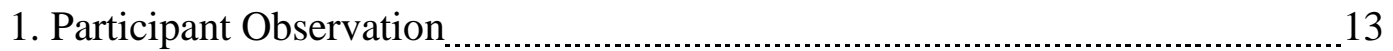

2. Formal Interviews

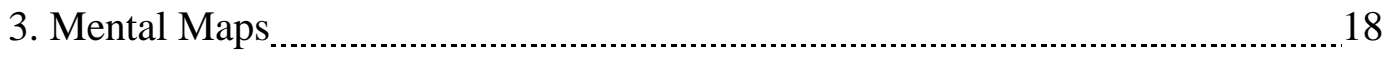

4. Landscape Analysis $\ldots$

C. Data Analysis

D. Summary and Lessons Learned

Chapter 3 - The St. Katherine Landscape 29

A. Introduction $\quad 29$

B. The Physical Landscape $\ldots$

C. The Historical and Sacred Landscape $\ldots$

D. The Urban Landscape

E. The Tourist Landscape

1. Engaging the Tourist Gaze

2. The Eco-Tourist

F. Summary $\quad 59$

Chapter 4 - Socio-Economic Transformations in St. Katherine 52

A. Introduction $\ldots$

B. The Tourism Fix

C. Pre-Capitalist Livelihoods $\quad 58$

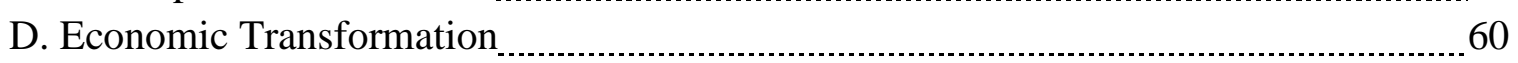

E. Social Transformation 


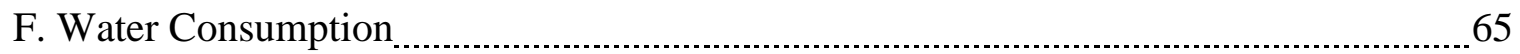

G. Summary

Chapter 5 - Hydro-Cultural Transformations in St. Katherine $\quad 68$

A. Introduction

B. Pre-modern Sourcing Strategies $\quad 71$

C. Modern Sourcing Strategies

1. Groundwater $\quad 7$

2. Nile Water $\ldots$

3. Drinking Water

4. Multiple Sourcing Strategies

D. Evolving Hydro-cultures

1. Map 1 - $\quad 82$

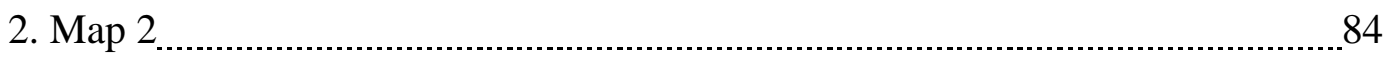

3. Map $3 \ldots$

4. Map 4

5. Map Difference as Data $\quad \ldots$

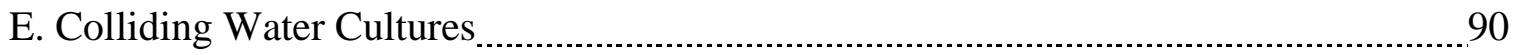

1. The entitled $\quad 91$

2. The hegemon $\quad 92$

3. The opportunist

4. The indignant $\ldots$

5. The perplexed $\ldots$

6. The rebel

F. Summary

Chapter 6 - Summary, Discussion and Next Steps $\quad 99$

A. Summary of Findings

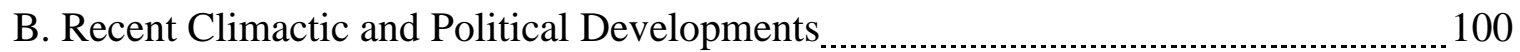

C. New Realities in Context

D. Dissemination of Research

E. Broader Impact of the Research $\ldots$

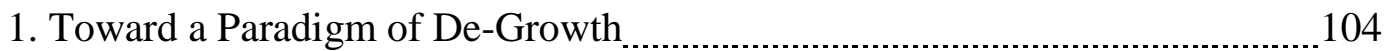

2. Implications for Future Development Critique _........................................106

F. Concluding Thoughts 107

Bibliography 


\section{LIST OF FIGURES AND MEDIA}

\section{Chapter 1}

Map of South Sinai

\section{Chapter 2}

Figure 1 (Mental Maps)

Figure 2 (Mental Maps)

Figure 3 (Mental Map)

\section{Chapter 3}

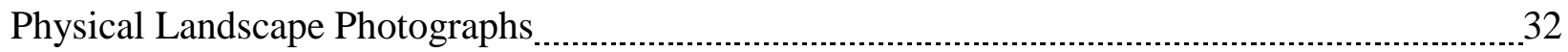

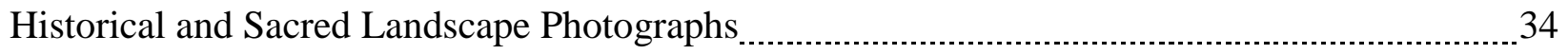

Urban Landscape Photographs

Tourist Landscape Photograph 1 1

Tourist Landscape Photograph $2 \ldots \ldots$

\section{Chapter 4}

Economic Transformation Photographs

Bathroom Transformation Photographs

Mental Map

\section{Chapter 5}

Groundwater Cross-Section

Wells Photographs

Mental Map 1

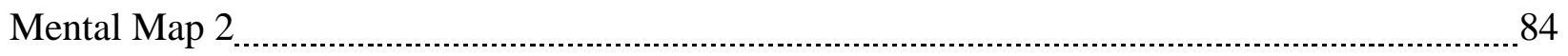

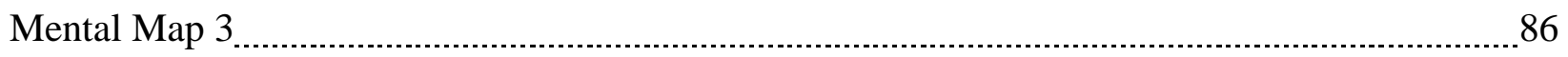

Mental Map 4 


\section{Chapter One: Introduction to the Research}

\section{A. Research Interest}

It would appear that there is very little water in Sinai's high mountains today. Waiting my turn to fill my jerry can at the most frequented communal well in St. Katherine ${ }^{1}$, the slow trickle of water stopped. The man filling his containers set the hose back in dismay. He had driven 15 kilometers from his settlement to fetch this clean mountain water "maya helwa" in arabic, and had been patiently waiting his turn. It was the first time he had ever seen this source go dry. The local waters that have maintained communities in this area for centuries are diminishing, yet cement is being mixed, gardens watered, toilets flushed and clothes washed in the growing urban center below. There is a strange irony in the fact that while area wells are low or completely dry, water is in fact ubiquitous in Katriin. How can such a contradiction exist?

The town and its surroundings offer a compelling geographical case study for analyzing the social dimensions of water specifically as they relate to the development of new economic activities. Katriin is the highest town in Egypt. At 1,586 meters it is nestled in the arid mountains of southern Sinai, the peninsula that bridges Africa and Asia. The St. Catherine monastery for which the town bears its name stands at the foot of Jebel Musa, the granite peak many believe to be the biblical Mt. Horeb, where God communicated the Ten Commandments to Moses. This place has drawn pilgrims for centuries, and over the past thirty years has become a major international tourist attraction. The area is endowed with relatively rich surface and groundwater that have supported human activities there for centuries ${ }^{2}$. Today Katriin attracts people from around the

\footnotetext{
${ }^{1}$ I will be employing three different spellings of this place name to differentiate between, the UNESCO bounded landscape (St. Katherine), the city (Katriin) and the monastery (St. Catherine)

${ }^{2}$ Archaeological evidence supports the presence of an ancient Egyptian turquoise mine as well as the presence of Nabataean settlements from the 4 th century B.C.
} 
world generating income for the tangled layers of the tourism industry and furthering development goals in the region. With a current population of around 6,000 Katriin is a multicultural mix of Bedouin, Nile Valley migrants, Greek Orthodox monks and expatriates, all of whom have a very different relationship to the place and the waters upon which their presence there depends. A twenty year drought, which was recently broken, coupled with the increased demands on water wrought by the tourism trade has led to community tensions over its allocation and use. The aim of this research project is to explore local perceptions of water's function in St. Katherine specifically as it relates to the nexus between recent socio-economic and hydro-cultural changes taking place there.

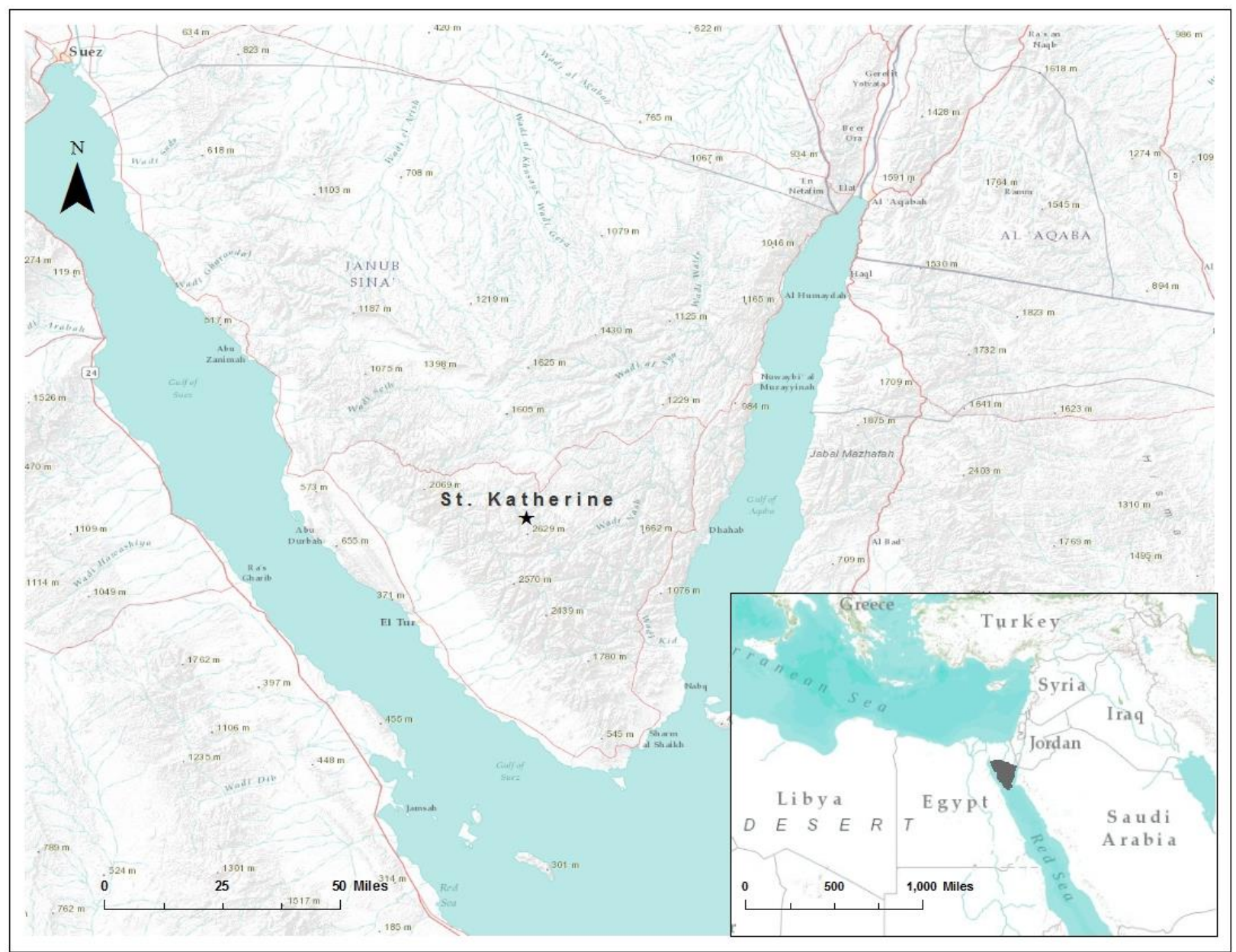

Map of South Sinai 
As in most places, water in St. Katherine serves many different functions. It feeds kitchens, showers, toilets, irrigates landscaped green spaces across town. Hotel owners use these water intensive luxuries to entice guests accustomed to such comforts. Increasingly residential homes are being built with these new luxuries as well. Water delivered by truck, in bottles and more recently through pipes is needed for a myriad of other activities that make up daily life and business in St. Katherine. The sale of bottled water is a lucrative income stream for both transnational bottling corporations and their local resellers. Most homes and businesses are dependent on water deliveries from trucks. A pipeline financed by the European Union was completed in October 2011 linking the town to the Nile River in support of the Egyptian government's wider economic development goals in the region. Yet, in the midst of these 'modern sources', there are still approximately 400 wells within the St. Katherine protectorate that are used in different capacities such as irrigation and livestock.

I became interested in the role of water within St. Katherine's changing landscape during my 15 month stay in St. Katherine from October 2007 to December 2008. I was there working on a European Union funded development project, the South Sinai Regional Development Program (SSRDP). A $€ 64$ million investment, this money was aimed at increasing the capacity of the tourism industry in South Sinai while maintaining social peace among local residents, many of whom are feeling excluded from the wealth generated by this sector. Working for three Bedouin grant recipients, my role was to market desert mountain excursions to European tourists. Part of this job involved mapping multi-day hikes around South Sinai. I walked hundreds of kilometers encountering people and places that had not been connected to the network of pipes, roads and water trucks that the town of Katriin now enjoys. 
The Sinai had not seen its usual winter precipitation over the past twenty years and water availability was always a major topic of conversation during my time there. I met engineers, contractors and consultants who were in town for short periods working on the Nile pipeline project. They all claimed that St. Katherine had a water scarcity problem and that it was important to pump water to the area to support the needs of businesses and residents there. I met people who owned their own wells and lived self-sufficiently on local water, but the vast majority of Katriin residents were highly dependent on water deliveries from the Egyptian government, who subsidizes $95 \%$ of its cost. Personally, I often had to purchase overpriced bottled water from local vendors to quench my thirst. As a resident, I became keenly aware of the commodification of water and the daily tensions surrounding it.

Tourism, and the cash economy it generates, is a powerful force shaping this landscape and overtaking the agro-pastoralist way of life and changing consumption habits that had maintained livelihoods in the region for millennia (Marx, 1980; Hobbs, 1995). Socio-economic transformations among area residents (Lavie \& Young, 1984; Perevolotsky et. al, 1989; Gilbert, 2011) are leading to environmental degradation (Hesham et. al, 2003, Grainger \& Gilbert, 2008). My conversations with now sedentary Bedouin ${ }^{3}$ often centered on a past that no longer existed and an apprehension about what their future held. Their concerns are not unique, Bedouin are present in all seventeen Arab States in Southwest Asia and North Africa and all are undergoing various degrees of social, economic and political change as new occupations are becoming available and their kin-based identities are confronted within the wider state systems in which they exist (Cole,

\footnotetext{
${ }^{3}$ The Bedouin are a desert dwelling people of Arab descent present across North Africa and Southwest Asia. They are known as nomadic herders although some engage in small scale agriculture, fishing, or the transportation of goods and people. There is a socio-economic and political gulf between many Bedouin and today the term is highly contested. While some have acquired great wealth and global influence (the Saud family ruling Saudi Arabia being a case in point), many tribes have been confined within artificial territories and feel marginalized because they do not receive the full range of services offered by the state.
} 
2005). An anthropologist born and raised as a Bedouin in Syria speaks of Bedouin culture today

as:

not one of simple and total transformation, but rather of an ongoing dialectic of continuity and change, an interplay between tradition and modernity. They are adjusting their material and political life to rapidly changing modern conditions and yet they continue to respect and adhere to a range of traditions that help them define and perpetuate their ethnic integrity, their Bedouin-ness (Khalaf, 1990, 241)

I found this dialectic unfolding in St. Katherine. Most Bedouin there are integrating the tourism economy and adapting their lifestyles to its mold, although they feel that complete dependence on tourist income is not prudent. Concomitantly, there is an increased reliance on government subsidized water deliveries even as many lament the lack of water necessary to maintain their previous livelihoods.

My own involvement within the SSRDP economic development apparatus, provided me with a privileged perspective on some of the changes taking place. My role was to act as a bridge between the various tourism related interests operating in the community. I became keenly aware that there was a relationship between water and tourism development. After leaving St. Katherine, I felt compelled to explore this issue further. While a number of scholars have engaged with the cultural effects that tourism has had in the Sinai (Hobbs,1992; Shackley, 1998; Jacobs, 2010; Hosni, 2011), none have explored the specific link between the production of the tourist economy and the changing social relationships surrounding water there.

I returned to St. Katherine for two months in the summer of 2012 to research water's function there in much more depth. Through the use of participant observation methods, landscape analysis, interviews and mental mapping exercises I worked to understand how businesses and residents in St. Katherine used water every day, where they sourced it from and how they understood the tensions that were playing out surrounding its wide ranging uses. I conducted 35 informal 
interviews and 14 formal ones with a variety of social actors, conversations which helped me understand views from a range of stakeholders in this multicultural town.

In order to provide a framework from which to understand how water has played a role for the people shaping this place over time, my study focuses on the St. Katherine landscape. Understanding the landscape helps us appreciate that the people view it from different perspectives. Egyptian elites see Katriin as a politically strategic and economically expedient settlement. Foreign tour agencies see it as a financially valuable component of the vacation packages they sell. Tourists see it as an opportunity to step into a rich cultural past. Local residents caught within these rapid changes succumb to the struggle to extract a daily living wage within the banalities of a place they had little choice in occupying and would now have difficulty leaving. Tensions between the many actors involved in fashioning this landscape can be made visible by looking at the resource required to maintain the seemingly normal state of affairs: in this case water.

\section{B. Theoretical Signposts}

Water research tends to focus on questions of quantity (Allan, 2002, Gleick, 2011) and quality (UNHSP, 2003) at the expense of an analysis of its function toward furthering economic development goals. My research contributes an alternative and critical inquiry into the nexus between water and development by examining the multifaceted relationship that St. Katherine residents have to water's changing function there. I argue that the introduction of a capitalist tourist economy through top down and one sided development initiatives is re-ordering social relations and altering hydro-cultures in St. Katherine, transforming what was a fluid resource into one that must now be controlled and fixed in place. To support this argument, I draw on a varied body of 
literature. What follows are theoretical signposts, each of which are revisited in greater depth in conjunction with my analysis throughout the thesis.

\section{Water and Development Discourse}

In his seminal work The Rule of Experts, Mitchell (2002) reveals how the modern discourse of economic development was shaped in Egypt, as the productive capacity of Nile waters came under the European gaze in the early 19th century. His argument is that the economy, as it is perceived today, has been fabricated to serve a neo-colonial system that protects the interests of a narrow set of actors and institutions. The production of economic discourse, he continues, must create a seemingly tangible object whose evolution can be rationally analyzed and predicted. In Egypt's case, the economy is framed as resource poor and topographically desperate case of overpopulation along the Nile whose desert peripheries must be made productive by channeling water there. The Sinai is one such territory, where water is inextricably linked to a particular idea of development, one held by a powerful set of 'experts' who want to see their financial and political projects come to fruition.

The South Sinai Tourism Development Plan (2008) stated that "there is an urgent need to diversify sources of water supply and to improve sanitation services in the St. Katherine region. The lack of basic infrastructure deters additional investment in accommodation and other tourist products and affects local populations as well" (P.A. Consulting, p.227). As development theorists before me have argued (Scott, 1995; Escobar, 1995; Rahnema \& Bawtree, 1997; Mitchell, 2002; Peet \& Harwick, 2009), a key component of economic development policies is the dismissal of indigenous knowledge that does not neatly fit within the growth paradigm. By highlighting some

of the stories that are not currently being told about St. Katherine I present what Escobar (1995) has described as hybrid negotiations of development. Urging researchers to seek out alternative 
manifestations of the development encounter in local settings he claims that "the deconstruction of development, coupled with local ethnographies, can be important elements for a new type of visibility and audibility of forms of cultural difference and hybridization" (p. 225). My study responds to his call. It centers on discussing the many different ways that residents in St. Katherine are negotiating the introduction of a new water management system, exposes some of the conflicts that it has created, and situates it within the context of capitalist driven development initiatives there. My analysis of the different perspectives on water's function within the contemporary landscape help demonstrate that ideas about this resource are more nuanced than the normative development discourse would lead us to believe.

\section{Water and the Tourism Economy}

Initiated in the 1990s, the National Project for Development of Sinai is one of the largest development initiatives in Egypt with investments reaching upwards of $\$ 10$ billion. The project was meant to attract three million people to new urban communities and provide around 1 million job opportunities there (Ali, 1998). In the South Sinai governorate, tourism is the vector through which these development goals are achieved. The growth of the tourism sector there has been astounding. Tourism is the leading foreign exchange earner in Egypt and a crucial industry for a state which owes over $\$ 30$ billion in external debt. Mount Sinai and its surrounding landscape provide a unique cultural attraction and sense of historicity to a South Sinai region increasingly known for the 'sun, sand and sea' resorts lining its coasts. St. Katherine has become a key part of wider tourist destination networks in Egypt, Jordan and Israel. A combination of public and private investments has undergirded this growth, all of which have been completely dependent on the availability of water to provide a profitable return. 
Building on David Harvey's (2001) theory of the spatial fix, I discuss the way tourism has created a particular space for itself in Sinai's mountains. St. Katherine is a spatial fix in that excess capital is being reinvested in a previously unexploited geographic location, and the commodities being consumed there are transient events, a tourist's experience of the place. Tourism is one of the world's largest industries and has become a major vehicle for transnational capital flows (Britton, 1991; Hazbun, 2008; Fletcher, 2011). In St. Katherine, hotels, restaurants, souvenir shops and trekking companies all employ a labor force increasingly dependent on a steady flow of visitors. Capital injections and the new forms of accumulation that they seek have "incorporated resources, people, activities and lands that hitherto were managed, organized, produced under social relations other than capitalist ones.” (Swyngedouw, 2007, p. 52)

Katriin's urban water reach today extends over vast spaces and is predicated on a series of ecological conquests in direct relationship to the city's growth. The capital necessary to support this sprawling water system must be generated by producing something that can be exchanged for money, in this case the tourist experience itself. Swyngedouw's (2006) research on the urbanization of water in Guyaquil, Ecuador has demonstrated how water becomes entrenched in the international divisions of labor. As people migrate to St. Katherine to be closer to income generating opportunities, most have become disconnected from their traditional water sources.

Water is now often discussed in the same breath as money, cash that must be earned through wage labor in order to afford its continued flow.

\section{Modern Water}

Jamie Linton (2010) has argued that the collusion of water experts has served to construct the idea that water should be thought of and managed in terms of abstract quantities (abundant or scarce) in particular places rather than through the social relations that give it its meaning there. 
The global water crisis, he argues, is really a crisis of modern water and the herculean attempt to maintain the economic productive capacities to which so much of the world's fresh water has been put to use through our large scale interventions with it. Linton stresses that we can no longer afford to ignore water's ecological, cultural and political dimensions especially "as marked by the distribution of economic benefits and affordances associated with particular modes of water governance.” (p.7)

St. Katherine residents are negotiating a hydro-cultural shift from "pre-modern" to "modern" water. I use the term "hydro-culture" to refer to both the material inputs required to access water and the habits surrounding its consumption on an everyday basis. Pipes, tanks, pumps, trucks, bottles and dams have become key components of St. Katherine's waterscape. This hydro-cultural shift began in the 1970s when Israel drilled the first deep water wells to support Katriin's emergence as an urban center and has culminated with a $€ 34$ million water pipeline infrastructure project completed in 2011. The shift toward modern water inevitably creates tensions in a community whose very identity is wrapped up in the historical precariousness of its availability.

Modernity is of course a contested idea, and while my work is not a philosophical treatise on what constitutes 'modern', qualifying my use of the term is important. I do not want my use of the concept to imply that there exists a binary between a static pre-modern condition and a new, dynamic or modern one. Such a division would reinforce false notions of linear development and 'progress' that have for too long been invoked to compel so called 'primitive' societies into becoming 'civilized' ones. I am using the word modern here specifically as it relates to technological change. Thus any reference to pre-modern water are those systems that use exclusively local water, accessed mostly through muscle power via shallow wells. Modern water on the other hand involves transporting water over long distances, or accessing it from deep wells, 
using inputs from fuel based energy systems and a variety of equipment only available with the advent of mechanization. I am also careful not to romanticize a past that will never exist in the present. It is my hope that my thesis will serve as a critique of ideas on either extreme. Negotiations of modernity have been taking place across time and place for over two hundred years and what has emerged in St. Katherine over the past forty years is but one of countless hybrid manifestations of this process. I will be arguing that St. Katherine residents are negotiating the shift toward modern water in different ways: some embrace it, others reject it, and most lie somewhere in between those extremities on a wide spectrum of sourcing strategies.

\section{Thesis outline}

My thesis consists of six chapters including this introduction. Chapter two will discuss the success and limitations of my methodological approach along with a brief reflection of my research. Chapter three analyzes St. Katherine's landscape, emphasizing the role water has played in fashioning the place. I discuss how the physical, historical, touristic and urban landscapes have fused to create the contradiction that while local water availability is diminishing, the growth of an urban center there continues apace. In chapter four, I retrace the introduction of capitalist modes of production via the tourist trade and discuss ways in which this has altered socio-economic relations and reordered the way water is used and managed in St. Katherine. Chapter five posits that new social relations have contributed toward a shift in hydro-cultures as modern means of accessing water are imposed on residents who have been disconnected from their traditional sources. In this chapter, I describe traditional mountain sourcing strategies and compare them to today's urban water deliveries to explain how engagements with the transition toward modern water are varied and contested. Ultimately, this thesis demonstrates that water holds deep seated 
ideological meanings that should not be shunted aside, but seriously considered in any future hydro-developments in the area. 


\section{Chapter 2: Methodology}

\section{A. Introduction}

The data that I draw on for this thesis was collected using a mixed methods approach over a two month period in the summer of 2012, though it also builds on my 15 months living in St. Katherine and a two-week visit in November 2011. Semi-structured interviews, heavily focused on mental mapping exercises, served as my primary data source. I was also a participant observer, recording informal conversations and personal reflections as daily journal entries. Interviews and research notes were transcribed and mental maps scanned into the Atlas.ti coding software, a qualitative data analysis tool. Landscape analysis provided the overall frame for interpreting my findings. Each method contributed to different portions of my analysis, but are amalgamated into one narrative throughout my thesis. The many intersections of this mixed methods approach provided unique and valuable insights into water's function in St. Katherine. For example, understanding the landscape helped me better appreciate the mental maps, and participant observation led to more constructive interviews because I understood the social context within which I was asking questions. This chapter offers a summary of each research method and then deliberates on the success and limitations of my methodology, including data collection and analysis.

\section{B. Methods}

\section{Participant Observation}

On May $21^{\text {st }}$, 2012 I stepped off of the Cairo - St. Katherine bus with my wife and one year old daughter. I had arranged lodging for us in Katriin with my former employer, but otherwise few people knew of our arrival. I had visited six months prior to reconnect with the place and assess 
the viability of my proposed research after nearly three years of absence, and had told my contacts then that I hoped to return in the summer months with my family. 'Insha'Allah' was always the answer I received, God willing. Katriin is a transient place. Tourists (sayeh') come and go, some staying longer than others and many Cairenes (masrii) working as civil servants or in the tourism industry stay for a just a few years before moving on to other opportunities. Foreigners (ajnabi) that settle in town for purposes other than leisure link themselves to the community in numerous ways. These are mostly Europeans who have decided to semi-permanently settle, establish businesses, work with NGOs or develop their own projects. Most foreigners come and go weaving themselves in and out of St. Katherine's landscape and social life. They are welcomed for their contribution to community, but still do not fully integrate into many spheres of private life in Katriin. That I had now returned as a family man opened up new spaces from which to strengthen the friendships that I first forged as a bachelor in 2007. We were invited into many homes and took part in family activities that I had not been privy to before. As a result my engagement with the community was strengthened and I was able to better understand different social dynamics that were unfolding there. My family was about to enter those dynamics for the next two months. As our presence in town came to be felt, we became more and more involved in its daily routines and relational dramas.

I am simultaneously an insider and an outsider in St. Katherine. Unlike most visitors that cycle through the place, many people know who I am or have heard of my work there. I established many lasting friendships and many more acquaintances between October 2007 and December 2008 while working to market desert and mountain excursions to European tourists. I know the landscape well and have a fairly developed understanding of the social dynamics around town. I speak enough Arabic to surprise those who don't know that I do, yet not enough to make myself 
fully understood. I remain an obvious outsider from whom much is still hidden, but am also a partial insider who is able to see and hear things that might not be revealed to other foreigners.

While it is difficult to speak to the ways in which I was perceived by the St. Katherine community, my previous involvement within the development sector may have had an impact on the research that was collected during my fieldwork there. My family was lodging in the same flats that I lived in when I was working for the E.U. funded project. These were built by one of the most influential Bedouin business owners in town. He generously offered to let me stay there free of charge. Though his support helped me through police checkpoints and other administrative hassles, it may have preconditioned the community's idea of why I was there. One of the first questions that I was always asked when reconnecting with people in town was what my business back in the area was, many assuming that I was still linked to the tourism sector. I would always frankly answer that I was there to research water in St. Katherine, and that I was now employed by an American university. This often sparked additional interest as to the exact nature of my work in the U.S. and the research itself. When I explained that I wanted to learn more about the ways in which water was connected to the town, to tourism, and how the Nile water was changing life there, I most always received invitations to discuss the issue further.

My position bridging the insider-outsider dichotomy placed me on the margins of the St. Katherine community. Because I was present without fully belonging, I found myself in a position to question water differently than a complete stranger or long-term resident would have. For example, I was an outsider when it came to discussions about water shortages. My tank at home was always full and securing domestic water on a daily basis was never a concern. I did not own a well that had gone dry. I never had to deal with the water company. Such experiences were outside the realm of my understanding, but not beyond observing and questioning. On the other 
hand, knowing the landscape and being able to discuss the whereabouts of the best drinking water, who owned which gardens and how many meters they had to dig to access water in their wells provided me with a valuable foundation from which to observe and question water's function in the production of St. Katherine's landscape.

During my first three weeks of field work I explored the question of water informally via conversations about my presence back in town, observations on water's use and the infrastructural changes that had taken place since I had been a Katriin resident. I felt it was important to reestablish connections with potential research participants and re-familiarize myself with the local context and language. Interviews are of course very social situations imbued with particular dynamics. It was of critical importance to me that these be performed in a way that disrupted everyday life as little as possible. For example, my first interview was conducted with a participant with whom I had had three visits ${ }^{4}$ prior to engaging with him in a more formal (ie: recorded) setting. We spent these times discussing, not only water issues, but work, family, marriage prospects, Egyptian politics and changes in town since I had last seen him. My goal in performing more formal interviews over the latter half of my stay, after I had somewhat normalized my presence in town again, was to develop familiarity and conviviality through my involvement with the flow and spontaneity of everyday interactions (Evans, 1988). I should note that not all of my interviews could fit within such social continuity and a few of them were much more abrupt, with very little rapport having been built between myself and the research participants.

As a participant observer, I not only established trust and rapport, but also examined social interactions within the landscape. I maintained a daily journal, recording 35 informal interviews, and many observations and conversations. This routine served to shape my understanding of

\footnotetext{
${ }^{4}$ A preliminary visit with my participants always entailed tea and often a meal. These would often last an entire morning or afternoon.
} 
water's function in St. Katherine a little further each time as I reflected on day to day discussions I was having about water, particularly as they related to socio-economic change. My formal interviews were critical in providing empirical data for the findings I present here, but these were enriched through participant observation and the journaling exercise.

\section{Formal Interviews}

I conducted 14 formal interviews all of which involved mental mapping exercises. These interviews were pre-arranged and audio-recorded. For its small size, the town of Katriin has a very diverse population, and my sampling attempted to reflect the multi-layered social fabric of the town. Traditionally women and children sourced water for the household and it would have been helpful to understand what effects the shift toward urban water has had on household economies in greater depth, particularly as it relates to gendered labor. While I had many conversations about water with women, the social context made it difficult for me to arrange formal recorded interviews with them, and I readily acknowledge the limitations of a heavily male-centric perspective on water.

Because Katriin is a tourist town, many of its residents speak English as a second language. I conducted nine of the interviews myself, eight of them in English and one in Arabic. I hired a research assistant over two separate days to help me translate and arrange four interviews with key participants that I would not have been able to access myself such as water company and government employees. These interviews, again, were supplemented by many informal conversations I had (both in English and Arabic) about perceptions of water in and around Katriin.

My interviews were semi-structured. I had five primary questions for each participant.

1. Where do you get your water from?

2. What do you use this water for?

3. How do you use water in your work?

4. How much water do you think you use every day? 


\section{Why is water important to you?}

As my interviewees answered these questions, I posed follow-up ones as necessary based both on their responses and the knowledge I was acquiring from past interviews and my participant observation work. Each primary question often led to multiple others and so every interview proceeded somewhat differently based on the responses received. Our conversations lasted 45 minutes on average and served to frame the discussion that would ensue as we proceeded to the mental mapping exercises.

\section{Mental Maps}

The second half of the interview was focused on the participant's spatial understanding of water in St. Katherine. Emerging in the 1960s as a tool to elicit a person's conception of their urban environment, mental mapping provides a physical illustration of the way people perceive their spatial realities (Tuan, 1975, Pocock 1979, Bailly 1987, Kitchin 1994). I drew my inspiration for this portion of my methodology from the work of Bjørn Ingmunn Sletto (2009). His research with communities in Venezuela and Trinidad demonstrated how the process of reflecting, imagining and then drawing a map is itself a form of story-telling, one that can explain and complement information received during an interview. Sletto's application of mental mapping methods brought "contests surrounding rights, identities and authenticities to the fore and simultaneously [facilitated] the unveiling of multiple complex relations of power that shape the production of local-global landscapes" (p.446). My application of this same method in St. Katherine confirmed that transferring this exercise in a different case study could yield unique insights into spatial perceptions of the transitions toward modern water currently underway across St. Katherine. 


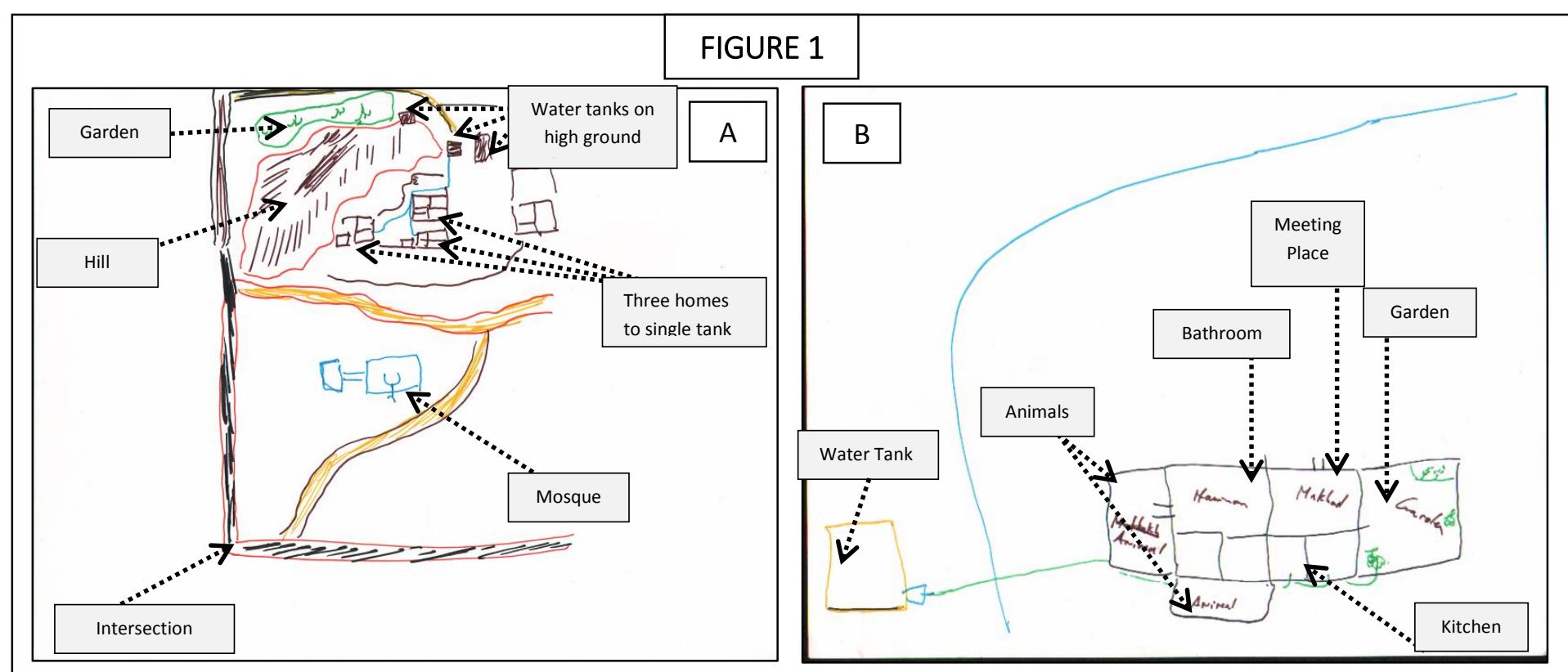

These maps were both drawn as a response to the same exercise about water in the home. Participant A chose to include a neighborhood, the asphalt road intersection on the bottom left and the dirt roads intersecting around the community mosque. His water tank is shared among three different households. His garden is behind a large hill, and has its own separate water tank. Participant B, who does not share a water tank with any other homes, drew his map at a larger scale. The asphalt road on this map is a thin blue line likely only there to show that the water pipe coming from his tank (green line) must intersect the road. The larger scale provides more detail about the way water is used in the household, while the smaller scale provides information about water relations within and between members of different households. The particular situation of each research participant conditioned the map that was drawn.

Note: The arrows and gray shaded boxes are my own annotations to the map

After completing the interview questions, research participants were asked to draw two different maps for me. I would provide them with six colored markers along with a sheet of drawing paper. On one side I asked them to map the home or business in which the interview was taking place, and then highlight all of the places water was used there. On the other side, I asked them to map the sources of that water, and how it got to their home or place of business. The exercise was originally conceived as a tool to elicit water's function in St. Katherine at different scales, but the maps helped me visualize much more than scalar dimensions and offered multiple perspectives on the waterscape. As I detail below, the images drawn by participants revealed facts that I would not have gleaned any other way, and prompted follow-up questions I would not have 
come up with unaided. What people chose to include or exclude was instructive as well (see fig. 1).

I had the opportunity to interact with the map as it was being drawn which often spurred discussions well beyond the end of the formal interview. At times bystanders would also begin interacting with the drawing, and on one occasion this led to new information for a third-party, who then invited me to interview him as well so that he could explain his views about water in town. Some participants narrated the strokes of their drawings while others remained silent for the duration of the exercise explaining their maps to me once it was complete. Either way, watching what emerged on the page was always fascinating and often challenged my own concepts of my participants' day to day interactions with water. This included everything from the infrastructure channeling water to their home or place of business, the institutional contexts surrounding its allocation, and contests over the capacity that different social actors had to access water.

I was surprised by how many of my participants focused especially on domestic water used for washing, toilets, animals and gardens. Drinking water was often not represented at all on the maps, whereas in my own experience living in the area this was a critical component of daily life in town. I never had to be concerned about the supply of domestic water because my landlord and host, a powerful and well-connected individual in the area, was always able to provide enough for me. The fact that so few participants focused on mapping their drinking water was an indication that my interview questions should lean toward an emphasis on understanding why domestic water was being represented so much more prominently than drinking water sources. The maps and interviews were thus a recursive process, each informing the other and serving to reorient my approach as the weeks of field work moved on. 
The mental mapping method also challenged my own cartographic biases. The following exchange provides one clear example of the ways in which the exercise disrupted my previous cartographic assumptions. As one of my participants drew a blue circle around his property he asked:

- A.S.: Do you know why I am using this (blue pen)?

- Me: Blue is for water right?

- A.S.: No, for peace!

I had been pre-conditioned to think about maps in a particular way. Through years of interacting with standardized 'scientific' maps that symbolize rivers, lakes and oceans with the color blue, I embarked on this exercise associating blue with water. Because of this assumption I encouraged my first few participants to use the blue marker that I provided to symbolize water flows through Katriin and into their homes. Somewhat to my frustration, neither of them followed my recommendations. Instead, one drew the entire map in blue, and another drew both the road and the pipe channeling water to his home in blue: what I thought at the time to be a most unhelpful differentiation. As I reflected on the process further, however, I began to understand that rather than influence my participants toward particular colors and symbols that worked for what I thought I wanted to see, I should instead open myself up to what Kitchin and Dodge (2007) refer to as a “de-ontologized cartography" (p.334). I had to accept that rather than representing space, my participants were "bringing space into being" (p.339) through their drawings, revealing important nuances in their personal perception of the landscape in the process.

Maps are not a part of everyday life to most of my research participants, so explaining the mapping exercise was always the most challenging part of the interview. One of my interviewees wondered if "they were the best person to ask" to draw a map, while others did not understand what I wanted at all until I rephrased my request to propose that they "draw me a picture" (sura). 
One participant did not feel comfortable with the exercise and asked her daughter to draw instead.

Even a government official who dealt regularly with maps for his work had a hard time with my request.

- Me: [...] I would like you to draw a map for me of Katriin, or the protectorate or whatever it is that you think is important after this conversation. Draw me the story of water in Katriin, do you understand?

- N.P: No I don't understand.

- Me: If you give me a map and it's an official map that's one thing. You say here are the wells, this would be good for me to see of course. But what is also good for me to see is how different people are thinking about water, and drawing it for me tells me the story of where you see the water, where it is coming from, maybe where the problems are, where the important places are for water. You understand? It can just be lines, or it can be drawings or whatever you want. And I have different colors for you. Use one, use six whatever you want.

I had to work toward finding a balance which would provide enough instruction to complete the exercise, yet remain vague enough to not explicitly influence the form that the map would take. While my requests for sketches were often met with a sense of confusion, participants eventually seemed to enjoy the activity once it was underway and they realized that it was only a vehicle toward spurring further conversation. I tried my best to explain that their maps helped me to "see what they see". Some provided intricate and multi-colored detail, while others were satisfied presenting their view of the subject with a few monochrome lines.

Some maps were surprisingly identical to one another (fig 2), but this was revealing in that it demonstrated a definite pattern in the way people interacted with water in the community. 


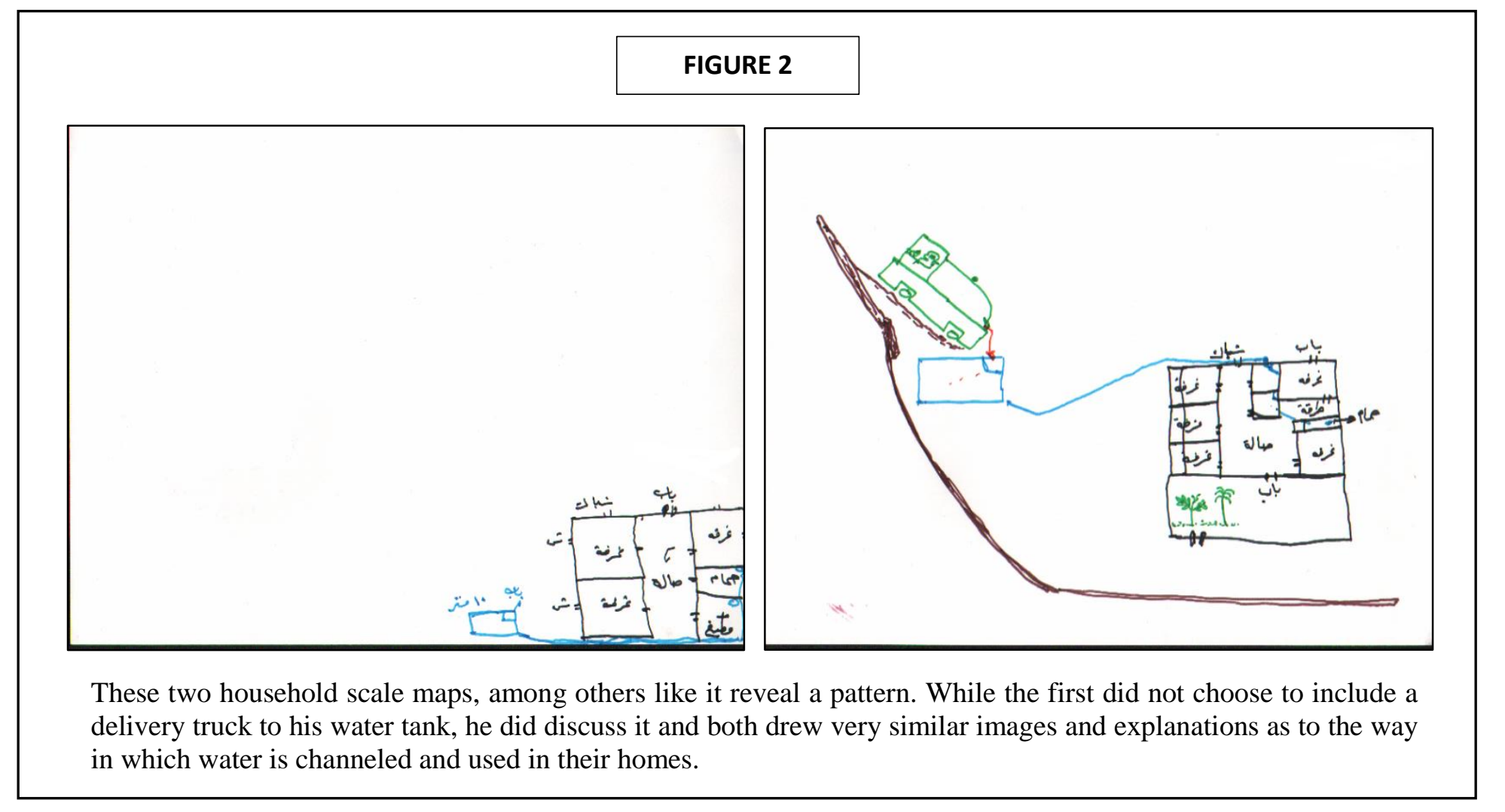

After each mental mapping exercise, I always learned at least one new detail about water in St.

Katherine. Figure 3 is one of the simplest maps that was produced, but I was able to collect some valuable information through my mutual interactions with it and the 'cartographer'. We had previously discussed how the family always ran out of water and that they often had to ask their

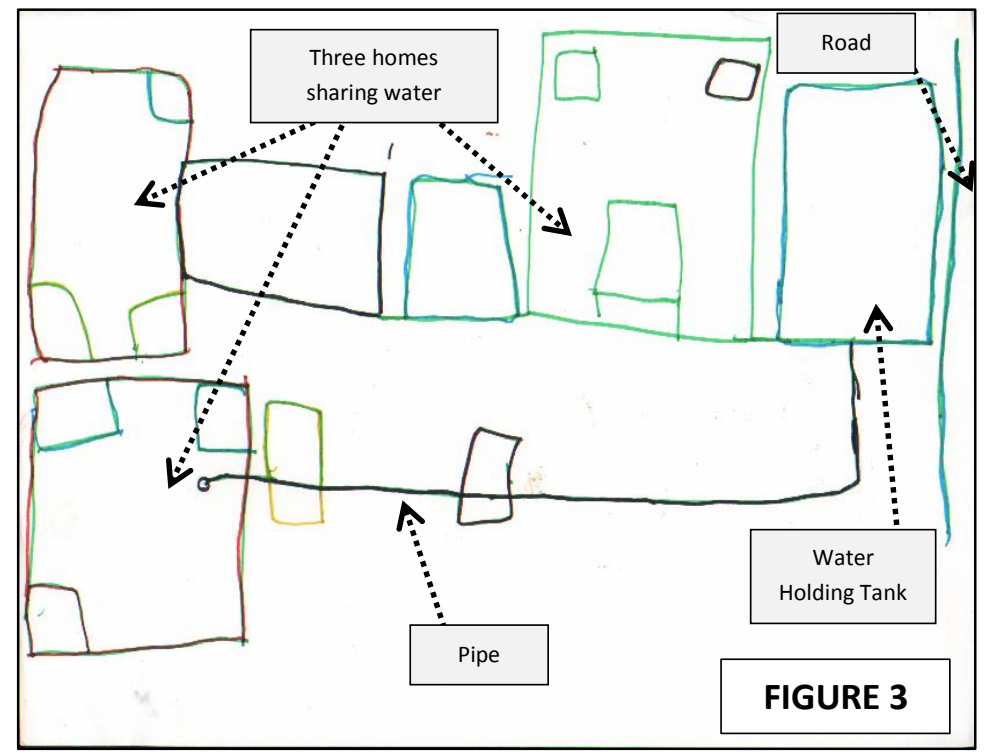

neighbors for water. When I visualized the problem, that one water tank was feeding three large households, I asked why they did not just construct another tank and get water deliveries to that one as well. The interviewee explained that each 
electric meter is associated with one water tank to facilitate billing from the central water company. Because the three homes were sharing an electric meter, they also had to share the monthly water ration. This turned out to be a very important fact toward building my argument that St. Katherine is transitioning toward modern water, one I would not have discovered had it not been for supplementing my interviews with mental maps.

Researchers can easily make false assumptions about what they are hearing or seeing in the field. Using mental maps as an interactive visualization technique served to narrow that gap for me in St. Katherine. These maps provided a direct form of engagement with the different perspectives that each participant brought to bear on the way water is circulating through St. Katherine.

\section{Landscape Analysis}

The St. Katherine landscape is one of stark contrast. Watered green spaces stand out against the reddish brown desert surroundings. Thousand year old structures are juxtaposed with contemporary buildings. Asphalt roads give way to narrow footpaths. Camels share space with pickup trucks. Hotel restaurants and souvenir shops contend with falafel stands and mobile phone stores. Walking through this landscape, I recorded my impressions of it especially as they related to hydro-cultures there. But just as important as what I saw in St. Katherine are the invisible processes behind its historical and present-day production. To uncover these hidden features, I draw on secondary archival research including travel accounts, articles, photographs and development reports to reveal the social relations that have driven its material production. Chapter 3 is dedicated to my landscape analysis, and provides an in depth overview of the framework through which the primary data I gathered during the research process is filtered. 


\section{Data Analysis}

The data from both my interviews and mental maps was analyzed using Atlas.ti, a computer aided qualitative data analysis software (CAQDAS). After uploading my transcriptions, I developed a detailed code book within the program. I created 117 individual $\operatorname{codes}^{5}$, with 47 of them having over 10 references each. 12 codes had over 20 references, these were:

$\begin{array}{lll}\text { Mountain water }-54 & \text { Transportation }-34 & \text { Consumption - 24 } \\ \text { Money }-46 & \text { Nile Water }-31 & \text { Moral Economy - 22 } \\ \text { Gardens }-41 & \text { Tourism }-26 & \text { Bathroom - 20 } \\ \text { Wells }-39 & \text { Trees }-26 & \text { Production }-20\end{array}$

While these codes were very broad in scope, each was linked to others using various functions within the application itself. For example, 'Money' was linked to 'Hotels', 'Nile Water' to 'Development' and 'Bathrooms' to 'Water consumption'. Once coded individually, quotations were also grouped into larger code families. The family code 'Modern Water' for example included 15 single codes ('dams', ‘drilling', ‘pumping', 'pipes', ‘subsidies', ‘tank', 'transportation', 'privatization', etc.), which when analyzed together helped to quickly sort through relevant themes both within particular interviews, and across my data as a whole. Different search functions (by code, keyword, and association) allowed me to recall particular pieces of conversation and call up relevant texts and maps as needed.

One drawback of using this software was the sharp learning curve associated with it. I spent considerable time understanding how to use the various functions available and determining which would be of value. I would often begin with a particular exercise only to realize that it was not leading toward any new information, but rather categorizing my data so minutely that I was at risk of losing my focus on the broader scope of my research questions. If I were to start the research

\footnotetext{
${ }^{5}$ These are my own categories. Codes were not pre-determined prior to engaging with the data but rather developed as I interacted with my transcribed interviews and maps in the Atlas.ti software.
} 
process over, I would have taken the program with me in the field, and uploaded my interviews and mental maps as I progressed with my interviews and research notes. Many categories that seemed stable and secure at the beginning of my analysis are no longer so now that I have combed through my findings multiple times and I am left wishing that I could ask some of my questions differently.

Qualitative research is a recursive process to be sure, one in which constantly interacting and revisiting data is paramount. The data analysis portion of this project continued to change my understanding of the water flowing through St. Katherine. Amalgamating all the different pieces of data that my mixed methods approach generated was a time consuming but valuable process. Put through the theoretical prism that I was continuing to develop via my readings eventually brought a concrete set of thoughts into focus, the result of which is this thesis. The most trying portion of the entire process was deciding what pieces of data to exclude from the analysis, letting go of the noise surrounding the main theme and honing in on the points that supported the conclusions I was coming to. I still have a hard time accepting the fact that there is original research not reflected in these pages, but am comforted by the idea that this will provide me with future opportunities to transform it into something of significance.

\section{Summary and Lessons Learned}

I arrived back in St. Katherine's for my field work with a particular agenda, needing to implement a research proposal that in and of itself was a long deliberative process. This was my first time conducting research professionally and I wanted to 'do it right'. I came prepared with my own ideas about what that meant, all of which were slowly changed over the course of the summer. My plans to interview very specific social actors, and be statistically fair in representing 
the waterscape's different stakeholders did not come to fruition. This was not possible, due to a variety of factors including lack of time, money for translators and the political balancing act that it would involve. Eventually I realized that the categories I had set out to represent were my own biased constructs of the social dynamics in St. Katherine.

I don't believe I could have come to the conclusion that socio-economic transformations are realigning hydro-cultures in St. Katherine, without approaching this work as a participant observer. Having been an embodied part of the St. Katherine landscape, contributing to its production (the apartment I lived in was specifically built to house me), and developing friendships and trust with the people residing there was a critical component of my methodological approach. Formal interviews always felt somewhat intrusive to me, and I kept wishing that there was a way to gather all of my data solely by recording informal conversations and observations in my ethnographic journal. But as uncomfortable as the interviews sometimes were, they were a critical component of the data that I gathered. I learned that the form of the interview drives its content, and that these may not always be the same, that in fact adapting them to each individual interviewee is preferable.

The mental maps too were a surprisingly rich data source. I set out to use this method especially to overcome language barriers. I thought that having my participants trace out what I wanted them to explain to me would help me better understand their perspectives, especially in light of the communication barriers that existed between me and many of participants. I did not envision these maps becoming such an embedded part of the analysis. I'm glad that they did and will surely build on this experience to try and improve the method's effectiveness. For example, it would have been helpful to perform participatory mapping in conjunction with individual maps. I did not feel confident enough to lead these sessions, but in hindsight I wish I would have at least tried to, with one or two groups to see what new data might have emerged from such an exercise. 
My research methods arose out of a variety of circumstances. Having already been an active member of the St. Katherine community, engaging with questions about water as a participant observer made sense. Being there with my family added a degree of engagement that I had not had as a single bachelor and opened new spaces from which to observe and ask questions. Informal discussions were recorded in a journal on a daily basis and that transcript is a valuable part of my data. Formal interviews were another large component of my data. My 14 formal interviews, all of which included two mental mapping components, provided insights I could not have gleaned through interview question alone and offered important new perspectives on the waterscape. These were especially valuable to synthesize the data I was gathering through the interviews since I was speaking with my research participants either in my broken Arabic or their broken English. The coding software Atlas.ti was a helpful amalgamation of the data I collected into a central database. A number of key functions linked the journal notes, interviews, and mental maps together and helped me elicit new understandings over the hydro-cultural changes currently underway in St. Katherine. 


\section{Chapter 3: The St. Katherine Landscape}

\section{A. Introduction}

Landscapes have served as an interpretive lens for nearly a century of geographic inquiry. While its popularity as a method and organizing principle has waxed and waned with the philosophical shifts in the discipline, landscape studies in geography provide a rich ground from which to investigate questions about the relationship between nature and culture. Understanding hydro-cultures in St. Katherine must then engage with its landscape.

Carl Sauer, in his seminal 1925 work The Morphology of Landscape called on geographers to read places as sums of their component parts. Buildings, infrastructure, production and population he argued could not be divorced from the rivers, mountains, forests or swamps upon which these came to exist. Landscapes as particular 'sites' were the sum of both the physical, those "natural resources that man had at his disposal"(p.29), and the cultural, "the impress of the works of man upon an area" (p.30). Landscape was thus conceived as an entity which could explain the interactions between people and their topography. While highly influential, Sauer's work was criticized for being static and homogenizing and for lacking depth. He never delved into the function of landscapes, who they work for, whose political and economic ends they serve and the struggles that arise out of the contest over their production.

Drawing on the work of cultural Marxists such as Raymond Williams (1977), the study of landscapes shifted in the 1970s toward critical interrogations and analyses of their ideological functions. Williams showed how power was prevalent in and through culture, how both individuals and institutions made and produced particular "ways of life". These in turn were inseparable from the material workings of political economic structures. A group of cultural geographers soon emerged arguing that images and representations of landscape worked to reproduce the values and 
norms of socio-economic elites (Cosgrove, 1985; Daniels, 1989; Duncan and Duncan; 1988). Landscapes were seen as texts and signifiers that transmit particular cultural meanings to those consuming them. They are far from the natural and static duality that Sauer had proposed. Landscapes are active, produced, consumed and re-produced by particular people for particular reasons. Don Mitchell (1996) provides one of the most well rounded interpretive frames for contemporary landscape studies arguing that they should be viewed both as discursive and material. His research on the production of the modern California landscape demonstrates how the development of regions and towns at the service of capitalist networks is a hegemonic struggle between different groups within the landscape, all of whom have different notions of what the places they take part in producing mean.

Landscape then can be understood as "a unity of materiality and representation, constructed out of the contest between various social groups possessing varying amounts of social, economic, and political power" (Mitchell, 1996, p.28). It is from this appreciation of landscape and cultural studies more generally that I interpret recent transformations in the St. Katherine landscape. After describing the physical and historical landscape that had conditioned the hydro-culture that emerged in St. Katherine, I highlight how powerful forces behind the development of the modern tourism industry have induced tensions over the urban water transformations currently underway to support it and set the scene for the next chapter's analysis of evolving socio-economic relations.

Gillian Rose (1993) has questioned landscape analysis as a method altogether for the dangers associated with bounding space into discrete objects of scientific inquiry. She argued that landscape studies promote a particular way of seeing the world, a disembodied and detached masculine gaze that invariably taints the knowledge produced as mere voyeurism. I heed her warning and am well aware that the following analysis can only provide but a partial understanding 
of this place. However, this study is far from being ethereal, and the conceptual foundation I seek to lay through my description of St. Katherine here is based on active involvement in the recent production and representation of this landscape. I should note too that it is not neatly bounded either, I am not categorizing this landscape as the expanding urban sprawl of the town of Katriin, the St. Katherine protectorate or even the perimeter of the UNESCO defined world heritage site. Rather, my analysis constantly shifts scales between the high mountain plateau as a whole and individual households within it. The vista from a particular peak is as important here as the one from a bathroom stall.

Having been an active part of this landscape for a year and a half and returning again for two months of field research, I used kitchens and bathrooms, drew water from wells and purchased it in bottles. I conversed with the boy bringing water on the back of his donkey to shopkeepers on Mt. Sinai and listened to my neighbor as he told me that his water tank was empty, and what that meant for his family. I witnessed a new water tower being built, and swimming pools being refilled. I helped friends dig their well a few feet deeper in an orchard a two hour walk from town. I draw on these participant observation engagements to introduce how the contestation over water in St. Katherine revolves around the productive capacities to which water is being channeled. I am using the landscape approach here to introduce the study area and present water's function in this landscape within its historical context. 


\section{B. The physical landscape}

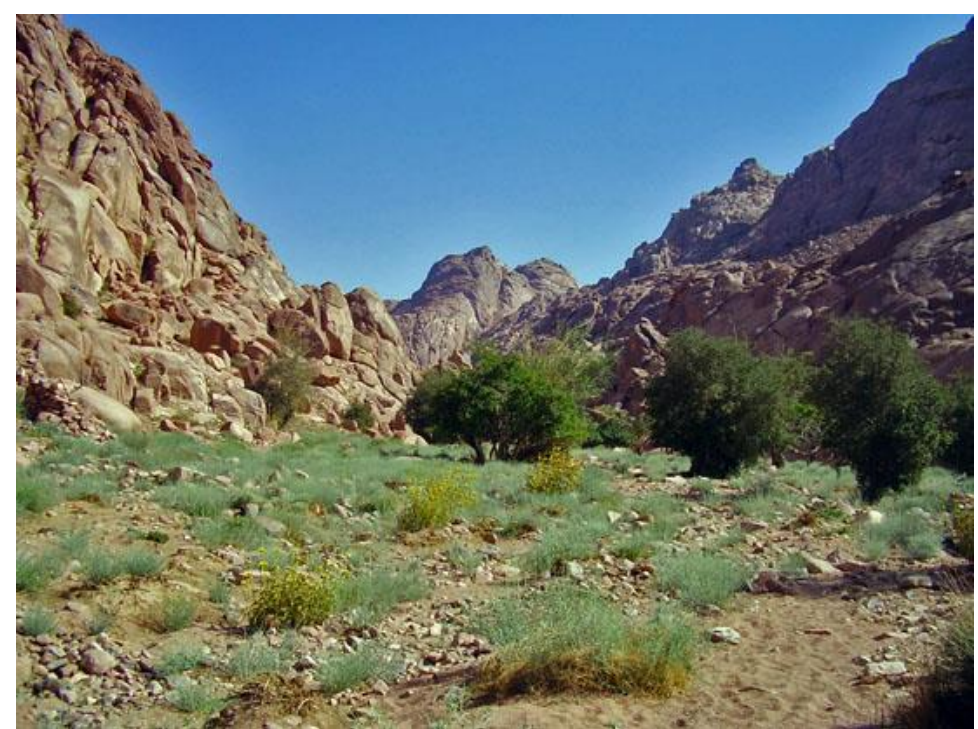

Farsh Rummana in bloom after winter precipitation

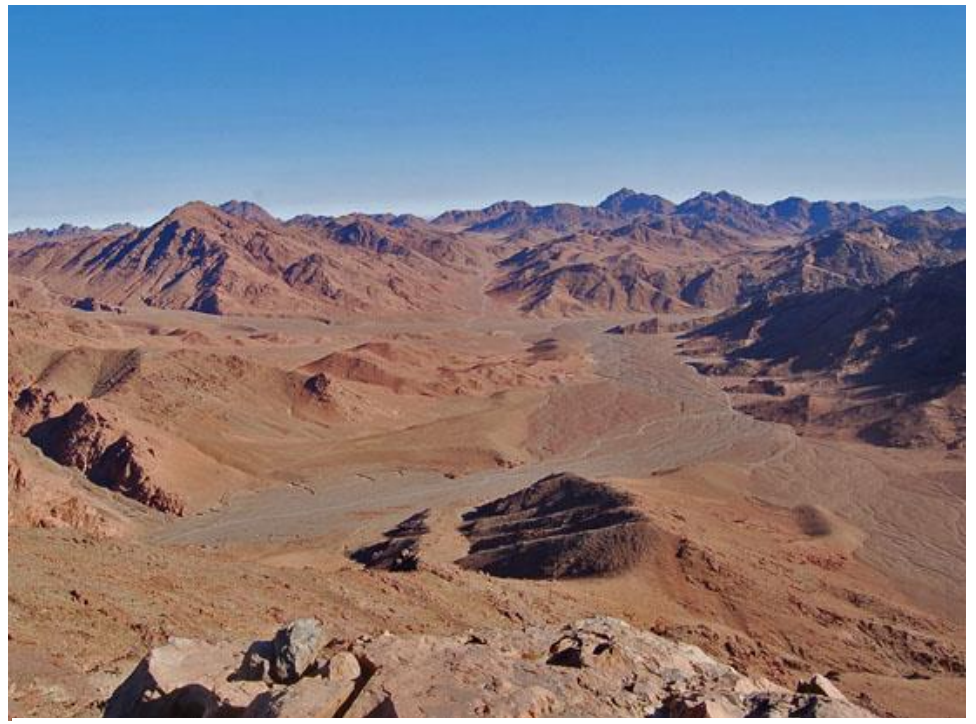

The dry riverbeds of lower lying Wadi Rumhan

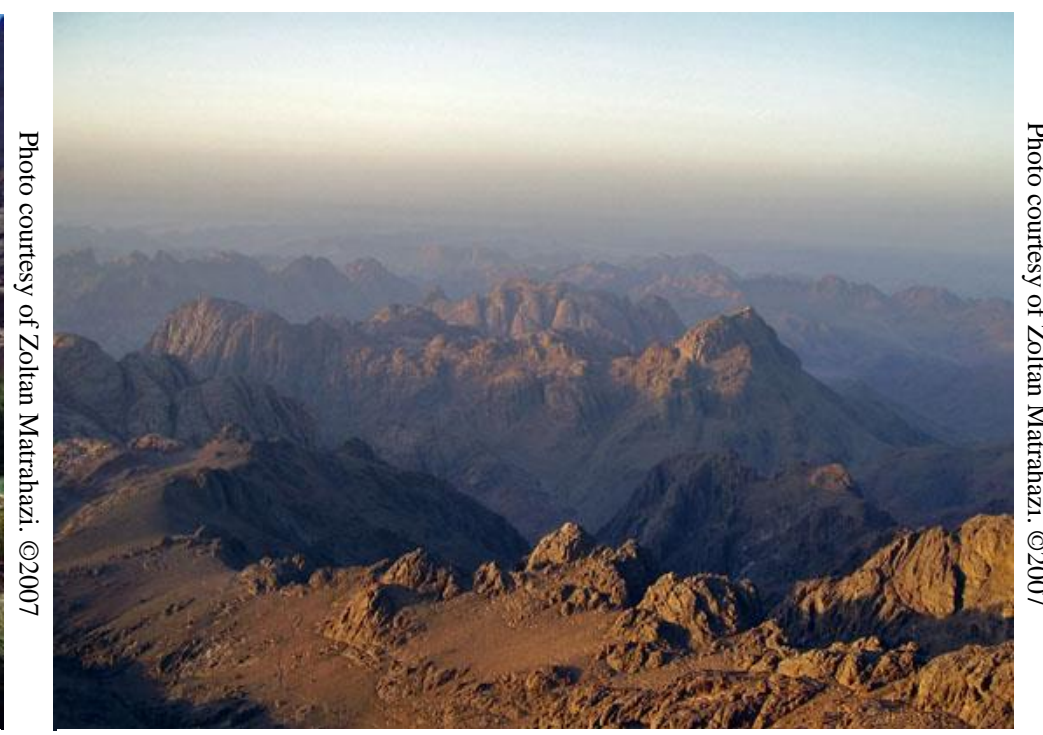

View of Mt. Sinai from the pass leading to Mt. St. Katherine

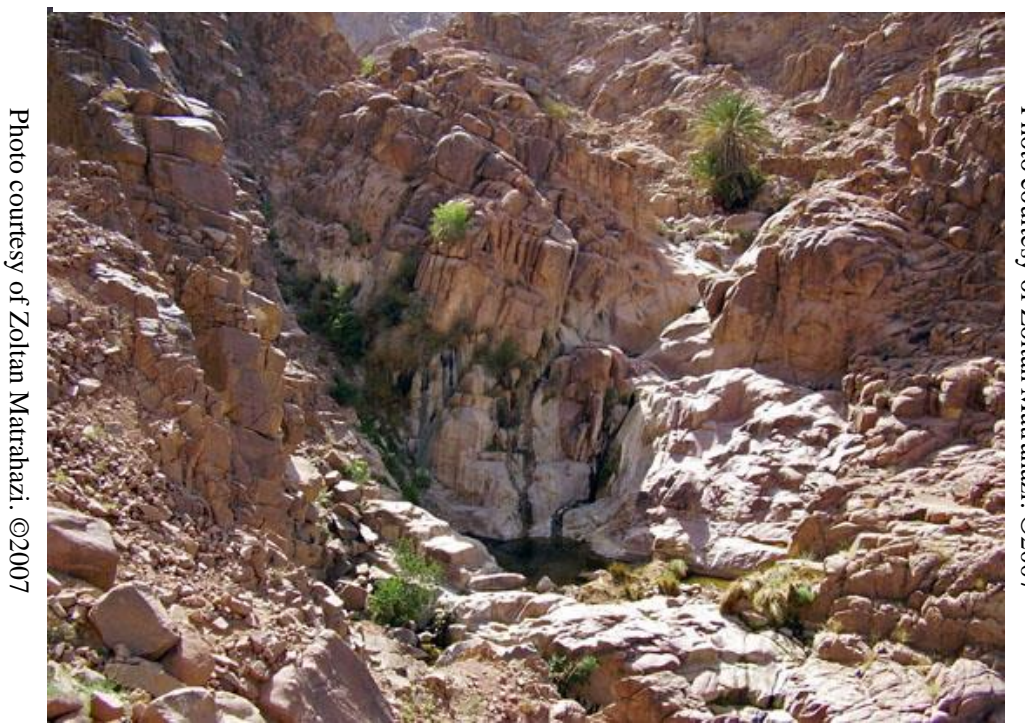

Kharazet el Shaq, a perennial pool in the high mountain

The Sinai is a dry stretch of land linking the African and Eurasian continents. In the southern portion of this triangular peninsula, lie some of the oldest geologic formations in the world, dating back to the late pre-Cambrian era over 700 million years ago. These crumbling granite peaks rise sharply from the alluvial plains along the red sea coast forming Sinai's high mountain plateau with elevations between 1,500 and 2,642 meters. The highest point is Jebel 
Katrina or Mount St. Katherine. At such altitudes, cool weather conditions increase the likelihood of condensation along with its morning dew and occasional cloud cover. As the coolest place in Egypt, November through March regularly experience nights below freezing and the Sinai Mountains are one of the only areas in the country to receive snow. While the bare granite surfaces of these mountains do not absorb water, the more geologically recent basalt dykes that transect them do, guiding rain and snowmelt into subterranean aquifers. Flash floods sporadically transform dried out river beds into torrents of water, rock and other debri reshaping the landscape in their wake. There are a number of perennial water pools throughout the high mountains and in certain places the rock is discolored by calcification from occasional waterfalls, rivulets and sitting pools that are fed by lighter rains or melting snow. Networks of deep valleys indicate that water was once so abundant that rivers flowed throughout a landscape that must have been much more verdant. Today much of the unique fauna and flora present in the high mountains are "relicts, marooned by increasing aridification over the last 10,000 years." (Grainger \& Gilbert, p.32). The water supply around St. Katherine is the most reliable of any region in Sinai with a mean annual precipitation of 62 millimeters, falling an average of 10 days a year. In fact, the high mountain plateau is Sinai's water tower, feeding as it does the primary drainage basins toward the gulfs of Suez and Aqaba. Greenwood (1997), concluding his survey of Sinai's geomorphology and drainage, writes that "only a few favored areas retain enough water to form springs or short intermittent streams, but their occurrence prompts a cultural response that is comparable to the biological richness of the oases so formed. Water is not only limited by factors in the environment, it thoroughly emphasizes them.” (p.50) 


\section{The Historical and Sacred Landscape}

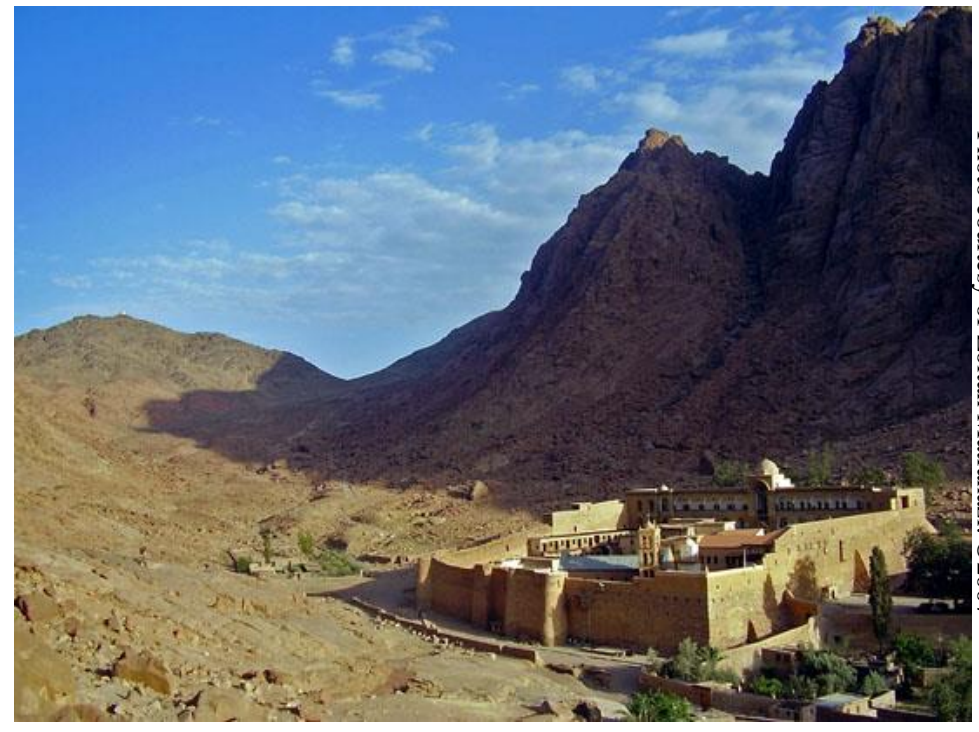

The St. Catherine Monastery

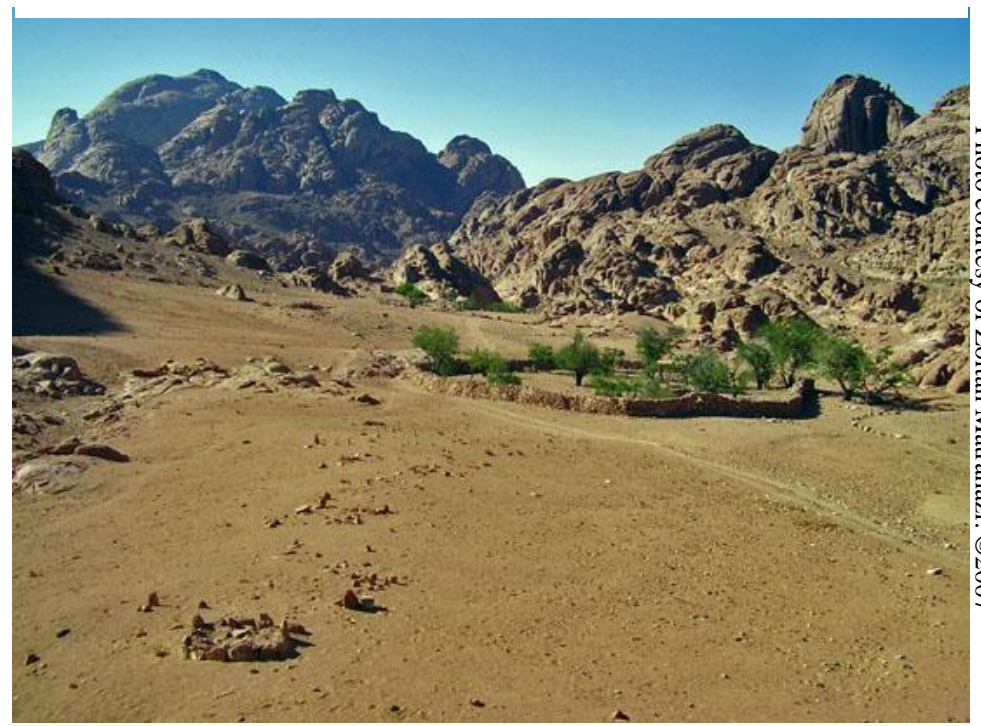

Orchards like this one in Wadi Matar are owned by Bedouin and modeled after monastery gardens.

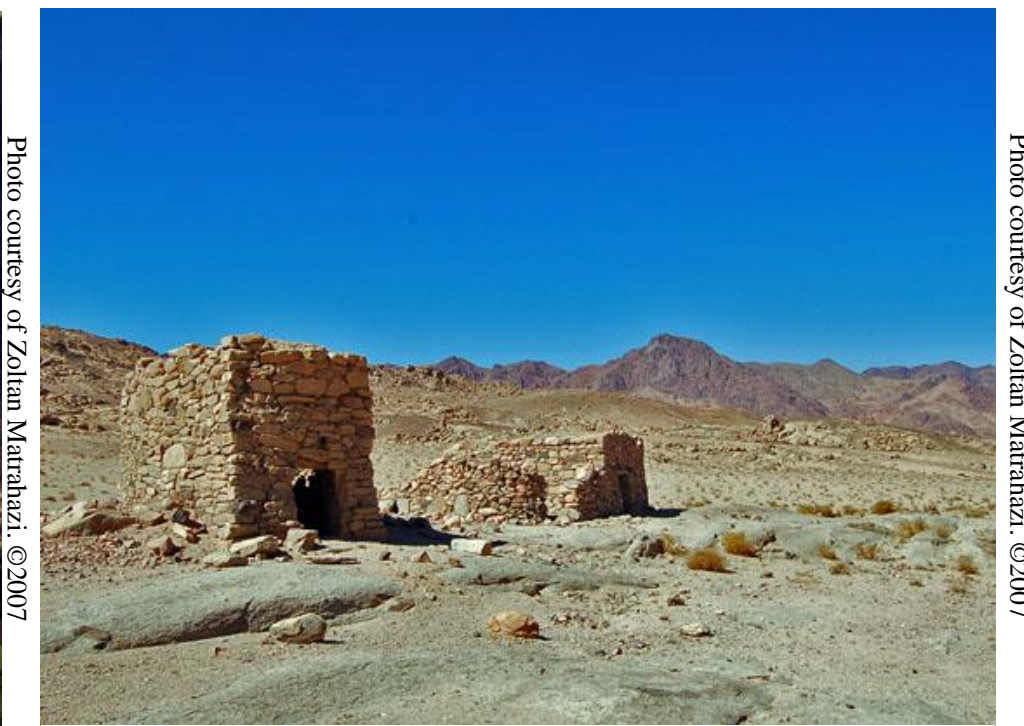

Ruins of Byzantine era homes in Wadi Rahaba

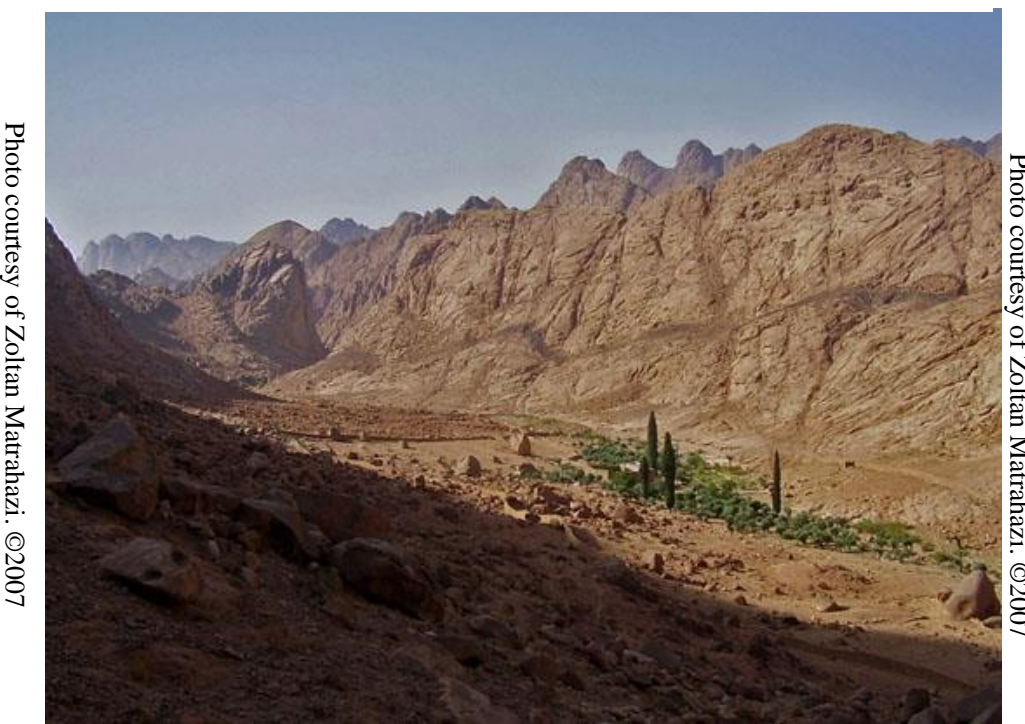

The monastery of Cosmos and Damianos is one of the seven large estates that make up church property in the area.

Water in the upper Sinai massif has contributed to the development of human settlements over time. Drawn away from cities of the Nile valley and into the deserts which were seen as places from which to cultivate the soul, Christian hermits laid the physical foundation for an ascetic culture which has been nurtured in this area since the third century. They were drawn to this place as "the vast and dreadful wilderness, that thirsty and waterless land, with its venomous snakes and 
scorpions" to which the Israelites fled after their escape from slavery in Egypt. It was a mythical land of hardship but also one of potential miracles and communion with the God that "brought the water out of hard rock" and provided just enough sustenance to "humble and test [them], so that in the end it might go well with [them]" (Deuteronomy 8:15-16).

While there is ample archaeological evidence of an ancient Egyptian and Nabataean presence prior to these Christian settlers, the catchment dams and water channels that supported Byzantine communities have had the greatest influence on St. Katherine's hydro-culture. A particular site known as 'the bush' was settled by a group of ascetics in the fourth century, named after a unique plant that they regarded as the original burning bush through which God spoke to the prophet Moses. They built a church dedicated to the Virgin Mary there along with a protective tower in which they could seek refuge when threatened. As this religious community grew, it attracted people from across the Christian world. One of the earliest records of pilgrimage is from Etheria, a noblewoman from Spain or Gaul who visited the site around 400 A.D. Her account provides clues as to how the monks sustained themselves through orchard based agriculture. She also relates her journey up Mt. Sinai, describing the church and religious service that were performed at its summit, and writes about all the sites that monks had attributed to the Jewish presence there.

There is a very pleasant garden in front of the church, containing excellent and abundant water, and the bush itself is in the garden. [...] Now it was about the tenth hour when we arrived in this place and so as it was late, we could not provide the oblation, but prayer was made in the church and also at the bush in the garden, and the passage from the book of Moses was read according to custom. (McLure and Feltoe, 1920, p. 8)

By the sixth century emperor Justinian commissioned the construction of a fortified monastery which would serve as a strategic outpost for an empire stretching from Western Europe to Mesopotamia. While there were a number of monastic communities that had sprung up across 
the wider region the site of the bush settlement was chosen (Hobbs, 1995). This settlement process brought the monks of the St. Catherine monastery, even if unwittingly, under the service of empire. The selection of this site is odd because it was so far removed from the most heavily settled areas of the more verdant Feiran Valley below, but is most certainly related to both the sacred bush located there and the availability of water.

"Despite the impressive walls it is actually a very poor defensive location, easily attacked from above and sitting in a narrow valley trough vulnerable to flood. This supports the theory that its location was determined by botanical rather than military considerations, since it covers the supposed site of the Burning Bush [...]. The location must also be related to the ready availability of underground water, via a system of wells and cisterns." (Shackley, 1998, p.125)

Regardless of the reasons behind the placement of his fortress, the protective hub that the emperor provided to the monastic community buttressed the mountain above it as the Holy Mount Horeb of the Old Testament from which God communicated the Ten Commandments to Moses. The construction of this site "marked the point at which Sinai moved from a mythical time-place into a concrete one. Sinai was no longer an evanescent 'somewhere' in the wilderness but a destination on the map" (Hosni, 2010, p.6).

A fortress requires defense, and to this end military families were sent from territories in Wallachia near the Black Sea and from nearby Alexandria to defend the monks from looting marauders and protect the treasury that was increasing with the growing number of wealthy pilgrims. These guards also provided the monks with a source of labor to tend the orchards (bustan) that were sustaining this growing population. The newcomers spread across the high mountain plateau and continued to enjoy a special relationship with the monastery "the convent - forming as it were, the nucleus around which almost all the traffic of the peninsula clusters" (Palmer, 1872, 
p.75). To this day, the Jebelaya ${ }^{6}$ tribe that claims the small high mountain territory around St. Catherine call themselves 'awlaad ad-dayr' - children of the monastery.

This symbiotic relationship led to co-dependence between the monastery and a people adapting their livelihood strategies to mirror those of Bedouin tribes around them. As Gilbert (2011) has claimed "the Bedouin economy has always included paid work, strategically combined with core occupations in order to minimize risk." (p. 11). Imitating the monks, Bedouin cultivated fruits, vegetables and grains for subsistence in walled gardens (karm) built to retain soil and counter-act the destructive effects of flash-floods. Small rock dams (agem) formed temporary reservoirs that fed irrigation channels (ganaa). Dug and lined with rocks, these ran downhill often feeding multiple orchards at once. Wells (abiar) were dug by hand and served different purposes depending on their location. Some wells fed gardens, while others were reserved for livestock. The person digging the well owned it, and on occasion someone would distinguish himself by digging a communal well to which everyone had access (Hobbs, 1995). This tradition continues to this day and water from a number of wells around Katriin are open to all. Animal husbandry was also an important source of household wealth and exchange. The Jebelaya developed a unique form of semi-nomadic pastoralism whereby families would move between low- and high-land grazing grounds depending on water availability and time of year, yet be firmly tied to particular places as a result of the orchard based agriculture made possible by the area's hydro-geology. The production and transport of charcoal to major city centers from the abundant acacia trees in the area was also an important source of revenue in times of dearth (Rabinowitz, 1985). Finally Jebelaya offered their services as guides to pilgrims visiting this area over the centuries, their flows waxing and waning depending on the shifting popularity and security of the route.

\footnotetext{
${ }^{6} \mathrm{Jebel}$ is the Arabic word for Mountain. Gebelaya means 'people of the mountains'.
} 
Livelihoods in this area were constantly re-adapted to the fluctuating climate and rainfall, as well as to regional political realities and the market demands around them. Along with the monastery's seven estates, the St. Katherine landscape retains over 400 walled orchards whose ownership can be traced back to either the monastery or particular Bedouin families. "Agriculture generated up to 60 percent of the family's expenses for the grains and other staples they were obliged to purchase from towns and cities. Unlike almost all other Bedouins in the Middle East, the Jebelaya established farming as a significant, regular, and reliable source of sustenance." (Hobbs, 1995, p.180). Some of these mountain gardens are still maintained today albeit in a much different capacity.

St. Katherine's historical landscape was fashioned by a set of different social actors. Christian ascetics, their disciples and the pilgrims that underwent arduous voyages to visit the monastic community that was springing up in the area imbued the landscape with a set of meanings now firmly tied to the Judeo-Christian heritage. Imperial Byzantium provided the material support that fixed the St. Katherine monastery on its present day site and the political force which led to the relocation of a permanent population in the surrounding mountains. While it is difficult to know today what role water played on a daily basis there, it is clear that a manmade-water infrastructure supported agriculture and pastoralism. The monastery claimed sovereignty over the entire region and secured those sites with the most abundant water resources, in turn offering their material support to the local population as needed. 


\section{The Urban Landscape}

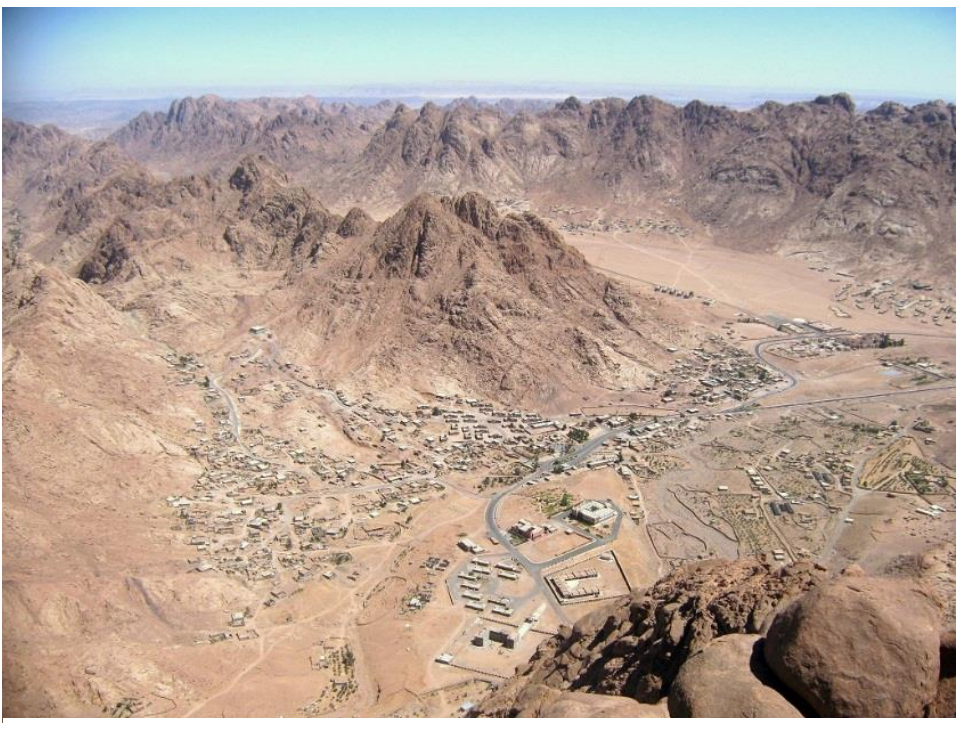

View of El Melga and beyond from the summit of Jebel Raba

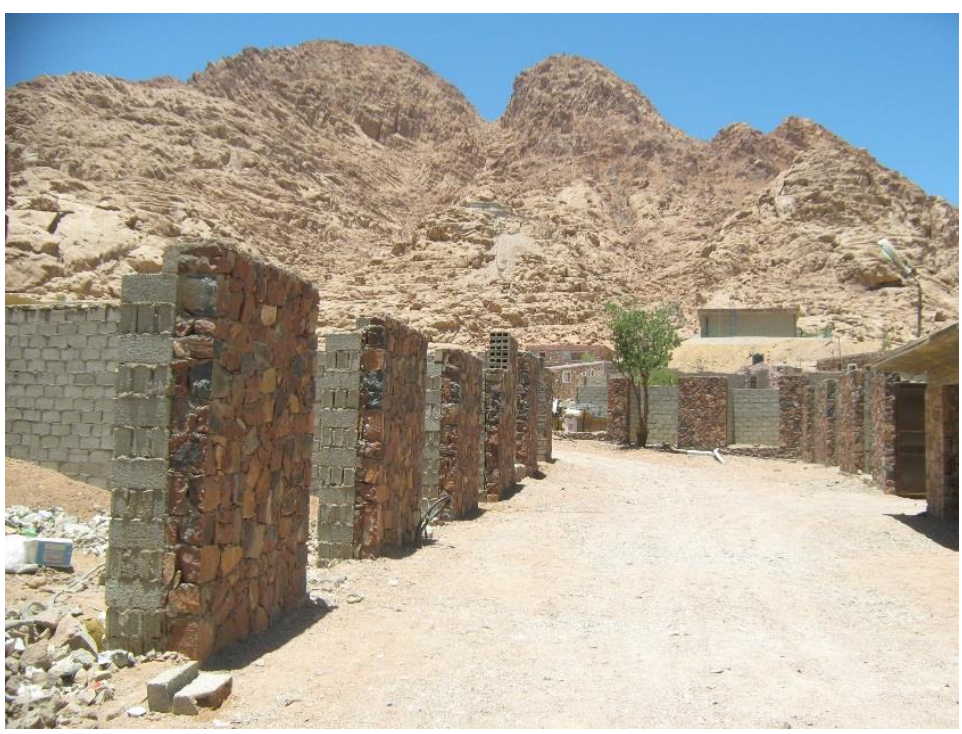

Ongoing construction of retail space downtown Katriin

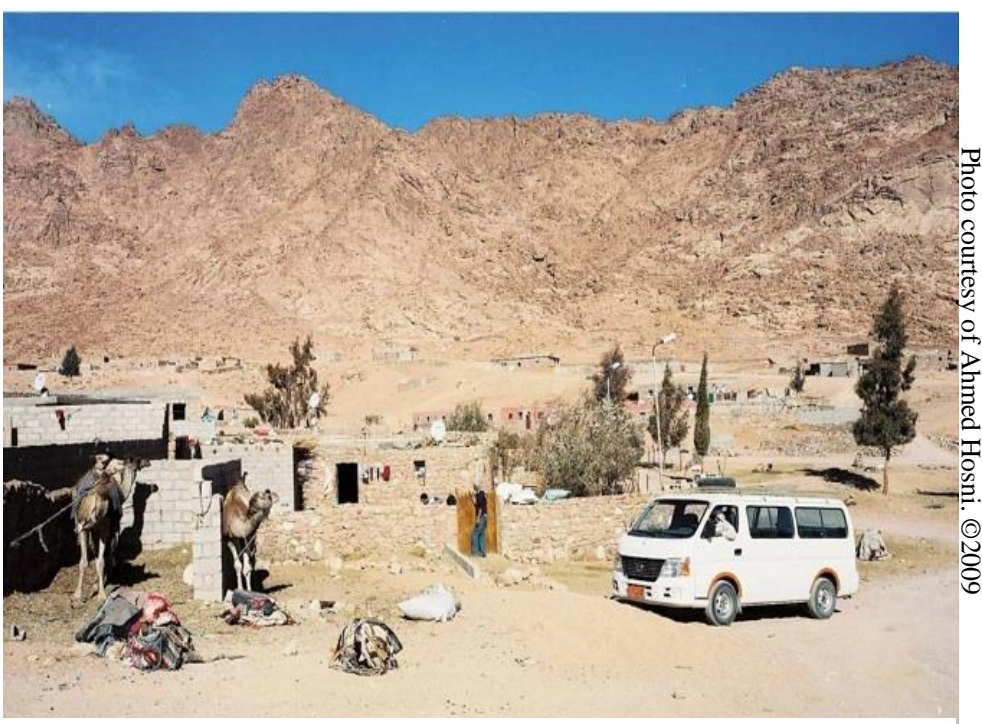

One of the multiple neighborhoods that form greater Katriin

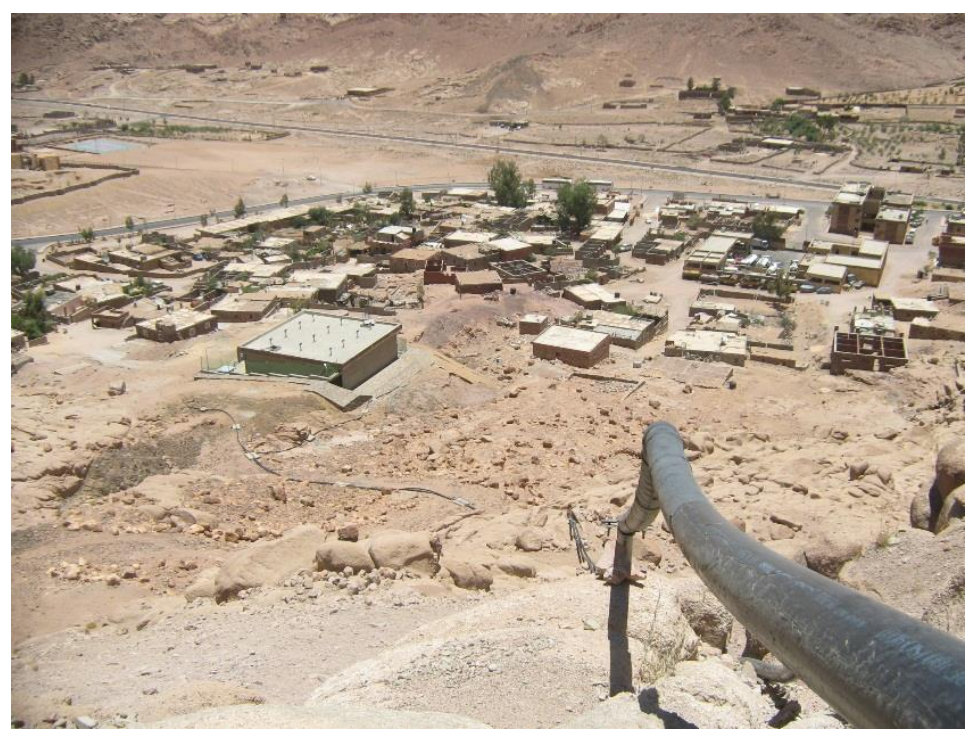

View of Shameya and the new water tower from the old Israeli tank

The head of the basin in which the town of Katriin stands today was known for centuries as El Melga - the meeting place. It is the physical meeting place of the water flowing down the mountains where it forms a confluence before taking its course toward the Red Sea. The valleys were also the routes connecting disparately settled Jebelaya families. People would meet in this area when calling on the monastery, tending their herds or migrating between winter lowlands and 
higher summer grounds. It was a temporary place of meeting and exchange where social activity existed but never left a long term imprint on the landscape. There were no permanent dwellings or wells in this area until the 1970s when the social capital in place provided the nucleus from which the urban center of Katriin emerged. Development funds from Tel Aviv first contributed to building up small scale infrastructure which became the basis for a cascading effect of investment and profitable returns by private tour agencies. The short-term contacts based on stories and exchange that had defined El Melga up to that point were transformed into long-term contacts based on capital investments and the wage relationship. "Melga was one incidence of those transient social nodes-turned-economic-termini” (Hosni, 2010, p.6).

The development of Katriin as an urban center began shortly after the Israeli occupation of Sinai in 1967. Environmentalists, nature lovers and academics took a vivid interest in the unique character of the area. The Israeli Society for Nature Protection, a voluntary civilian organization, built a field-study center near the monastery combining ecological research with tourism related activities. Public employees of the 'Administration for the Development of Southern Sinai' were also present there and used it as a base from which to provide medical and other social services to the disparate population spread out among the mountain valleys. As the community grew it obtained financing to dig wells in the area, some as deep as $60 \mathrm{~m}$, and the steady availability of water along with new work opportunities available encouraged the Jebelaya to begin settling there. This also benefited the Israeli administration as they could now "predict more accurately where the interior population was to be found" (Lavie \& Young, 1984: 39). The Israelis built an airfield $12 \mathrm{~km}$ outside of St. Katherine originally intended for military use but which began to accommodate civilian passengers as the number of Israelis interested in visiting Mt. Sinai increased. Tourism began to play an ever larger role with "flights from Tel Aviv and Eilat 
delivering up to 550 tourists daily in 1978. On a peak day in April 1979, nearly 3000 persons came in 70 large buses and 50 private cars, in 1979 the last year of Israeli occupation, 50,000 people visited the area." (Hobbs, 1992: 105)

After the peninsula reverted back to Egyptian control in 1979, St. Katherine was seen by administrators and elites in Cairo as a place to be built up for consumption by the tourism industry. The first major capital investment to this end was the construction of an asphalt road connecting the town to the coastal roads linking Suez, Abu Rudeis, Tur, Sharm el Sheikh, Dahab, Nuweiba and Taba. Accessing this remote mountain locale was now much easier and with it a steady flow of tour buses began arriving as part of pre-packaged circuits. President Sadat himself built a resort compound in the 1980s tapping the aquifer beneath it to water his lawn (Lavie \& Young, 1984). The monastery, which had traditionally enjoyed sovereignty over much of South Sinai was limited to a 60 meter sphere of influence around its walls. These two political symbols served to claim the space for the state and foreshadowed the development policies that were to be implemented going forward. Shortly after President Sadat's death, the Egyptian ministry of tourism inaugurated the St. Katherine Tourist Village on the site of his villa, a four star, 164 room capacity hotel. Bus service from Cairo began running four times a week and by 1986 was running daily (Hobbs, 1992). With each new facility improvement, more European and Israeli tourists arrived in the area to take in the sacred sites. By the early 1990s Joseph Hobbs observed that:

"accommodations have had to keep pace with the addition of a 200-bed hostel at the monastery, a hotel at the airport, and campsites five kilometers Northeast of the monastery at Abu Zaytuuna. New wells, a touristic commercial center, research center, museum, medical clinic, school, and many shops and cafes opened at the Bedouin market center of al-Milgaa, now known as Katriin.”(Hobbs, 1992: 105)

By 2006, there were 291,000 visitors to St. Katherine staying on average one night in a hotel (PA Consulting, 2007). Many visitors do not stay in town at all, but arrive in the evening, 
climb mount Sinai to see the sunrise, visit the monastery in the morning and head on their journeys. The growth of the tourism trade in St. Katherine has led to the Jebelaya's rapid sedentarization. Their permanent homes are a large contribution to Katriin's built environment today. Workers seeking economic opportunity from mainland Egypt have also migrated to this town in search of work in the tourism industry, its associated construction jobs or to establish small businesses. Teachers, police, soldiers, doctors, lawyers, city officials, national park rangers and other state related jobs have swelled the ranks of the Egyptian community there. Many have left their families behind in large Egyptian cities and perceive their time in St. Katherine as a transient experience in one of Egypt's small frontier towns. Today Katriin's population stands at approximately 6,000 with a forecasted growth to 17,000 by 2017 (Sims \& El Miniawy, 2003).

Water has clearly contributed to these developments. As the urban landscape emerged, the aquifer was tapped further than ever before. Government drill rigs made it possible to provide enough water to a concentration of people that this area could never have supported without deep wells. Eventually even those were not enough to supply the town's growing population and water began to be drawn from boreholes further away, trucked to individual households and businesses. Investments in water infrastructure have tried to keep pace with urban growth, with varying degrees of success. A water treatment plant was constructed 10 kilometers beyond Katriin five years ago and is meant to recycle wastewater, but the sewage system is not connected to every home yet and there are funding and logistical issues remaining before it becomes fully operational. While there are plans for a central water grid connecting every household, these have yet to be implemented. As in many urban and peri-urban centers across the global south, a decentralized network of water holding tanks now dot the landscape. The Nile pipeline project was completed two years ago to supplement the growth of the town even further, but it remains to be seen how 
viable this project will be in the long term, as the energy requirements necessary to continue operating the pumping stations are not constant. What is certain is that the town needs water to function. Because it has outgrown the ecological limits of the physical landscape in which it is set, water for Katriin is drawn and transported from far beyond the city's boundary. As chapter 5 will discuss this transition is bringing about important hydro-cultural transformations across St. Katherine.

The urban landscape was and is actively produced through the intersection of particular political economic factors. The Israeli administration laid the foundation for government oversight in a territory that had long been out of reach to central authorities. Today an Egyptian army general manages the town and the state's presence is strongly felt there. Only one paved road leads to St. Katherine, and anyone entering or exiting must cross through two police checkpoints, complete with identification checks and questions about the purpose of travel. Public services are accessed in Katriin government offices by a number of other Bedouin tribes across the area who must come to town to register for food and water subsidies. The population is increasingly accounted for and monitored, something that was not possible 40 years ago when Bedouin were still migrating from place to place, subsisting off the grazing and agriculture that the landscape permitted.

Katriin's political expediency as an urban settlement is matched by the economic potential that the Egyptian government and private tour operators see there. While visitors to the St. Catherine monastery have been cycling through for centuries, the ardor and expense of a long foot journey from Cairo or Jerusalem limited the number of pilgrims that made it to the site. The construction of an airport and asphalt road has opened the possibility for the mass consumption of this landscape. As the number of tourists increase, so do cash flows to both the Egyptian 
government $^{7}$ and private tour agencies organizing trips to the area. In turn guiding opportunities and other services provide a good source of income to a population drawn to the relative comforts of life in this new urban center. The tourist in St. Katherine is ubiquitous, but while their presence has directly contributed to the production of an urban landscape, most do not know the full extent of the transformations that their presence there has wrought. The following section is a description of the role that these visitors play in consuming and re-presenting a landscape which is being produced to suit their needs.

\section{E. The Tourist Landscape}

Arabs call it Gebel Musa, or Moses' Mountain, where the prophet is said to have received the Ten Commandments. Accordingly, Mt Sinai is a venerated site for Jews, Christians and Muslims, who all make pilgrimages to this patch of stark desert just inland from the Red Sea in Egypt's Sinai Peninsula. At its base is St Katherine's, a Greek Orthodox monastery that basically hasn't changed in the 17 centuries since it was established. But it's easy to forget the entire cultural context when you're halfway up the trail, your lungs burning from exertion and your nose running from the cold. You might even be tempted to mutter, 'Why did I want to climb this damn mountain anyway?' - Lonely Planet Guide Book

I first encountered the St. Katherine landscape as a tourist. Although I planned to stay longer than most, my first few weeks there were not dissimilar to what many visitors experience. I spent two nights at an eco-lodge and two months in a Bedouin owned hostel. I climbed Mt. Sinai, visited the monastery and went on a 5 day trek. These experiences were led by Jebelaya guides accustomed to taking people like me into the mountains. As my work there evolved, I moved into my own apartment in town, and eventually became a link between Jebelaya guides and their guests. In my role marketing desert and mountain treks to tourists, I sought to understand our target

\footnotetext{
${ }^{7}$ Every visitor to Egypt must pay $\$ 15$ for a tourist visa. Furthermore, each tourist entering the St. Katherine protectorate must pay $\$ 4$. Private tour agencies must register with the ministry of tourism, and pay yearly fees to maintain their operating license.
} 
consumers, how we could reach out to them and sell the tour packages that I was promoting. A large part of my job involved training Jebelaya guides to tailor our tours to the needs of each market segment (walking pace, day lengths, food options, rest stops...). As customers arrived, I went out with the groups and acted as a bridge between them and their guides, explaining how the project and their involvement in it was meant to benefit the Bedouin community. With each new tour group, my gaze on the landscape shifted from that of the tourist toward that of the guide, providing me with a unique perspective on both. The following narrative is a reflection on the various tourist engagements with the St. Katherine landscape and the water flowing through it. It is drawn from my personal experience working with tourists there. Though a somewhat generalized account it exhibits the way that many visitors likely interact with a physical, historical and urban landscape refashioned to suit their needs.

\section{Engaging the Tourist Gaze}

Every night buses shuttle hundreds of people toward the edge of a town sprouting in an arid drainage basin. The bright street lights illuminating the road announce that their journey through the desert is nearing its end. Stepping off the bus and into the cool mountain air, the granite peaks towering above come into focus. Many try to reconcile the environment they have just stepped into with the imagery and representations layered through centuries of religious art, traveler accounts, and biblical imagination. Their minds are on the climb to come. Most check-in to their hotels to rest and wash up; as expected water flows from the faucet. 
Further up the road young men and their camels begin their nocturnal walk from town toward their new guests to offer services as guides and porters. By 2:00 AM most have been hired to take part in the nightly procession forming a heterogeneous crowd more or less prepared for the

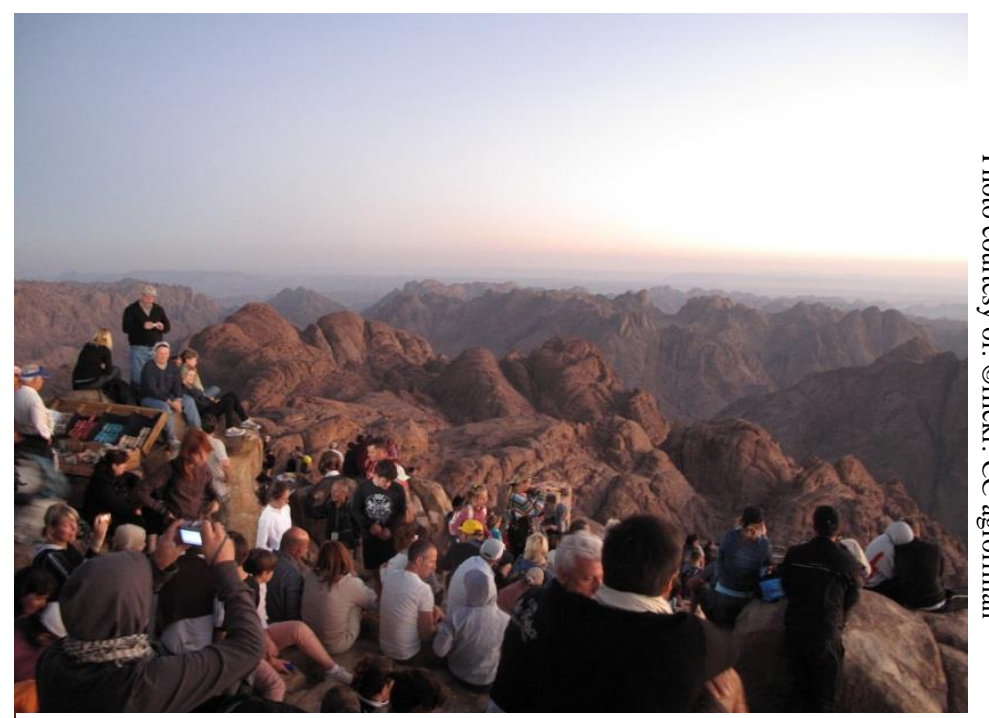

Tourists at the summit of Mt. Sinai jostling for the best sunrise vista arduous walk ahead. They all hope to reach the summit in time to watch the sunrise. Guides stop their panting guests at cafeterias set up along the path from which calls for "coca-cola, hotchocolate, bottled water, twix, blanket, mattress" ring out into the night. As the peak nears the concentration of shops intensifies, guides fall back and tourists jostle for the best location from which to capture the sunrise they have come to experience on Mount Sinai. The twilight illuminates a vast desert expanse revealing no sign of life in the valleys below. Some have their expectations met; others are disappointed, all have consumed landscape and begin their descent before the scorching sun they have come to see rises too high.

To many tourists this experience is but a passing memory among a host of others they will have on a two week hiatus from their jobs back home. For others, it is a deeply moving experience, one they have looked forward to for a very long time. Mt. Sinai is presented to these consumers through a slew of brochures and guidebooks as a holy place. These remind them that the landscape was classified by UNESCO as a world heritage site in 2002, and that the sacred site is guarded by the oldest Monastery in the world still in use for its initial function. This massive building is the next stop for the crowd descending the mountain that morning. They meet day-trip arrivals from 
coastal resorts and all converge on the site to see the flourishing 'burning bush' that it protects along with one of the world's richest collections of icons and ancient texts. By noon the monks see them out, shutting the medieval fortresses door in a well-rehearsed daily routine of hospitality and retreat. Outside the walls, concessioners and souvenir peddlers hawk their wares until the last guests get back on the bus to consume their next pre-packaged experience ${ }^{8}$.

Most visitors leave St. Katherine reinforcing the perception that they have just encountered a place outside of time, disconnected from the world they are vacationing from. They do not realize that there is an urban center that provides the logistic and administrative support to the masstourism complex they are enjoying for it was intentionally hidden by the view-shed at the summit of the sacred mountain. Acknowledging its presence would spoil the image that has been carefully constructed to serve the majority of people that come here.

\section{The Eco-Tourist}

Some have heard that the area offers an escape from peddlers and the scent of camel dung concentrated around the monastery. These are the 'eco-tourists' - trekkers, mountain climbers and quietude seekers who venture beyond the traditional vacation model to support alternative tourist economies. They do venture into town, opting instead to stay for a longer period of time usually at one of the locally owned accommodations on offer. Taking in the scenes of this quaint Egyptian town, even savvy travelers do not realize that Nile water flows through it. Pumped over 600 kilometers and mile high, it is there to support the expansion of a city that tourism has directly engendered.

\footnotetext{
${ }^{8}$ Most trips to the St. Catherine monastery are but one of many combined activities for tour groups over the course of a week or two vacation. Many arrive on pre-paid, all inclusive trips that include hotel, meals, transportation and guiding services, preferring to forgo the hassle of arranging their travel needs at each site.
} 
The eco-tourists seek out 'authenticity', Bedouin lodging and interactions with local people. They hire guides that take them further into the mountains where a part of their overnight fees support the owners of a few well-tended orchards. Here water plays an important role too. The

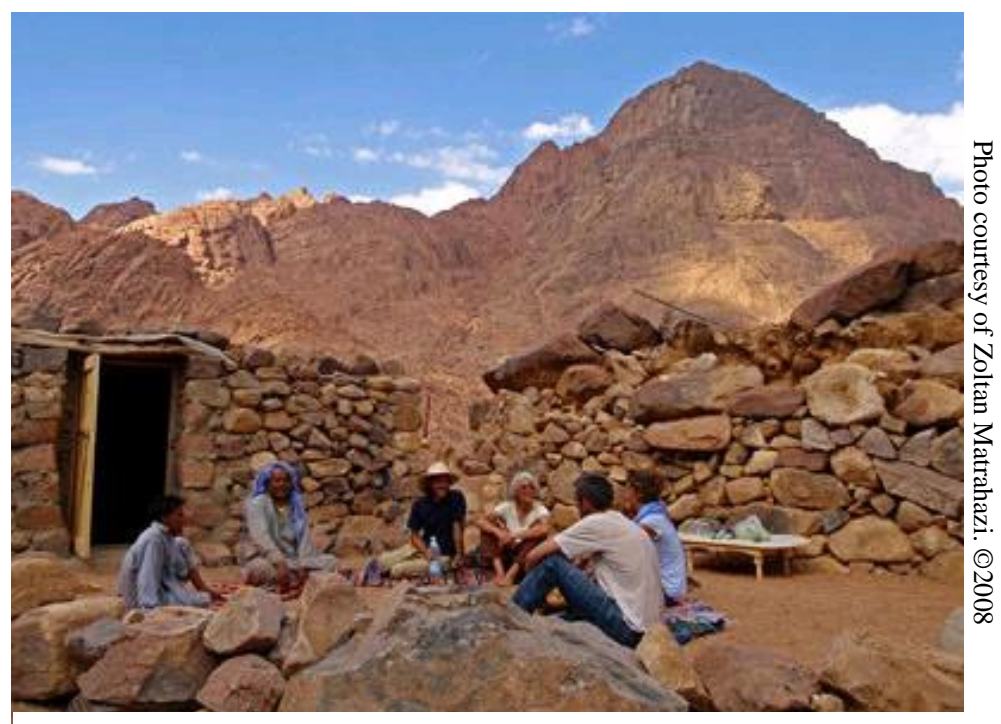

Tourists at resting in a Jebelaya orchard gardens that still have enough have transformed into 'eco-lodges'. Guides tell their guests that their people lived and worked in these places before they began moving into the city below. While the visitors listen to these accounts, the historical function and current contestation over the water that cooks their soup and irrigates the trees providing them shade is hidden from view. Like their counterparts on Mt. Sinai, the places eco-tourists visit are tailored to their needs and expectations. Responsible tourism packages are sold through the same mass tourism channels that these consumers believe they are escaping. Both market segments, in their search for an experience which fulfills their desires, reify what they want to see consuming a product re-produced for them from the remnants of a past they think they are entering but which no longer exists. 


\section{F. Summary}

I think the nature of a place changes very very much. It's interesting to come here and have a sense of its history but I'm very realist in as much as accepting the place will be different. In fact our [human] relationship to the place has completely changed. Once I think it was seen as a threat, now it's seen as a victim. It's a victim of urban growth, excessive use of its resources. So our whole relationship to the landscape has changed in fact, it's now we are a threat. ${ }^{9}$

The St. Katherine landscape today supports 6,000 permanent residents and thousands of daily visitors in a place where average yearly rainfall would not fill a small cup of water. It is tempting to think of landscapes as tautological, true by the very essence of their form. This foray into St. Katherine's physical, historical, urban and tourist landscape has demonstrated that it could have been otherwise and that other economies could have taken shape there. Given the bio-physical realities of the region, the urban and tourist landscapes materialized as a result of specific social actors over time. Christian ascetics began imbuing this landscape with sacred meaning in the $3^{\text {rd }}$ century establishing a large monastic community there. Justinian I used their presence there as a trade and communication outpost for his $6^{\text {th }}$ century empire commissioning a fortress which still stands today. The Jebelaya who were sent to the area as soldiers developed long-term livelihood strategies including self-provisioning and waged labor on monastery estates and as guides for pilgrims. Over the past 40 years, development planners and tour operators have built on this historical landscape to encourage economic returns on investments and Egyptian administrators have used the urban center supporting tourism activities there to extend the state's political control over the region. Despite what many visitors coming to consume this landscape might believe, it is not static and locked in time but rather is undergoing continual change.

Landscapes, as Mitchell (1996) has well argued tend to become totalizing, conditioning everyday life and making it difficult to see how any alternatives to it could be possible. Put to the

\footnotetext{
${ }^{9}$ Interview \#13: June $29^{\text {th }}, 2012$
} 
service of tourism capital, the St. Katherine landscape is being sold as a commodity. Its historical function is idealized and the details of its contemporary production hidden from view to the majority of people consuming it. "As a produced object, landscape is like a commodity in which evident, temporarily stable, form masks the facts of its production, and its status as a social relation. As both form and symbol, landscape is expected by those who attempt to define its meanings to speak unambiguously for itself.” (p. 30). The early pilgrim Egeria read the landscape and believed that the bush in front of which her prayers were being heard was the one through which God spoke to Moses. The landscape conditioned and reinforced an ideological response. In turn, that ideology continued to reinforce the primacy of St. Katherine's status as a sacred landscape. In much the same way, those who have settled in the town of Katriin today believe that tourism and the reverberating economic activity it brings through the urban landscape can provide a livelihood for their families. Most modern tourists engage with this same landscape and believe that they too are stepping into the past without thinking about the implications that their presence might have on the present. In other words, just as the historical landscape served to reinforce a particular ideological function, so too does the contemporary landscape. Increasingly it is being put to the service of capital, which has very little respect for social, economic, political and cultural boundaries, although it does use those pre-existing 'ways of life' to its advantage.

Water has always been central to the production of this landscape. While physical realities have conditioned its availability, St. Katherine's historical production has defined its accessibility. Urban growth has brought increasing pressures to bear on the water resources available and required serious interventions into the ways in which water is sourced, distributed and consumed. While there are inequalities that have surfaced as a result of reordering hydro-cultures in the area, these disparities have not yet emerged into open contestation because the existing landscape has 
been produced to maintain a new form of cultural hegemony based on capital intensive tourist economy. Over the past forty years, a new status quo has emerged which has significantly altered socio-economic relations in St. Katherine. The Egyptian government and mass tourism companies, supported by international development organizations, have coalesced to transform this landscape to meet the needs of political economic growth imperatives. This new cultural norm is dependent on a constant flow of water and tourists both of which are not assured in a place with a history of drought and political instability. Tourists will stop travelling to St. Katherine if there is insufficient water to support their presence there or if they perceive the area to be unsafe. Laborers will leave Katriin if there are not enough tourists to pay the wages they now depend on for water and food. Maintaining St. Katherine's contemporary landscape thus requires a constant flow of both capital investment and water. The following two chapters will explore this intersection by discussing the socio-economic and hydro-cultural transformations currently underway. 


\section{Chapter 4: Socio-Economic Transformations in St. Katherine}

\section{A. Introduction}

Three weeks after arriving in St. Katherine for this research project, I was invited along with my wife and daughter to take a two day trip into the mountains with a Jebelaya family. The father of this family was born in a small mountain settlement of four homes and spent much of his childhood there. His wife tended goats until they were married. They now live in town, he is the manager of a guesthouse and she maintains the household. They have three kids aged three, seven and ten, for whom this excursion into the mountain ranges above Katriin was a fun and exciting event. These children only had a cursory understanding of the lives that their parents once lived. The father told me that he felt guilty for not taking them out more often, but that his job kept him busy in town. Our destination was an orchard located four hours from Katriin and only accessible by foot. It was apricot season and while the garden itself was in complete disrepair the trees still bore fruit. ${ }^{10} \mathrm{We}$ harvested over 50 lbs of apricots, which were divided upon our return to town the following day among the extended family that collectively had claim to the land.

The apricot season in St. Katherine is a brief one, coming to an end seemingly as soon as it starts. Apricot trees thrive in Sinai’s high mountain climate and their ripening in mid-June always marked the beginning of the harvest before giving way to almonds, quince, pomegranates, grapes, apples, pears, figs and plums. Seasons regulated grazing and migration patterns for the Jebelaya living in St. Katherine's high mountains but for most the brief two week apricot harvest has given way to servicing brief tourist visits to the area. Most tour operators bring their clients to the area for less than twenty four hours. The cash that tourists spend during their time in St. Katherine

\footnotetext{
${ }^{10}$ The well in the garden was dry because it had not been maintained, but these trees are very old and their roots are still able to access water from the aquifer below. If trees had been well tended and watered from the surface as well, their production would have been even more abundant.
} 
provides the subsistence that so many households in Katriin have come to depend on today. Like those apricots, as suddenly as the cash comes, so too does it disappear. Maintaining a garden far away from the site of daily tourist consumption has become increasingly difficult when workers must be present on a regular basis to offer guiding services, staff hotels or hawk souvenirs.

Over the course of one generation St. Katherine residents have seen incredible transformations to their everyday lives. While many speak of much better living conditions than what their parents experienced, they also realize that their situation is in many respects more precarious today as a result of dependencies that formed during their transition to sedentary and urban lifestyles. One of my interviewees summed up these feelings well discussing the changes he had seen over the course of his lifetime:

Forty years ago all of these mountains had snow on them in the winter and in the summer they were green. There were many gardens in the mountains. But then the weather changed no water, no rain or anything. European people now think they can bring it from the Nile, only one day this will be a problem because it works with electricity. Maybe one day there won't be any more or the pipe will break and after this the whole village won't have water. If anybody closes off this water many people will die, this is a problem. ${ }^{11}$

This dependence on water deliveries is being reinforced by the fact that so many have lost access to their traditional water sources and no longer have control over their own means of production. Their water 'dispossession' has its roots in the one sided development policies that have transformed this landscape to cater to the demands of the tourism industry. Appreciating the relationship between water and tourism development in St. Katherine requires an exploration of the multiple stakeholders involved in producing the urban space that services it.

In this chapter, I present my findings on water's function in Katriin incorporating data from my field work to highlight the contradictions inherent in neoliberal economic development

\footnotetext{
${ }^{11}$ Interview \#14: July $7^{\text {th }}, 2012$
} 
policies. In the context of this particular study we have a population which in 1970 , prior to the expansion of the tourism industry, was living off their own means of production for a significant part of the year (Gilbert, 2011). With a few notable exceptions, the subsistence of Katriin residents is now completely dependent on the vagaries of global markets. Most of the population is living with the new imperative of exchanging money for water and food. Ninety nine percent of households are dependent on state subsidized water deliveries from a private company while tourism related businesses purchase and consume groundwater for their operational needs, reaping a significant financial surplus from its appropriation (Sims \& El Minawy, 2003). I argue that top down development policies and the socio-economic changes these have introduced are the primary drivers toward the reorganization of water relations in Katriin.

\section{B. The Tourism Fix}

Tourism is a phenomenon that comprises a collage of producing and consuming moments. It is essentially a global process, which manifests itself locally and regionally, and explicitly involves the construction of place. Milne \& Altejevic, 2001, p. 386

David Harvey (2001) has used the term 'spatial fix' to explain the attempt to avert contradictions in an economic system based on financial growth. As I discussed in my introduction, he argues that as profits from capital investments are collected, they must be channeled into new economic activities to avoid devaluation. Spatial fixes take on two different forms which simultaneously complement and contradict one another. The first is an immobile fix, grounded in a new geographic location where there is an incentive to develop markets, fresh labor powers or raw materials. These types of investment must pin down capital in support of structural improvements on the landscape (see chapter 3) channeling funds toward the construction of roads, pipes, electric and communication infrastructure that will facilitate further investments there. The second is a transient fix aimed at absorbing surplus capital and attracting it to the new site, which 
itself competes with other locations across the world for the most compelling return on investment. The two types of fixes co-constitute each other, but mobile capital is constantly in flux and its withdrawal from a place devalues the longer-term durable investments made in the area. Spatial fixes are thus a balance between capital's mobility and the permanent structural improvements that it makes possible in any given landscape.

As one of the largest industrial complexes and avenues for consumption in today's global economy, tourism is an ideal industry through which spatial fixes are executed. The UN World Tourism Organization claims that between 1950 and 2008 international tourist arrivals across the world grew from 25 million a year to an astounding 922 million, generating nearly $\$ 1$ trillion in global receipts last year alone (UNWTO, 2012). Britton (1991) argued that this massive industry formed "a major internationalized component of Western capitalist economies" (p. 451) constantly creating new consumptive spaces to forestall crises inherent to the accumulation process itself. Tourism combines both large scale investments in infrastructure and smaller scale transient capital flows. International tourism reflects contemporary globalization as transnational flows of people, commodities and capital across international borders are coordinated within production networks governed by large multinational firms such as airlines, tour operators and hotel companies (Hazbun, 2004). A steady 4\% growth rate in global tourism revenues since 1980 (UNWTO, 2012) tends to confirm that it is an important vehicle toward maintaining capitalist growth based economies. While continually reinventing and diversifying itself into a variety of niches, tourism based capital blends different industries and informal economies together into a hybrid economic formation which "spills outward from the edges of organized capital to saturate all other elements of place" (Gibson, 2009, p.529). 
The tourism products being sold are primarily the tourist experience itself, an ephemeral and instantaneously consumed 'soft' product rather than a durable one. Tourism opens up new avenues for consumption in situ bringing people into the service industry and swelling the ranks of the consumptive class (Fletcher, 2009). Cash flows from tourist consumers provide reverberating effects down an extremely convoluted supply chain involving actors at a variety of nested scales from global multi-national firms to local taxi drivers. Beyond the souvenirs that are taken home (themselves an important vehicle for accumulation) what is sold is the creation of meaning, an experience. This evanescent product reduces the time necessary for firms to turn a profit because the consumer pays for the experience upfront, often packaged as an all-inclusive tour, prior to consuming it. The margins between service providers and brokers are hidden from the consumer's view usually benefitting those at the top of the supply chain.

Tourism then is a convenient spatial fix that produces new places and attracts capital investments by global firms and their tourist clients across the globe. Waleed Hazbun's (2008) examination of the politics of tourism in the Arab world explains how state planners there actively incorporate new territories into transnational tourist networks as a springboard toward national development goals. In the 1960s and 1970s tourism was perceived by many of the newly independent states in the Middle East as a rapid path toward their country's modernization. The influx of hard currency that visitors brought with them would provide governments with the capital necessary to industrialize their societies and establish a market based economy. Rapid revenue generation would also bring economic benefits and political stability to what were still highly fragmented territories. Such plans reshaped and often completely altered pre-existing economic, cultural and political landscapes in which they were executed. 
In Egypt, where tourism is the leading foreign exchange earner (UNWTO, 2012), the South Sinai governorate has been targeted for development and modernization. The past twenty years have seen vast tourism related developments driven by policies in Cairo and supported by international agencies such as USAID and EuropeAID (Ali, 1998; Silberstein 2001; Sarnowski, 2010). The leisure industry in South Sinai is, to most development planners, an economic success story, turning what was 'unproductive land' into one of most dynamic economic spaces in Egypt. Today, the city of Sharm el Sheikh plays regular host to international political and economic conferences attracting people from around the world to its resorts. St. Katherine is a small part of these wider transformations in Sinai, but is nevertheless considered a critical node in the South Sinai tourism network and an important component of the region's "marketing mix". Tourism consultants claim that St. Katherine could become a "stand-alone product" for its strengths as "the authentic, rugged, historical $[\ldots]$ Bedouin heart of South Sinai $[\ldots]$ the center for adventure and mountain tourism" (Baca, 2007, p.2-12)

Tourism in St. Katherine epitomizes Harvey's notion of the spatial fix. A conflagration of political economic factors combined to transform what were a few dispersed homes around the St. Catherine Monastery into a place for capital investment, increased consumption and an important administrative municipality for the South Sinai governorate. As my landscape analysis uncovered (chapter 3), water has played a crucial role in this process. In order to recognize how hydro-cultures are evolving however (chapter 5), it is crucial to first understand the socio-economic changes through which St. Katherine's recent metamorphosis has come to pass. I use the term socioeconomic change here to refer specifically to the transition from a pre-capitalist to capitalist based mode of production. The remainder of this chapter looks at these changes by integrating previous scholarship in St. Katherine with my own research findings. 


\section{Pre-capitalist livelihoods}

For centuries the St. Catherine monks acted as rulers and arbiters over their Sinai realm, governing via a quasi-feudal system. For the right to cultivate church lands, the Jebelaya, whose ancestors were brought in to provide defense and labor, were required to provide half their harvest to their patrons, an arrangement which lasted in some form up until 1967 (Marx, 1980). The monastery had formal contracts of employment and security with many Sinai tribes, governing everything from rights of passage, trade commissions and caravan routes, but its closest relationship was always with its immediate neighbors. In 1988 the Wulad Sa'iid tribe sent a delegation of 250 men to the monastery insisting that they should be permitted to supply guides and camels to tourists around Jebel Musa like their Jebelaya counterparts. The archbishop located a two hundred year old document stating that the region around the monastery was exclusively under the purview of Jebelaya labor (Hobbs, 1995). While historical precedent is central in fashioning economic relationships in this landscape, these types of arrangements are changing. The introduction of capitalist driven social relations is quickly altering century old traditions and habits in the region.

In the 1970s, anthropologists based out of the newly established settlement of Katriin engaged in long-term studies of Jebelaya household economies and livelihoods around St. Katherine prior to the introduction of the mass tourism economy there. Core occupations were grounded in both semi-nomadic pastoralism and horticulture. On average each family had a herd of about sixty animals, divided between sheep and goats. A yearly combination of horizontal and vertical migratory patterns was in place to manage the limited fodder available within the tribe's small territorial radius. In the winter months, grazing grounds were limited to lower lying valleys, while the summer saw a transition to higher altitudes where shrubs and grasses thrived 
(Perevolotsky et. al 1989). Orchards were cultivated by individual families and each had at least one water source associated with it. Agricultural surplus was sold in the port city of Tur and could provide income sufficient for up to six months a year (Perevolotsky, 1981). These core occupations were always supplemented with other forms of work (charcoal manufacture, guiding pilgrims, hunting, herding, leading caravans, smuggling or working for the monastery) but oscillation between different jobs never led to particular specialization or permanent waged labor (Rabinowitz, 1985).

This situation began to change drastically under Israeli occupation of the Sinai from 1967 - 1979. While old markets became inaccessible, new ones also opened up. The Bedouin economy became linked to the Israeli market in which the cost of living was much higher than the Egyptian one. Exchange values fluctuated as the development of oil fields, mining deposits, tourism enclaves and their associated construction sites created new lucrative and seemingly unlimited employment opportunities. But this all unfolded at the expense of breaking down the possibility of maintaining previous core livelihoods.

"Having lost Egyptian markets for their fruit, [Bedouin] could not afford to invest in keeping their gardens productive; and the effect was similar in herding. As the cost of living and inflation rose and the need to earn cash increased, more people settled close to roads and population centers where work and transport were easier to access. This put immediate strain on winter pasturage close to settlements. The impact was severe. For the first time, regular supplementary fodder, expensively transported from Israel, was essential to see flocks through the winter months. Dramatic reduction in flock size were required if herding was to remain viable [...] by 1975 anyone keeping a flock through the winter would actually be making a loss" (Gilbert, 2011, p. 12)

Under Bedouin law (urf), grazing grounds were not to be overexploited, but this became inapplicable with the advent of rapid sedentarization. Furthermore, the concentration of what was once a spatially dispersed population into concentrated settlements changed the way water was accessed and the uses to which it was put. Wells that had previously provided sustenance to one 
or two families quickly became sources supporting entire neighborhoods. As more and more people chose to build homes and settle down to access good paying tourist related jobs, the Israeli administration was compelled to drill deep wells in order to supply enough water to the growing population. Over the following decades, both the Israeli and Egyptian governments became key players in water provisioning for people living in population centers, and thereby beginning negative notions of dependency.

\section{Economic transformation}
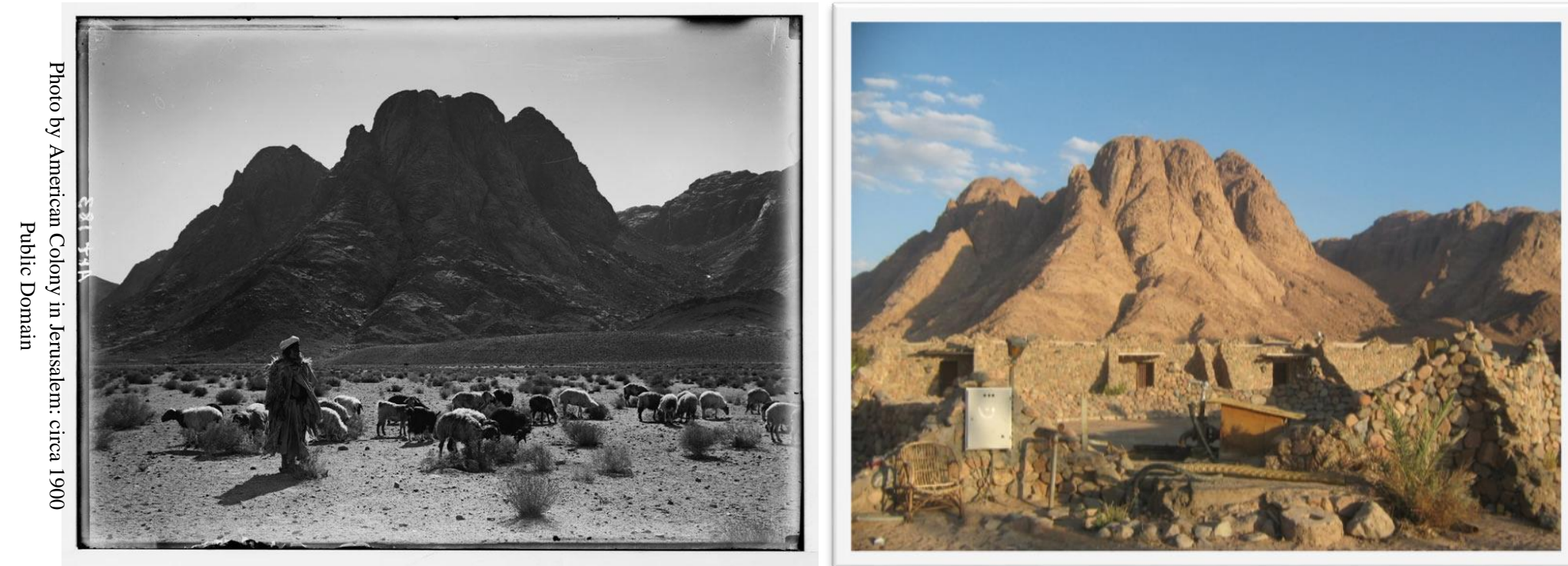

These two photographs, taken over a century apart tell a visual story of the socio-economic changes that have taken place in St. Katherine. The image on the left depicts a Bedouin grazing his goats and sheep in Wadi Raha with Jebel Safsafa rising in the background. I took the photograph on the right from nearly the same vantage point on the grounds of the Wadi Raha hotel.

Martin Glassner (1974) examined the economic, educational and healthcare transformations that the Israeli administration brought across the Sinai and summed up the changes underway as "irreversible forces" claiming that for the Bedouin there could be "no return to the pre-1967 way of life" (p.60). The introduction of a socio-economic system based predominantly on the wage relationship and the provision of government subsidies and services continued apace after Egypt regained control of the Sinai. The new government crafted a plan with the support of 
USAID (Dames and Moore, 1985) that envisaged massive economic development of the area and the transfer of 5 million Egyptian residents to the Sinai. While these grandiose plans never came to full fruition, subsequent development initiatives built on the ideas proposed in the 1970s (SEAM, 2003; P.A. Consulting, 2007) and have had a major impact toward refashioning economic relations across South Sinai (Gilbert, 2011).

In St. Katherine, the implementation of economic development projects focused on tourism expansion and have had a direct effect on the Jebelaya's ability and willingness to exercise the livelihoods that they were once accustomed to. The growth of this transient industry has led most to depend on a steady flow of tourist based income to provide for their families. Some maintain small herds ${ }^{12}$ and continue to tend their gardens if it is not too distant from the city, but my own observations in the area revealed that these were few and far between. The vast majority have permanently entered the tourist economy as guides, shopkeepers, taxi drivers, hostel owners or government employees. Most have been separated from the resources that previously sustained them, and their labor is now tied to wages necessary to purchase food, water, clothing and other materials needs.

While it would be naïve to claim that the Jebelaya have gone through the same experience as $18^{\text {th }}$ century English serfs, what has unfolded in St. Katherine over the past thirty years does present some similarities to what Karl Marx saw as the emergence of a laboring class parallel to the introduction of capitalist social relations. In his words, this transition occurs in "those moments when great masses of men are suddenly and forcibly torn from their means of subsistence and hurled as free and 'unattached' proletarians on the labor market" (1954: 878). The Jebelaya have

\footnotetext{
${ }^{12}$ A number of homes have small enclosures for animals which are mostly fed from fodder purchased in town. Many households also have a space for a camel or two which are critical part of the tourism trade, but also incur food and water costs for their maintenance.
} 
had little choice but to abandon the livelihoods that had sustained their presence in St. Katherine for centuries. A combination of climactic and capitalist pressures have compelled them to enter new modes of production through wage relationships, in the process engaging with a set of global economic processes over which they have very little control.

\section{E. Social transformation}

The Jebelaya relinquishing their means of production is not necessarily perceived negatively. Linking to wider capitalist processes has significantly increased material wealth in the St. Katherine community, and many expressed that they would like to see more investment in the area. Cars and motorcycles, televisions, computers, gas stoves, and other luxuries that were never a part of nomadic lifestyles are now prevalent. Washing machines, toilets, showers and kitchens are being installed in homes, and while these increase the amount of water consumed for domestic purposes, they have become a status symbol and pre-requisite for many fathers negotiating their daughter's marriage agreements. Gender is not an explicit focus of this study, but it is worth mentioning here that the socio-economic changes underway have had an isolating effect on many women. The disappearance of their primary economic roles as goat herders has altered their habits. While previously free to roam the mountains for the entire day in search of fodder, many are now confined to the home. Furthermore, sewing and beading, which were occasional crafts for special events such as weddings and births, have now become a new source of income with the high tourist demand for 'traditional Bedouin crafts'.

Even as families now live closer together in urban neighborhoods, some communal ties are breaking apart. During a conversation with a group of women, one of them said to me: "We used 
to do laundry together, now we have our own washing machines. "13 Traditional customs confront the appeal for material possessions seen through television screens and foreign tourists, altering consumption standards and the perception of everyday necessities. Income disparities in the community are on the rise as some have understood how to negotiate the economic changes underway better than others. Simultaneously the desire to maintain an identity tied to a previous way of life has led to an upsurge in urban gardens. Many Jebelaya have developed spaces beside their home in town to cultivate fruit trees and vegetables. There are now hundreds of green spaces in an area where there used to be none, an undertaking which requires significant amounts of water and has created tension among neighbors: "If one person digs down with his well to get more water for his big garden, then other people whether they have the money or not, also must find some way to go down."

Sedentary Bedouin in Katriin have been joined by Nile valley workers seeking to ameliorate their economic status. They have migrated in search of better paying jobs and their numbers are expected to surpass the Jebelaya population there. Mountain vacation residences are being built for Egyptian elites looking to escape the crowds and smog of Cairo and multi-story apartment complexes provide housing for a population forecasted to grow three fold by 2017 (Sims $\&$ El Miniawy, 2003). This population increase leads to further consumption possibilities and retail spaces are being expanded across town. Grocery stores, hardware supply shops, restaurants, internet cafes, pharmacies, cell phone outlets, and a laundry now service the diversifying material needs of Katriin's residents. Speaking directly to the population growth driven by Egyptian migrants, one Bedouin research participant held the view that Egyptian presence there is leading to an amelioration in overall social conditions because the small businesses that they operate contribute to the well-being of the whole community.

\footnotetext{
${ }^{13}$ Ethnographic notes: June $3^{\text {rd }}, 2012$.

${ }^{14}$ Interview \#11: June $24^{\text {th }}, 2012$
} 
"The more people here, the better the life will be. Now there is a supermarket, but there was not that before. When the Egyptians are coming there is more life, it's better to have more people. Of course when there are more people we need more water, but for us it's better that there are more people." 15

Tourists are also generating major consumption shifts. The cash they spend in St. Katherine drives the entire consumptive process forward and hotels must match the standards that travelers expect during their vacations. Guide books rate accommodations and the services provided there and owners must keep up with market demands if they want to continue to attract customers to their facilities. I asked the manager of one of the Bedouin owned hostels in town about the renovations that took place on his property over the past five years, particularly investments into upgrading their bathroom facilities. He told me: "you have to deal with the market around you, because if people are coming here for two or three days they want to have it comfortable. Some people are on honeymoons, or happy to be together and if I don't do the bathroom I will lose this customer, so I have to improve it."16
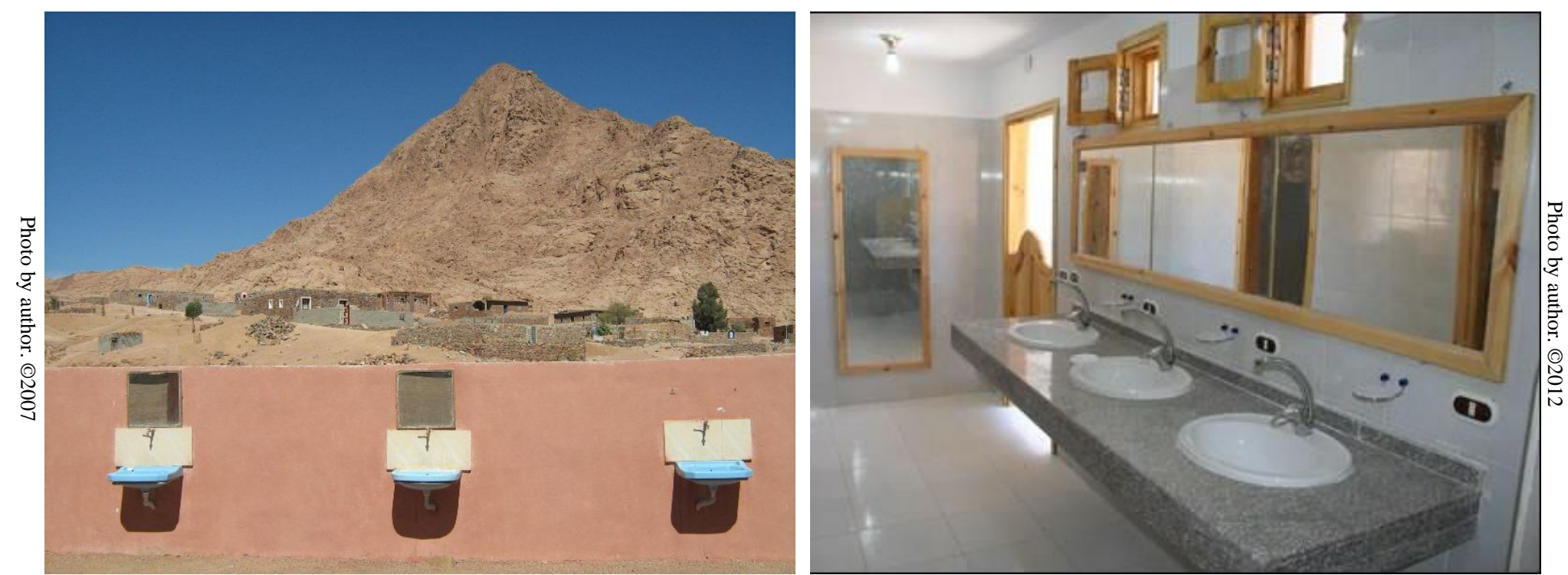

These two photographs were taken five years apart from the same Bedouin-owned accommodation in Katriin. The investment in upgrading bathroom facilities is clearly noticeable. The enclosed bathroom on the right is much more familiar to visitors but its enclosure disconnects it from the desert landscape. The manager told me that water consumption rates have increased since the upgrade.

\footnotetext{
${ }^{15}$ Interview \#3: June $13^{\text {th }}, 2012$

${ }^{16}$ Interview \#9. June $15^{\text {th }}, 2012$.
} 


\section{F. Water consumption}

St. Katherine has become a consumptive center in a much larger network of global capital circulation, staving off ever so slightly the problems of overproduction that a system based on financial growth engenders (Fletcher, 2011). The increases in water consumption associated with the socio-economic changes described above are enormous. While I have analyzed economic and social change separately here, they are in fact co-constitutive, one continually reverberating off of the other. The production of St. Katherine as a spatial fix through tourism has only been possible via the transition from a pre-modern water system to a modern one (Chapter 5). Modern water systems require high capital inputs for pipes, reservoirs, pumps and their energy inputs. Public funds into modern water infrastructure have provided the lubricant for private investments and maintained the engine of capitalist growth there. A cost-benefit analysis of infrastructural projects in the South Sinai governorate in 2003 estimated that $98 \%$ of the water supplies in the province are used by hotels and restaurants. (Makary Consulting, p.23). While this figure is likely lower in St. Katherine, the statistic is telling of the water resources necessary to maintain the tourism economy that has developed there.

As groundwater levels have receded during the last two decades of drought, the government, the monastery and wealthier Bedouin families have pumped from deep boreholes to provide for increased water needs associated with urban lifestyles. In 2007 the European Union sponsored South Sinai Regional Development Program (SSRDP) commissioned the construction of a pipeline and water treatment plant for the water supply of St. Katherine and Feiran villages. The tender included the connection and transmission pipe over $95 \mathrm{~km}$ and $1400 \mathrm{~m}$ difference in altitude, four new water pumping stations and two new water reservoirs at a cost of 34 million 
euro (EuropeAID, 2007). A sewer system transports grey-water out of the city, but many homes have yet to be linked to the central pipe, and its capacity is not large enough for the swelling demand and many wells are contaminated by urban pollutants leeching into the aquifer (Hesham et. al, 2003).

Monthly water deliveries are now supplied through a public-private partnership with the national water company. Each household with an electric meter is permitted to have water delivered to a kharzan built near their homes - cement tanks that hold between 10 and 12 cubic meters of water. These now dot every neighborhood feeding water into kitchens and bathrooms, urban gardens and livestock pens, fixing water in place. Water consumption is tied directly to

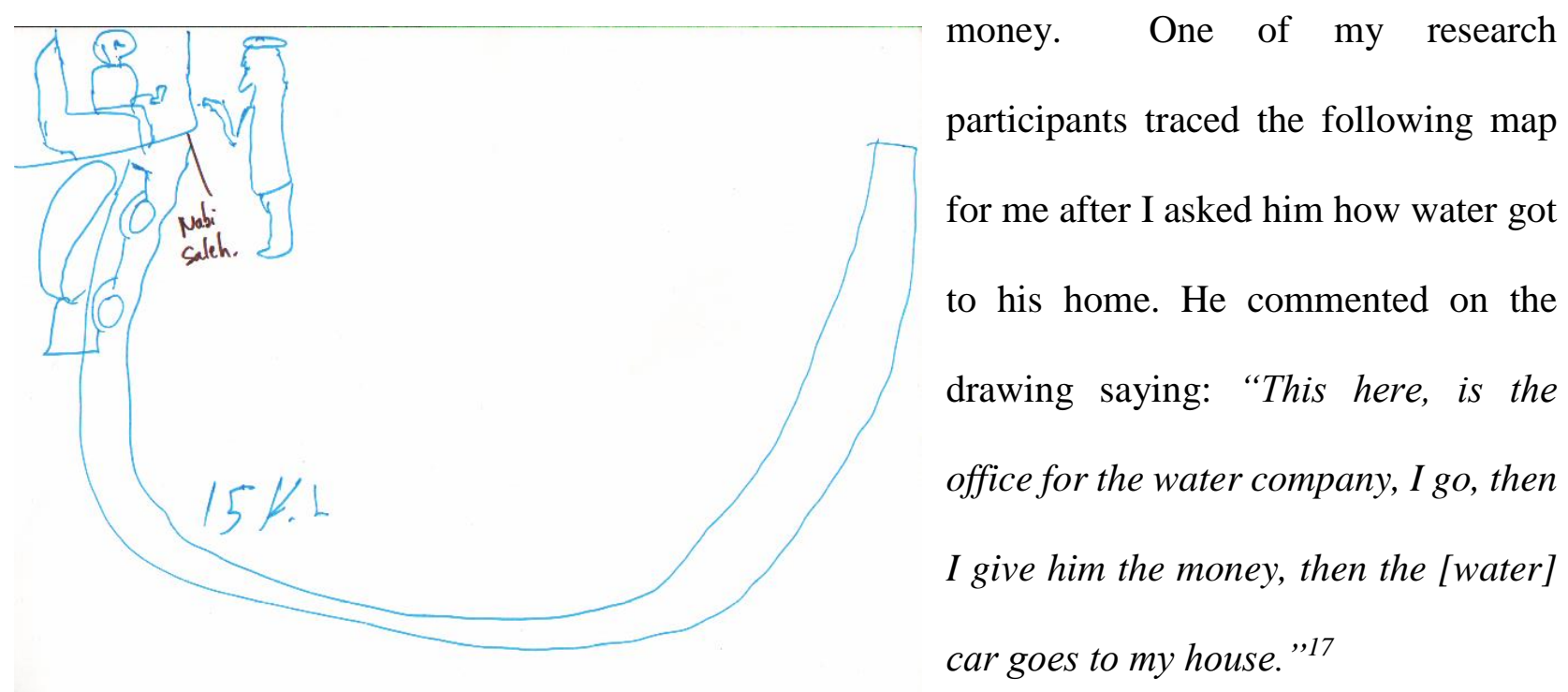

\section{G. Summary}

The production of a tourist enclave in St. Katherine is a spatial fix. Since Israeli administrators first developed this place as an urban center, capital investments undergirded by international development agencies have converged on the area seeking a profitable return on

\footnotetext{
${ }^{17}$ Interview \#2: June $10^{\text {th }}, 2012$
} 
investment, through one of the largest industries in today's global economy. Waged labor accessed through tourism has broken down previous economic structures and altered social configurations. Most do not perceive the socio-economic transformations that additional money flows have provoked to be negative. Many of my interviewees mentioned that healthcare and education opportunities, along with steady food supplies and the new domestic comforts available in town are much preferred to their days of spartan living in the mountains. But maintaining these new comforts requires a steady flow of water and tourists, a balance that can only be maintained through continued capital investments in the area.

Over the past 20 years, the Sinai has undergone an extended period of drought. In previous dry times the local population would adapt by moving away and returning once the rains were more generous (Hobbs, 1995). Today, however, the availability of drilling rigs to tap water that was not previously accessible and the recent introduction of Nile water to the area have allowed a permanent population to flourish in Katriin. Changing consumption habits there have come at the expense of disconnecting from previous livelihoods and the local water sources associated with them. As they integrate wider macro-economic systems, Katriin residents have become dependent on policy decisions made in Cairo and vulnerable to global fluctuations in commodity exchange values. I argue that the abandonment of a pre-modern water culture for a modern one has reinforced these vulnerabilities, but is paradoxically the only way that St. Katherine's spatial fix can be maintained, a theme I explore in depth in the following chapter. 


\section{Chapter 5: Hydro-cultural Transformations in St. Katherine}

\section{$\underline{\text { A. Introduction }}$}

Socio-economic change in St. Katherine is intimately linked to the hydro-cultural transformation underway there. While I have separated each into its own chapter for the sake of organization and clarity, I want to emphasize that this does not denote a break between 'society' and 'nature' in my analysis. The pre-modern water systems under discussion here are associated with pre-capitalist livelihoods just as the introduction of capitalist modes of production compel the transition toward modern water forward. The hydro-cultural transformation in St. Katherine cannot be discussed separately from its relationship to socio-economic change, but rather through a relational dialectic with it, considering how these seemingly independent processes are in fact tightly linked. Studied in this sense, water becomes a historical subject in the St. Katherine landscape, one that must be 'historicized' and set against the chronology of social change there.

The South Sinai Tourism Development Plan (2008) recognized that water was a key commodity toward fulfilling St. Katherine's economic "potential", claiming that diversifying water sources and improving infrastructure was "urgent" to spur "additional investment in accommodation and other tourist products" (P.A. Consulting, p.20-18). The primary discourse emerging from development documents over the past decade is the completely incongruent notion of preserving a particular local Bedouin way of life while providing a hydro-fix to the problem of deteriorating water supplies induced by drought, urbanization and the tourist economy. The fact that these issues are juxtaposed is telling of the oft invisible negotiations taking place between a hegemonic class bent on imposing a particular way of seeing and managing water and one struggling to make sense of the new hydro-culture being overlaid over their existing one.

'Culture' has been a highly contested theme in the field of geography and the social sciences in general. I hold the view that cultures emerge out of the material realities that people find themselves in, and that they are constantly in flux, made and remade through contestations 
over particular ideas about the way that resources should be allocated and distributed among various social actors. Water has a profound effect on the cultures that emerge surrounding its use and as Baviskar (2007, p.1) reminds us, water is "an intrinsic element in the ecological processes sustaining social production and reproduction". Although it is important not to idealize or exaggerate the benefits of indigenous water systems, development planners too often ignore the fact that these have materialized in conjunction with local ecological realities. Targeting indigenous water systems for replacement by modern techniques can create new socio-economic relations (Chapter 4) while exacerbating pre-existing inequalities over water access. While the Jebelaya are still tied to local mountain water, their everyday relationship to it is changing. Sedentarization has led to new sourcing strategies and consumption habits that are colliding with long held water management practices across the area. "The water in the village is not enough because we are all consuming more water here and now there is less of it. The Bedouin do not have enough water. Those who live in the mountains ok, but those who live in the village...mmh-hmm." 18

The paradox of water scarcity in Katriin is that the historical landscape emerged out of relative water abundance. As I have discussed, the water flowing through St. Katherine provided the possibility for agro-pastoralist livelihoods that had sustained monks and Jebelaya Bedouin there for centuries. If water became scarce, as it often did, people were forced to adapt to that reality by adjusting the productive capacities to which water was channeled. Today, the spatial fix that has locked St. Katherine into wider capitalist processes and transformed socio-economic relations has produced scarcity. Barbara Rose Johnston (2003) argues that water scarcity should be studied as the

"The best water is from the mountains. It's the healthiest but it's not enough for this amount of people. It's enough for 10 homes, not 100. The Bedouin are now more in numbers than before, the families are growing in number, two families can be like 100 individuals. This is also in addition to the people coming from Egypt, like teachers, government employees. There is not enough water."

\footnotetext{
18 Interview \#1: June $9^{\text {th }}, 2012$.
} 
result of social, not ecological factors. These include increased water demands for economic growth, surface and groundwater pollution, structural readjustment policies and the enclosure of successfully managed common water resources to fit the demands of industrial capitalism. It would of course be troublesome for those behind the production of water scarcity to acknowledge that their economic activities are the cause for the deterioration of fresh water supplies. Instead, 'nature' is cast in pole position as the culprit taking the blame for what are in actuality particular political economic configurations through which water becomes scarce. Droughts tend to be coopted into the accumulation process itself. Maria Kaika's (2003) research on the drought affecting the city of Athens between 1989 and 1991 treats drought as a discursive tool to facilitate neoliberal market-driven 'solutions' through large infrastructural upgrades that served specific social, political and economic interests.

The decline of local water resources in St. Katherine is directly connected to changing water cultures there. There is no longer enough groundwater available beneath Katriin to provide for increasing population densities, a problem exacerbated by the stream of visitors liberally consuming water in hotels and rest houses every day and the drug fields irrigated in areas beyond the tourism enclave ${ }^{19}$. Rather than addressing the structural incongruities associated with building up a consumptive space for tourism in an environment that cannot support it, the development discourse that has emerged has centered on water scarcity. Low precipitation levels in St. Katherine over the past two decades have served as a convenient catalyst toward reinforcing the idea that there is not enough water in the area. This 'natural' phenomenon is positioned as the culprit for deteriorating waters supplies, something that must be overcome through development intervention.

\footnotetext{
${ }^{19}$ Opium and Marijuana are cash crops that are in high demand in the coastal resorts along Sinai's coast. Some Bedouin who do not have access to income from the tourist economy have turned to drug production for their livelihoods after the shift to a cash based economy. For further reading on the drug economy in Sinai see: Hobbs, J. Troubling Fields: the opium poppy in Egypt or Marx, E. Hashish smuggling by Bedouin in South Sinai.
} 
As Katriin residents transition from artisanal to industrial modes of water supply, 'modern' sourcing strategies are being overlaid on top of ‘pre-modern' ones (Linton, 2010), an effect which has paradoxically reinforced the production of scarcity. In this chapter, I present contemporary sourcing strategies in light of traditional ones and explore reactions to the transition toward modern water from the perspective of different stakeholders there. Drawing on original research from my two months of field work I challenge the idea that water is scarce in St. Katherine. I argue instead that replacing premodern sourcing strategies (well adapted to the physical landscape) with modern ones (requiring outside material and energy inputs) is at the root of most of St. Katherine's current water woes.

\section{B. Pre-modern Sourcing Strategies}

Water in Sinai's high mountains has never been assured and when precipitation does occur it is often over limited areas. Rain and snowfall fluctuate from year to year, providing periods of relative abundance and drought. In 1384, monks told visiting pilgrims that they had not seen rain in six years (Bellorini and Hoade, 1948, p.108), and there are other accounts of long droughts in the area (Hoskins, 1909, p.1016). By contrast in 1929, after a very wet spring, the well of Moses within the monastery walls overflowed with water (Hobbs, 1995, p.12). The cyclic nature of rainfall is well understood by the Jebelaya community: "In the Sinai here, every forty years the weather changes. My grandfather told this to my father, and my father told me, and I tell my children. Every forty years it is green, and every forty years it is dry. Now we've had twenty dry years. ${ }^{20}$ Although I never witnessed large amounts of water flowing through St. Katherine's landscape during my time there, many of my research participants recall days when streams flowed through the valleys nine months a year and water pools provided areas for children to play and bathe in the summer months.

\footnotetext{
${ }^{20}$ Interview \#10: June $17^{\text {th }}, 2012$
} 
The water springing out of this alpine desert, sporadic as it is, has served to construct a particular culture surrounding its use. In such an arid environment, the contrast between water rich locations and dry ones is evident and many place names identify the streams, waterfalls or types of plants that can be found there. The names attributed to different types of sources, naggat (dripping place), galt (pool), kharaza (bead), masak (gripper), umshaash (soaker), thamilla (dregs), ma'iin (cliffside seeps) are a testimony to local knowledge about the water flowing through this landscape. The Jebelaya Bedouin are tied to these waters, and its movement across and under the earth. Abundant snow (telg) assures a copious year as melting provides water for months on end. A 'rocket' (saruukh) is the term used for flash floods, short bursts of hard rain that descend slopes quickly often leaving destruction and death in their wake, but also enriching the valley floors with the silt it transports. The strong rock walls built around mountain orchards aim to divert these powerful waters and prevent them from washing away the years of work accumulated there. Everyone hopes for lighter rains (ray) as the runoff from this type of precipitation forms consistent streams that collect in natural pools and refill the aquifer below.

Accessing water for productive purposes has until recently depended entirely on the force of gravity in conjunction with muscle power through human and animal labor inputs. A network of catchments barriers, built by constructing rock walls in strategic locations (agem), slows and collects the water flowing downhill. It is redirected using channels dug into the rock and guided into holding cisterns. When surface water is not available it is accessed via wells (abiar) that tap into subsurface groundwater. After water is drawn from a well, the well refills as the porous rock in which the shaft is dug slowly lets water enter again. The course of subterranean flows can shift, and a productive well does not always ensure a steady supply. A source that has produced for decades might go dry in a matter of weeks, and people inhabiting this landscape have adapted to this reality. There are hundreds of wells in the high mountain region today, though not all currently have water, and the remnants of catchment and channel systems can be seen in many different places across the landscape. Today small 
plastic pipes run along valley floors channeling water toward gardens and certain homes still connected to mountain water. Although these pipes are modern inputs, it is important to note that their use enhances that of traditional water systems and remains well adapted to the bio-physical realties of the St. Katherine landscape.

\section{Modern Sourcing Strategies}

Drill rigs, water trucks, diesel pumps, sewer pipes and water relay pumping stations have become essential components of St. Katherine's contemporary waterscape augmenting the existing network of catchment, canal and well systems. A large portion of the water flowing through the St. Katherine today is delivered to consumers by the Holding Company for Water and Wastewater $^{21}$ (HCWW) or individual well owners who have the capital to drill deep wells. Modern inputs have made it possible for an urban center servicing tourism to emerge, but they have also led to a 'race to the bottom' as private parties seek a return on their investments into waterworks selling water to the highest bidder. Money and water are now interconnected in St. Katherine, and a commodity that had long been perceived as a commons is increasingly being allocated based on who can pay more for it. The government has been able to reduce tensions surrounding water commodification by subsidizing nearly $95 \%$ of the cost of water for St. Katherine residents, but it remains to be seen how long such a subsidy will last under the current financial difficulties the country is facing. Although there are a few places where surface water is still available ${ }^{22}$, most of the water flowing through this landscape is drawn from deep below ground or pumped from the Nile River.

\footnotetext{
${ }^{21}$ The Egyptian government underwent water sector reform in 2004 with the assistance of western donors. Fractured service providers were privatized and consolidated under the HCWW an umbrella for 26 private companies that now own and operate all water related infrastructure in Egypt. This holding group is supervised by the Egyptian ministry of water supply and sanitation.

${ }^{22}$ Kharazet el Shaq and Galt el Azraq were the only surface water pools in the area at the time my research was conducted.
} 


\section{Ground Water}

Groundwater is a hybrid between pre-modern and modern inputs. There are approximately 600 active wells across the St. Katherine protectorate all of which tap into an isolated underground water system. Some are dug by hand while others are bored using drilling equipment. Unlike most aquifers, impermeable basement rock means that water recharge to this system comes almost exclusively from precipitation and its ensuing runoff, although a limited

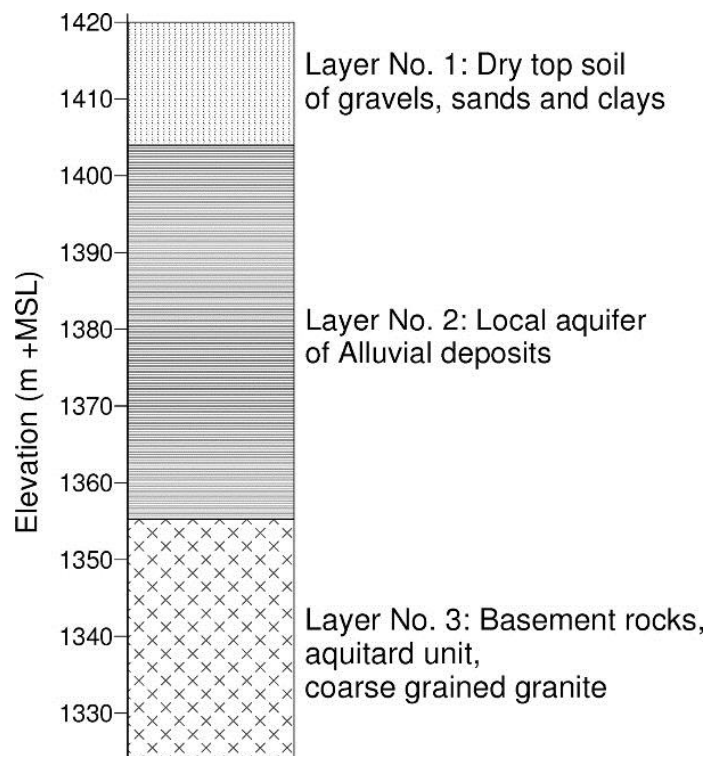

Generalized stratigraphic section of St. Katherine's subsurface Source: Khalil, M. (2009) amount of fossil water does seep in through some faults and joints in the rock (Tantawi et. al, 1995). Irregular dikes cross-cut the aquifer and act as underground dams resulting in an elevated water table in certain places, and a lower one in others. (El-Sayed et. al, 2012). This 'underground river' is interconnected across the watershed and just a few millimeters of precipitation increases water levels throughout the region in a matter of weeks. The reverse is also true. Drawing more water from the wells than is replenished by rainfall results in an overall drop in the water table and necessitates deeper wells in order to continue reaching the source. The aquifer contains mineral salts (halite, gypsum) that are dissolved by groundwater and control salinity. As water levels decrease, salinity rises and vice versa.

As of the summer of 2012, the high mountain region (above 1,800m) wells were approximately 3-10 meters in depth. Continuing down the alluvial plain
"The groundwater is the same everywhere. It draws from the same water store. As long as it's slow, it's slow everywhere. But in this area where our well is there are three wells at the moment. But if they make ten wells, instead of sitting there for 10 years, it will only be available for one or two years because it is taking it from the same source."

Interview \#4: June $13^{\text {th }}, 2012$ 
toward the town of Katriin $(1,600 \mathrm{~m})$ water levels were significantly lower making it more difficult and expensive to access. Most wells in and around town are between 25-30 meters deep. At lower altitudes still in Wadi Feiran $(700 \mathrm{~m})$ some wells as deep as 50 meters have gone dry, and one interviewee had a 70 meter well that was providing less than enough for his daily needs. Those who have wells on which their livelihoods still depend have been forced to dig ever deeper in order to continue reaching groundwater from them. Many of these are still dug by hand, but increasing depths require diesel motors to draw up the water. It is a two or three person job chipping away at the bedrock, lifting the refuse out of the well shaft and reinforcing the walls with rock and cement so that it does not collapse on itself. If the owner of the well can afford it, he pays day laborers to do this work for him ${ }^{23}$. One of my Bedouin interviewees said that he invested around L.E. 6,000 (approximately $\$ 1,000)$ on labor and materials in order to dig one additional meter, a very significant cost equaling two months of an average wage in Egypt. Over twenty years water levels have dropped from a depth of 5 meters, to his current 30 meters compelling him to invest every year to maintain his source. He uses a diesel pump to draw the water, as it would be very difficult to draw by hand at such depths. Every three days the motor consumes 25 liters (6 gallons) of fuel another cost associated with drawing water. This is not uncommon, in fact most wells in the area now use diesel pumps to draw water.

The hand dug wells in the photographs below provide a visual perspective on water table levels in different locations. Figure 1 and 2 are shallow wells in water rich areas, while figure 3 and 4 are closer to the city where levels have dropped significantly in the past decade and now require diesel pumps to draw the water out.

\footnotetext{
${ }^{23}$ These are most often Saidi, migrant workers from Southern Egypt who hire themselves out as day laborers for construction related jobs.
} 

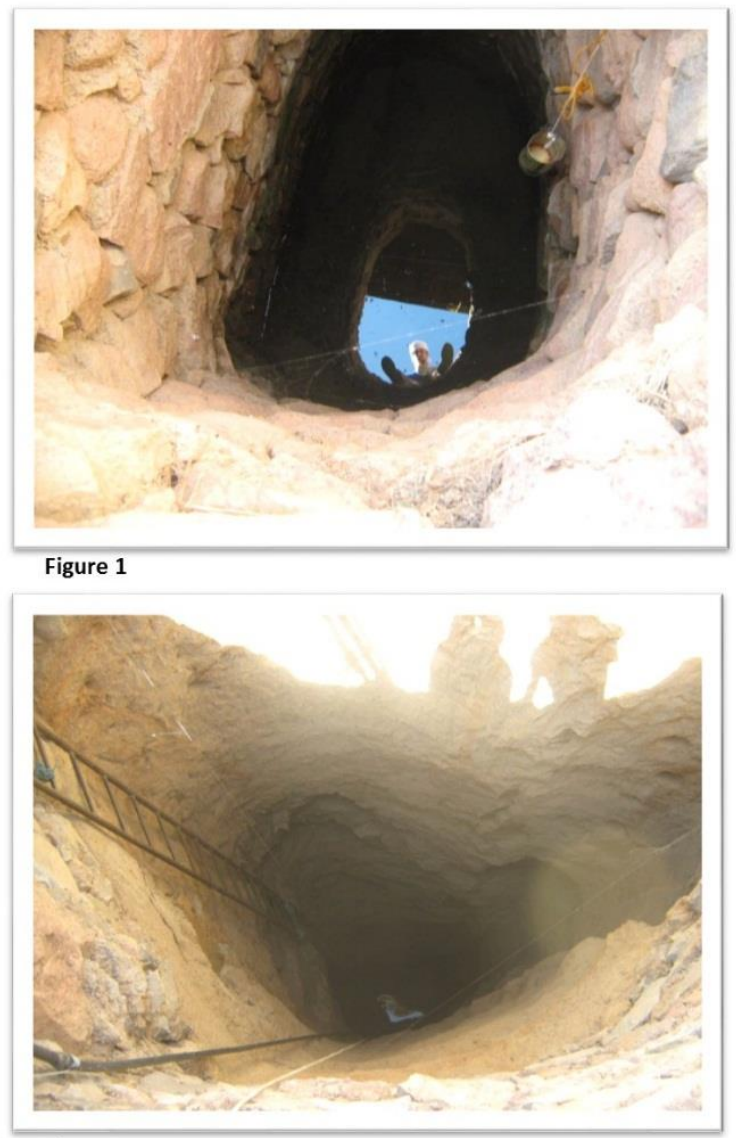

Figure 3

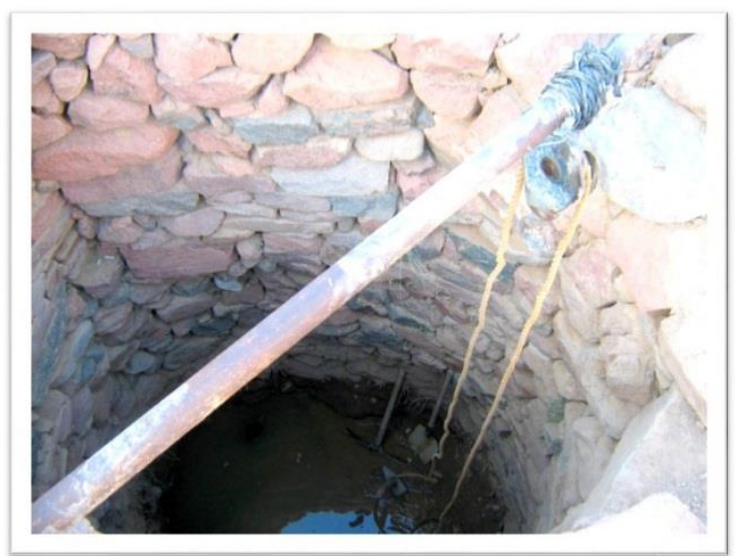

Figure 2

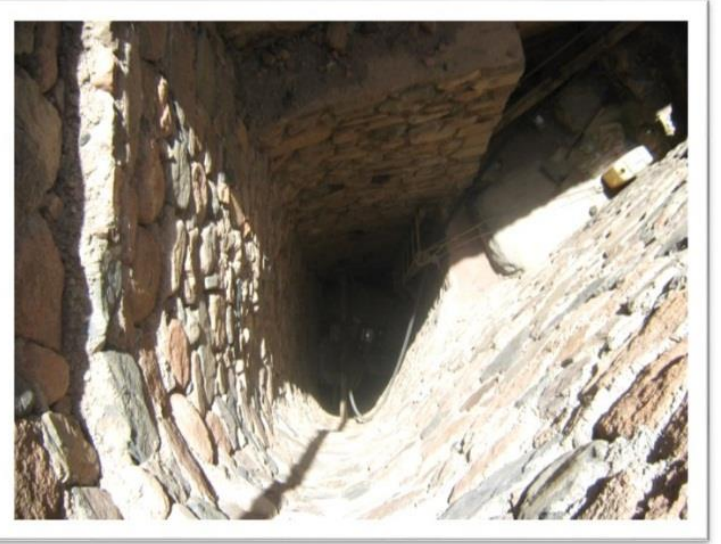

Figure 4

The irony of the shift toward modern inputs in St. Katherine is that while water is now

located at greater depths, the introduction of motorized pumps has increased withdraw rates significantly and resulted in a major reduction in overall groundwater levels across the region. Hand dug wells are not the primary culprits for this lack of groundwater however. Deep wells have been bored using drilling equipment. The monastery owns one such well right at the edge of town, an investment which has assured a steady high pressure flow of water to its multiple properties despite the drought. The water feeds its ongoing agricultural activities in the area as well as the 150 bed guest house adjacent to the monastery. Other private "When things were done by hand, the wells used to bring blessing (Baraka). Now with motor pumps people have become lazy and the well do not give as much as before."

owners in the area have invested in deep wells outside 
the city as well, some in collaboration with the government. These 'water barons' provide to the area's businesses including the local water company when its supply falls short.

\section{Nile Water}

Lack of rain combined with over-pumping has limited groundwater stores and created a compelling excuse for bringing additional water to the area. In 2008 the European Union funded a waterworks project for the town of St. Katherine to pump Nile water over 90 kilometers and up to an altitude of 1,600 meters. The project cost 34 million euro and was completed in late 2011. The pipes and pumps were handed over to HWCC who now owns and operates a network with the capacity to draw 300,000 liters of water to the area every day. The opening of the pipes was met with skepticism by most of the community especially as it became clear that this new source was not very reliable. The water company is currently having trouble providing regular deliveries to resident homes. The system is not yet working to its full capacity because

I won't connect my home to Nile water because it isn't reliable. The holding tanks are not big enough to supply the town even for one day. If the pipe breaks somewhere I will be out of water. I prefer to keep my tank and have water delivered by truck which guarantees me a month's supply.”

- $\quad$ Ethnographic Notes: June $17^{\text {th }} \cdot 2012$

there is not enough electric power to draw the water up from sea level to the mountains. The project was supposed to link homes directly to a central network, but this has only happened in certain places thus far and to date most are still receiving their deliveries by truck into $10-12 \mathrm{~m}^{3}$ holding tanks built above their homes.

Residents pay L.E.10 for an $8 \mathrm{~m}^{3}$ delivery every 25 days. They must go to HWCC offices in Nabi Saleh 10 kilometers outside of Katriin to pay their bill (recall the mental map in chapter 4). The costs that they pay for this water are not a reflection of the true price of transporting it over 600 kilometers and 1,600 meters in altitude. The government pays HWCC L.E.150 per domestic delivery, subsidizing the cost of water for local residents. This arrangement is extremely beneficial 
to both domestic consumers, most of whom would never be able to afford such high prices, and the recently privatized the national water company. Businesses must pay a full rate at L.E.160 for an $8 \mathrm{~m}^{3}$ delivery or L.E.300 for $17 \mathrm{~m}^{3}$. The non-subsidized price of Nile water from the HWCC is much more expensive than paying a private party to deliver groundwater from a local source. I spoke with the managers of two of the largest hotels in Katriin and was surprised to discover that they still contract with a Bedouin family for all their water deliveries. The prices varied for each hotel, reflecting the extreme inconsistencies associated with water pricing mechanisms in the transition toward modern water. One pays L.E.200 for a $17 \mathrm{~m}^{3}$ delivery the other, L.E. 120 for the same amount. Either way, the fact that hotels in the area, some of which include swimming pools, are consuming groundwater resources is inconsistent with the development discourse which claims that improvements in water infrastructure there are meant to support the tourism trade. If tourism related businesses are still sourcing ground water, than this brings up important question about the role that Nile water plays in maintaining the cultural hegemony of capital development in the area. Though my data does not directly speak to this issue, I contend that the Nile water pumped to St. Katherine is serving to gain quiescence from a local population whose groundwater is being robbed for commercial interests.

Ninety Nine Percent of Katriin residents depend on HWCC deliveries, but there are not enough tanker trucks circulating to keep up with the growing demand. Many of my interviewees mentioned that there are significant delays in deliveries and that they run out of water at times, requiring them to ask their neighbors to share with them. Those who have the means to pay for it call one of the truck drivers on his personal cell phone and request an immediate water delivery 
for a bribe of L.E.50 or L.E.100. The driver pockets the cash and splits it with HWCC management who turn a blind eye to the fact that the delivery was not scheduled. Backlogged deliveries and delays have
"If you do not have any water at home and they say the trucks stop you have to bribe, you have to pay a lot to bring the water in a not legal way. But you have to do this, I mean there is no other way."

- $\quad$ Interview \#4: June $13^{\text {th }}, 2012$

created tensions in the community and during my time conducting fieldwork a group of protesters blocked the main road into St. Katherine for an afternoon to demonstrate over insufficient water deliveries.

\section{Drinking Water}

All my interviewees, save those living exclusively off of their own wells, differentiated between the water they used for domestic purposes (bathing, cleaning, flushing, animals, plants) and that used for direct consumption (drinking and cooking). The latter was always perceived as being of higher quality, in terms of taste, cleanliness or both. There are different types of bottled water available in St. Katherine. Water under the Dasani (Coca-Cola), Baraka (Nestlé) and Aquafina (Pepsi) brands are sold in local grocery stores in 1.5 or 5 liter bottles. Their cost is exorbitant considering the price of the other locally available bottled water. The biggest market for these bottles are tourists and short term Egyptian residents who do not have connections to a good local source. Most Katriin residents source their higher quality water from a set of local wells that have lower levels of salinity and have not been polluted by grey-water runoff. Drinking water is always free if the person travels to the well to get it, a tradition that is consistent with the idea that water is a common resource. Many residents do not own cars but for 2 or 3 L.E. they can purchase a jerry can delivered by pick-up truck directly to their homes. 


\section{4. $\quad$ Multiple Sourcing Strategies}

There are vast inconsistencies in both the quality and price of the different types of water flowing through the St. Katherine landscape today. Contemporary sourcing strategies are an amalgamation of local groundwater, Nile water and bottled water. Although the cultural tradition of providing free drinking water remains, its commodification in the domestic and business spheres is a major and ongoing evolution. Social connections and cash now provide certain social actors with greater access to water at cheaper rates than others. While most residents dependent on HWCC for their water needs, many are not yet convinced that the Nile water scheme it manages will be successful. As water is increasingly urbanized, the inputs required to access it and the habits surrounding its daily consumption are changing. Hydro-cultures are evolving with the material realities of a shift from a pre-modern water provisioning systems to a modern one.

\section{Evolving Hydro-Cultures}

The shift toward modern water in St. Katherine has been gradual and is by no means complete. It is rather an ongoing process arising out of a variety of factors, not least of which are the socioeconomic transformations currently underway there. The waterscape is quickly evolving from one based on human labor and locally sourced materials to a complex network of outside energy inputs operating complex infrastructural expansions. As the transition toward modern water unfolds, Katriin residents are increasingly disconnected from their traditional water sources and more dependent on a rather limited number of powerful social actors that control water resources within the landscape and provide water to the majority of residents there. 
To illustrate this hydro-cultural shift, I provide a comparative analysis of four mental maps. These maps all emerged during the exercise in which I asked participants to "draw the source of your water and how it got to your home [or place of business]". The data that I present here comes from both a direct analysis of the map itself, and from the conversations that I had with my research participants as they were drawing or explaining their mental maps to me. The diverse representations of water provisioning strategies in these maps reveal that the waterscape in St. Katherine remains an evolving patchwork of differentiated and often highly contested sourcing strategies, out of which a hybrid water culture is emerging in a grey zone between pre-modern and modern water. These maps show a clear contrast between material inputs and people's perceptions of the water flowing through the St. Katherine landscape. Analyzed together, these different ways of viewing water serve to confirm Linton's (2010) assertion that "water is a cultural product in the sense that different people possess different knowledges of water, ascribe different meanings to water, and appraise and engage with water in very different ways." (p.53) 


\section{1. $\underline{\text { Map } 1}$}

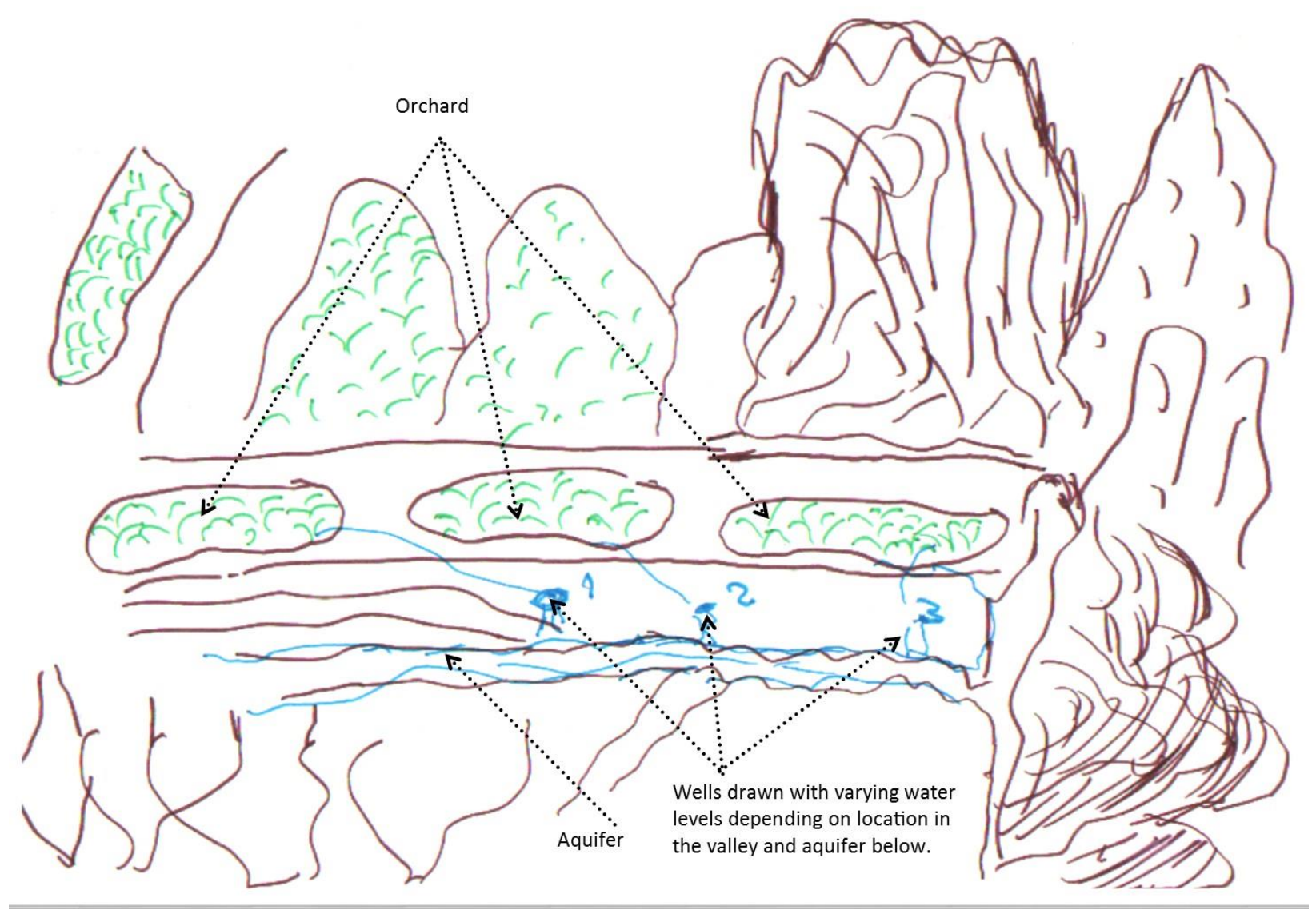

Map 1 reveals a pre-modern water culture still very connected to the region's bio-physical realities. The participant needs to know when water levels are high or low, and needs to negotiate with neighbors around him. This drawing provides a clear example of the pre-modern water culture that I argue was prevalent in St. Katherine prior to the emergence of an urban landscape there. It was drawn by a Bedouin who lives in Katriin but still sources all of his water from his wells in the mountains. Using the force of gravity and small pipes to channel the water down to his home at the edge of town, he is one of the few to still enjoy clean water from a source over which he has full material control. The space represented on the map does not include any urban developments and the orchards reflect the productive capacities to which water was channeled prior to the introduction of capitalist social relations there. 
The interviewee understands that certain areas in the landscape are more water rich than others, reflected in the contrast between green and brown spaces. The underground aquifer system represented as blue lines flows through the valley. He explained that the water table provides varying levels of water to orchard owners depending on their geographic location. I asked how endowed his property was with water compared to those around him, and he stressed that his wells provided an average amount of water (\#2). There were some who had more further upstream (\#1) and some who had less further downstream (\#3). When I probed him to explain the three different well locations in greater detail, he explained that differential water access has always existed in the area, but that the introduction of motorized pumps to quickly extract water from wells has opened up the possibility for upstream owners to take water that would have previously been more equitably shared. This has created tensions between neighbors at times.

This participant was the only one of my formal interviewees to still be completely dependent on mountain water, and the only one who drew a three dimensional map to explain where his water comes from. The fact that no other participants drew maps that come close to matching this one is telling of the hydro-cultural transformations that have taken place over the past forty years. His drawing clearly demonstrates hydrological knowledge and water's circulation through St. Katherine's physical landscape. It also demonstrates that this water can still be accessed without the use of large capital inputs into infrastructure improvements. 


\section{2. $\operatorname{Map} 2$}

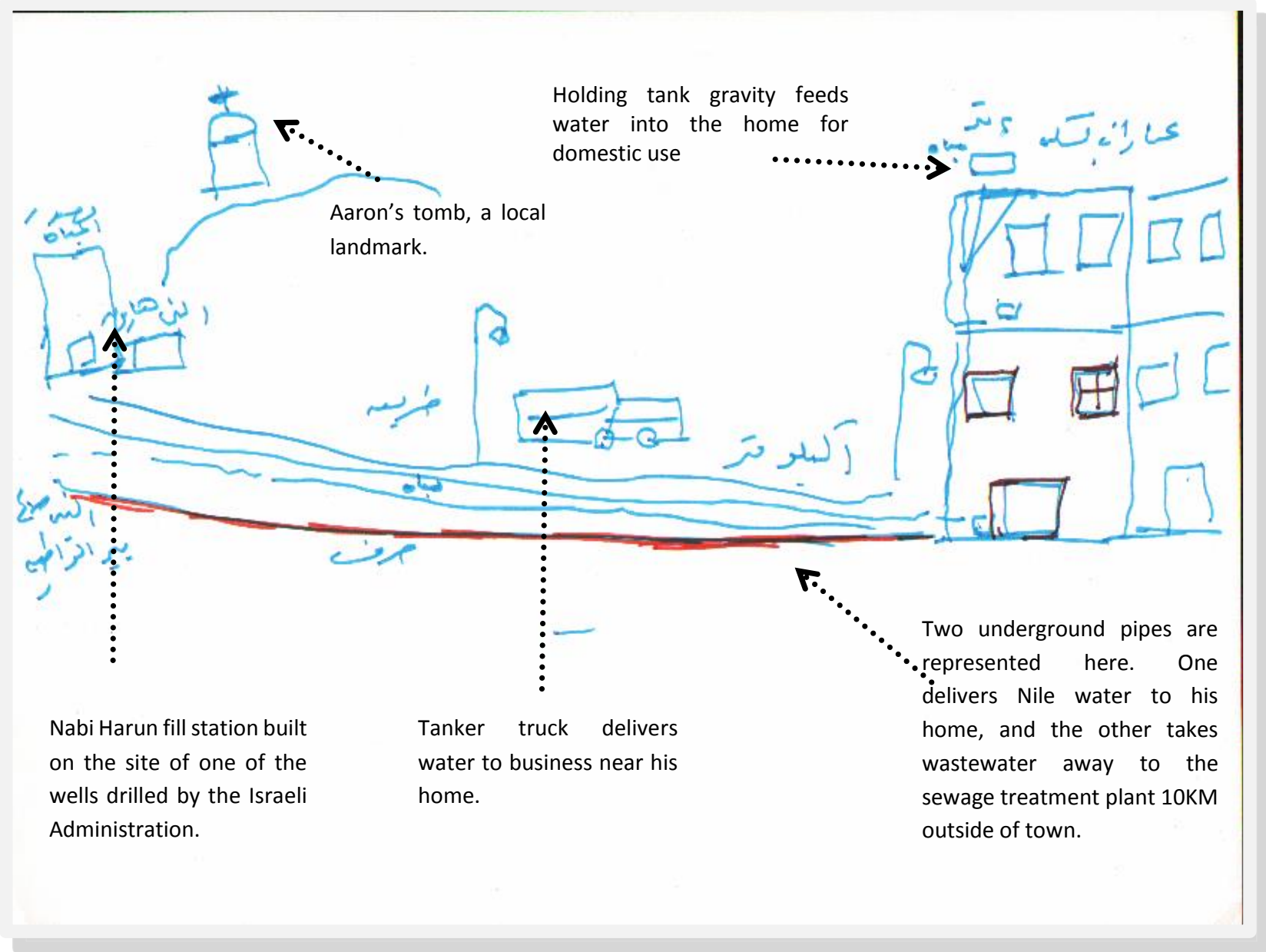

Map 2 epitomizes the transition toward a modern water culture in St. Katherine in conjunction with the urban development underway there. Unlike the previous map, this drawing shows no knowledge of the hydro-geological realities or bio-physical landscape. Instead it emphasizes the urban landscape by representing buildings, roads, street lamps and cars. The historical and sacred landscape emerges here only as a landmark, drawn for me so that I could situate the pumping station in relation to Aaron's tomb, a place that I as a short-term visitor to St. Katherine would recognize.

The person who drew this map is an Egyptian migrant who has lived in St. Katherine for the past 25 years. He used to live outside the town where he shared one water source from a well 
with all of his neighbors. Today he resides in a two story government owned apartment complex in the center of Katriin. His home has been connected to the central water grid. A line drawn under the road symbolizes the water pipe that delivers Nile water directly to the holding tank on his roof. The red line below it indicates the pipe that channels his sewage in the other direction, toward the water treatment plant outside the city. He receives 4 cubic meters of water every week for L.E.4 that he must share with the apartment below. This is more water than families not connected to the central grid receive every month and is priced at a lower rate. He owns a small restaurant, one of the only businesses in town to serve fish. The retail space he rents is not yet connected to the water grid and still receives water deliveries from a tanker truck. This other major component of modern water in St. Katherine is represented on the map as well, travelling on the main road through town. The truck fills up with water at the fill station on the far left side of the map. This water is more expensive with one cubic meter costing L.E.10. 


\section{3. $\quad$ Map 3}

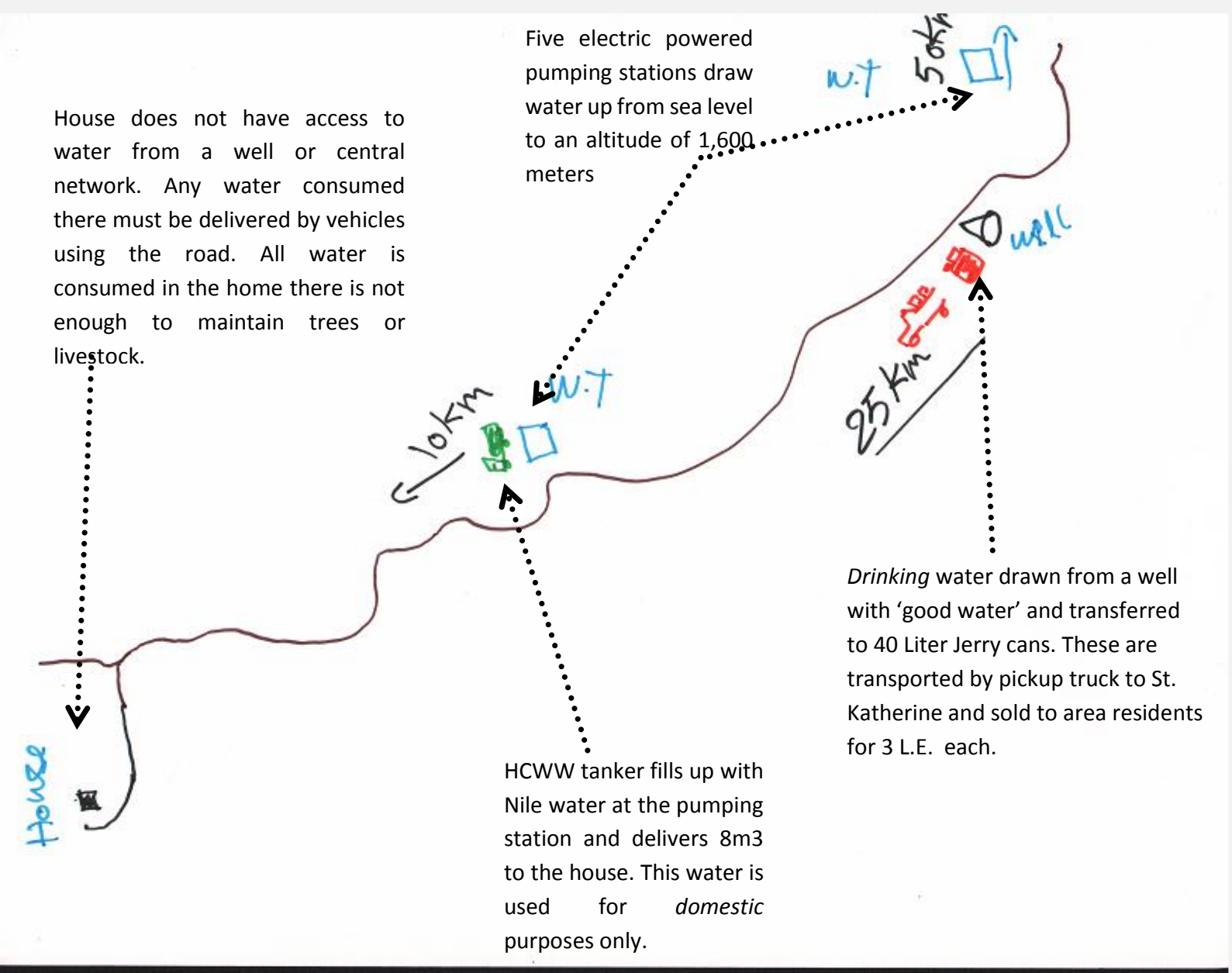

Map 3 is the smallest scale map that was drawn by my participants. The arrow at the top of the map indicates that the participant understands that his domestic water is sourced from beyond the St. Katherine landscape. The main feature represented on the map is a road (brown line), which is a critical part of the infrastructure that provides him with water since he is completely dependent on truck deliveries. This participant is a Bedouin, who was employed as a local project monitor for the SSRDP, the Egyptian development agency that was subcontracted by the E.U. to oversee the funding and construction of the Nile pipeline. This research participant does not have access to his own well, but is still very aware of where his water comes from. For 
this reason, he is in the middle of the transition toward modern water. Even though he is disconnected from his sources, the map he draws demonstrates that he understands where those are, and how they interact with the surrounding landscape (ie. pumping water uphill over large distances). The infrastructure necessary to channel water to his home includes multiple pumping stations, two different vehicles and an asphalt road. The only material component that he owns in this network is the holding tank to which his water is delivered beside his home.

Although he is knowledgeable about his water sources, it is important to note that unlike Map 1, this map is two dimensional. His household is completely dependent on outside water deliveries for all of its consumption needs. He is aware of the distances over which the water he consumes must travel to reach his home, and emphasizes that domestic and drinking water are sourced from two different locations. $8 \mathrm{~m}^{3}$ of Nile water are delivered to his home by an HWCC tanker truck every 25 days. These 8,000 liters provide approximately 10 - 15 liters/person/day, not enough to maintain any animals. His family owns a few orchards in the high mountains, but he is tied to a wage in the town and only visits these places on occasion. He pays 10 L.E. for his domestic water delivery at HWCC company offices who in turn receives a government subsidy of L.E. 150. His domestic water is not always delivered on a timely basis and he often runs out. His drinking water is sourced from another location, from a deep well 25 kilometers away. The household uses 40 liters of this water every 3 days or so for drinking and cooking. Sometimes he goes to the well himself to fill up, but also finds it more convenient to pay for the L.E. 3 delivery service. 
4. Map 4

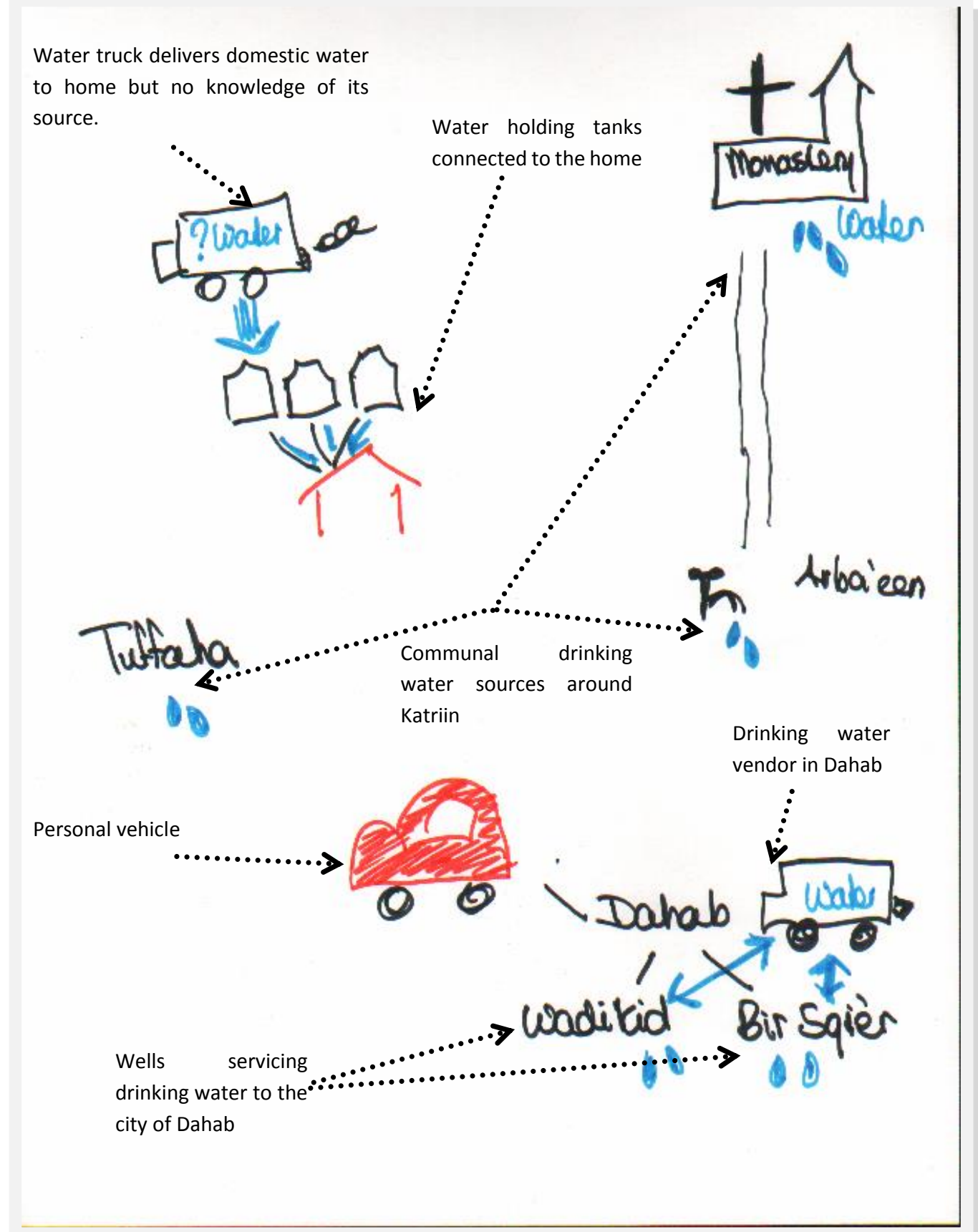

Map 4 provides a stark contrast to all the previous ones. It was drawn by a European expatriate living in Katriin full time. Water for her domestic use is provided by her landlord and delivered by tanker truck but she is not sure where that water is sourced from, whether it is from 
the Nile or groundwater. The cost of this water is included in her rent and so it is not of great importance for her to know. She owns a car, which makes it easy for her to transport drinking water to her house. Because she often traveled to the city of $\mathrm{Dahab}^{24}$ for her work she buys drinking water from local water sellers. She knows the sources of this water, which is drawn from two different wells outside of Dahab and services the drinking water needs of the entire town. Many people there have become water resellers, since there are not as many local drinking water sources as in Katriin. She also sources her drinking water around Katriin but does not like waiting in line at the communal wells as it can take a very long time to get water, especially in the summer months when the water pressure is low. Although not reflected in this drawing, the participant also buys bottled water especially since she had some recent stomach problems which she attributes to an amoeba in some of the water she drank.

What is especially interesting about this map is that it is drawn by a participant who is coming from a fully-fledged modern water culture into one that is still in transition. The map provides a glimpse into the water culture that visitors and short-term residents bring to the area, concerned especially with conveniently accessing clean drinking water and less so with the actual source of the water used for domestic purposes. Emphasis is on the multiple different sources and the fact that she has to drive to get them. It also reflects the privilege that expatriates enjoy within the waterscape. Landlords take care of the hassle of provisioning domestic water and there are multiple drinking water sources to pull from, in her case even ones far beyond the St. Katherine landscape. It is also interesting to note that there is nothing indicating water flows through a physical or urban landscape on this map. Droplets of water 'appear' as though they are not connected to any other hydrologic or hydro-social processes.

\footnotetext{
${ }^{24}$ Dahab is $100 \mathrm{~km}$ East of St. Katherine.
} 


\section{Map difference as data}

The mental mapping exercises that I performed in conjunction with my formal interviews provided me with a wealth of data, particularly as it relates to the hydro-cultural transformations underway in St. Katherine. While I have only discussed four of them here, many others have served to frame my understanding of St. Katherine's evolving waterscape and the way that it is perceived by different stakeholders there. For example, a fifth one was also used in chapter 4 to demonstrate that water was increasingly connected to financial transactions.

Part of the value of asking research participants for mental maps is that it shows differences between responses along with incongruities incongruities and gaps that can be analyzed together to make sense of broader research questions. The maps analyzed here were all drawn in response to the second map-making exercise which pertained specifically to the means by which water reached participants homes from its source. The first exercise, which asked participants to draw their homes and the way water flows through it, were more consistent with one another (see chapter 2 for examples) because most residents in Katriin today live in the same type of basic housing structure. The stark contrast between these maps presented above, in response to sourcing strategies are a testament to the fact that St. Katherine is undergoing serious hydro-cultural transformations, none of which are complete or static.

\section{E. Colliding water cultures}

Culture is constantly being made and remade through contestations over material realities within the landscape (Mitchell, 1996) and hydro-cultures emerge out of the different ideas that people hold about water in a given place (Baviskar, 2007; Linton, 2010). The participants' mental maps show how water in St. Katherine is undergoing major transformations and reveals the extent to which, over 
the span of just one generation, a significant shift toward modern water has occurred. As Katriin residents become disconnected from their sources, three dimensional understandings of water flows through the landscape are being replaced with two dimensional ones. Modern water has facilitated and encouraged socio-economic change, but it has also produced the perception of scarcity. Growth based development initiatives and the urbanization of water associated with them are colliding with water management practices that provided sustenance to people in this landscape for centuries, albeit in a more frugal capacity.

The collision of these water cultures, has produced both contestation and cooperation among different social actors in Katriin. Through the six vignettes based on the data gathered through both interviews and participant observation, I now highlight the way people are adapting to the new water culture being imposed by the socio-economic changes underway in St. Katherine. These vignettes are descriptive accounts based mostly on individual interviews but reflect what I perceive to be some of the major ideologies in the transition from a pre-modern to modern hydro-culture.

\section{The entitled}

The monks currently living in the St. Catherine monastery remain powerful social actors, even though their political influence has waned with the advance of state administrative control. After all, the capital flowing to this place is supporting visitors to the sacred landscape that their predecessors had such an important role producing. The monastery owns the most property in the area, cordoning off its largest estates with walls as high as three meters. These are set in water rich locations, and have produced olive oil for sale, grapes for wine, and food for "token self-sufficiency" 25 , since most of their food is now sourced from Cairo. There are two wells within the monastery grounds and one in the large garden outside of it. In the 1970s the Israeli administration diverted a stream flowing through a valley nearby (Wadi Arbaeein) to a large reservoir located above their library. This water was then

\footnotetext{
${ }^{25}$ Ethnographic notes: June $10^{\text {th }}, 2012$.
} 
gravity fed into the kitchen and bathrooms for domestic use. An organization concerned over the safety of the manuscripts housed under the water tank built a new one outside the cloister walls with an electric pumping station now supplying water within the grounds. There is a spigot there open to the public from which townsfolk come to draw drinking water. One of the monks was "concerned at how much they take at times", but "had not been into the city center in years"26 although he travels internationally to attend conferences about his work. Four years ago the monastery drilled a deep 270m well to tap water in Wadi Arbaeein just above the city of Katriin. Pumped up and fed through a $4 \mathrm{~km}$ network of pipes, high pressure mountain water now flows into the 150 bedroom guesthouse and gardens adjacent to the monastery.

\section{The hegemon}

The St. Katherine tourist village in Wadi Raha was the first of many hotels to spring up in the large valley across from the monastery. Built on the site of former Egyptian President Anwar Sadat's resort compound, its 164 rooms offer four star accommodations. Inaugurated in 1985 by Hosni Mubarak, his ministers of construction and tourism along with the governor of South Sinai, it has housed multiple world leaders and is a symbol of Egyptian commercial interests in St. Katherine. This hotel caters to tourists who are seeking the highest level of comfort available during their stay. The 68,000 liters of water that makes this possible on a daily basis is trucked in by a Bedouin who delivers it from a deep well on his own property and into the three tanks on hotel grounds. The Plaza Hotel next door has a water tower for all its storage needs. Not counting the times it changes the water in its swimming pool, this facility consumes on average 51,000 liters a day. A curt interview with its manager revealed that water was contracted in the same way: "The hotel supports a Bedouin family by buying water from them" 27 . Upon confirmation of this pattern, I was surprised that Nile water, which had been framed by the SSRDP commissioned report as being needed to support the tourism sector,

\footnotetext{
26 Ibid

${ }^{27}$ Ethonographic Notes: June 30 ${ }^{\text {th }}, 2012$
} 
was not in fact used in any of the hotels in St. Katherine. "Nile water is not for the hotels, it's for the Bedouin homes" 28 .

\section{The opportunists}

Bedouin accommodations can be found across Katriin as well. Some have connected with 'responsible tour agents' who provide a steady flow of visitors, while others are still trying to make something out of the properties that they own within the city. I spoke with the owner of one of the more established hostels in town to understand how a transition to water usage in tourism was being perceived. The amount of water delivered to his facility was much smaller than the mainstream hotels, averaging 17,000 liters a week. Nile water was delivered by truck, the cost of it negotiated down from the normally unsubsidized rate for businesses. Significant investments have gone into upgrading the facilities, including the planting of trees, a 'western style kitchen' that offers a varied menu to guests, new common bathrooms and water heaters, suites with balcony and private bathrooms. If there is a large influx of guests and the two holding tanks run out of water, a backup well is used for the hour interval needed for an emergency delivery. Cleaner and better tasting water used for tea and cooking is brought from a well 40km away where he "has a deal with [his] cousin who brings [him] the

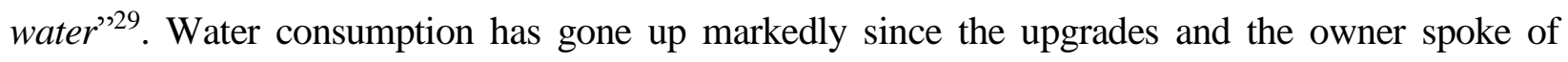
building more awareness among his guests: "I want to advise people that we are here, we are not on the Nile"30

\section{The indignant}

St. Katherine hosts over forty varieties of plant species that are endemic and unique to the area. Due to the impact of a denser population, many are on the verge of extinction. One of my research participants received a development grant to conserve these rare specimens. In the two greenhouses

\footnotetext{
28 Ibid

${ }^{29}$ Interview \#9: June $15^{\text {th }}, 2012$

${ }^{30}$ Interview \#9: June $15^{\text {th }}, 2012$
} 
built for the project, he grows "medicinal herbs" along with a variety of saplings traditionally found in Jebelaya orchards. He is proud of his Bedouin knowledge and its fusion with the modern garden space he has built in town, where he hopes to create a hub for environmental tourism and produce oils, soaps, herbal teas and other products for sale. He depends on Nile water deliveries for his home and the 2,000 liters that his hand dug well provides on a daily basis. The drip irrigation system consumes 60,000 liters of water a month just about what his well provides. He is very angry at the monks for "taking all the water" 31 from their deep well and pumping station located just above his garden. "The hotels are using a lot of water, but at least they are buying this water, they are making business for the people, for the Bedouin. [...] But the monastery he is taking all the good drinking water and giving it to the tourists, and the tourists buy Baraka" 3233 . Due to dropping water levels he is forced to dig an extra meter every year to access the water on which his business relies, a cost that grows with the depth. When I probed about money, he said: "If I have water, I don't need money, I can make everything I need"34 and went on to explain how his garden and goats would provide for all his material needs.

\section{The perplexed}

A ninety minute walk up from Katriin's center, a man in his sixties lives in his mountain orchard year round. His relative proximity to town has seen his space become one of the primary overnight stays on the trekking circuit. He offers a rudimentary yet comfortable accommodation for 10L.E./person (\$2) per night. A foreign charity providing service based eco-tours sent a team to construct a dam nearby. It collects rainwater and provides a steady source for the garden while recharging the aquifer below it. ${ }^{35}$ Unlike the traditional agem this dam is built with cement, and thus

\footnotetext{
${ }^{31}$ Interview \#10 June $17^{\text {th }}, 2012$

32 Ibid

${ }^{33}$ Baraka is a brand of bottled water owned by Nestlé. Tourists are told not to consume local drinking water due to the possibility of developing gastro-intestinal ailments.

${ }^{34}$ Interview \#10: June $17^{\text {th }}, 2012$

${ }^{35}$ Makhad Trust has been operating in St. Katherine for nearly a decade. According to their website the mission is to "sustain the natural heritage of the people who live in [arid regions] and, while doing so, to appreciate and to learn from their traditional wisdom". The dams are very controversial. Some claim that they serve to recharge the aquifer, while others decry their poor positioning where evaporation is higher than recharge rates.
} 
does not allow water to seep through and continue its course down the valley. While he realizes that the natural fertilizers that rains transport get caught behind the wall, the owner is happy with the dam. This "thousand year structure" 36 has put him in the awkward position of being the brunt of much gossip over the fact that other orchard owners are not receiving this water. He is perplexed by the social changes that he has seen over the course of his lifetime. "There used to be streams flowing through these mountains, and everyone could have a garden." 37 The $100 \mathrm{~kg}$ of apricots that his trees produce used to provide enough cash for him to buy all the staples (rice, lentils, flour, salt) he needed for a year. He does not understand how the cost of food can be rising so fast when his fruit is now worth relatively so little.

\section{The rebel}

One of my research participants did not hold the dominant view that there was a water shortage in St. Katherine. Choosing to remain in his mountain garden full time, he lamented the fact that his kin-folk had settled in town, choosing to adopt what he deemed a strange way of life. "If you want a shower, go to Cairo that is not the Bedouin way" ${ }^{38}$. He spoke of the fact that save monastery wells and a few gardens there was never any water in El Melga prior to the work of Israeli drill rigs boring biir Harun and biir Abu Zaytuna. His garden is productive and a three hour walk from the city center. He welcomes tourists but claims that he does not need their business to survive, that he does not even need the food deliveries from town after I inquired about the canned goods stacked in his rock walled home. "I have six wells here, and I am digging a seventh. People used to travel two days by camel at times to get water. And they say 'there is no water" 39 . He explained that dry times like these had always been opportunities for people to maintain their existing wells, dig them deeper and explore other sites from which to tap the aquifer. This 63 year old elder claims his people have become lazy, that they no longer

\footnotetext{
${ }^{36}$ Interview \#13: June $29^{\text {th }}, 2012$

${ }^{37}$ Ethnographic notes: June $11^{\text {th }}, 2012$

${ }^{38}$ Ethnographic notes: July $2^{\text {nd }}, 2012$

${ }^{39}$ Ethnographic Notes: July, $2^{\text {nd }} 2012$
} 
want to dig wells and live like Bedouin because they are attracted to "cars, televisions and who knows what else?"40 When prompted to speak about the Nile water flowing through town he said: "But this is not water we are talking about, it's oil. It won't work" ${ }^{41}$ He does not believe the town of Katriin is sustainable and suspects people there will start leaving soon enough to return to a way of life more adapted to the physical realities of their surroundings.

\section{F. Summary}

Development 'experts' reinforce the idea that transitions from pre-modern to modern water cultures are straightforward linear processes, so long as enough funding is allocated to infrastructure improvements to that end. The six vignettes and four mental maps discussed above disprove that notion, demonstrating instead that the social aspects of water, imbedded over centuries of adaptation to the bio-physical realities of a landscape, are not easily brushed aside. Each of the social actors under discussion here represent a broad spectrum of views that St. Katherine residents hold about the waters flowing through their landscape. Taken together, they demonstrate that hydro-cultures there are in fact changing, but that this change is being contested, that it is far from following a pre-determined trajectory nor is it complete. The inconsistency between these different perspectives is also telling of the effect that forty years of economic development interventions have had on this community. All of these subjects live in the same place, inhabit the same arid landscape with all of the bio-physical limitations that this entails. A common sense understanding of resource use is being confronted with the idea that water should be channeled to support a particular type of economic activity and urban growth. A once much

40 Ibid

41 Ibid 
more homogeneous understanding of water in St. Katherine has been fractured into multiple parts, each break reinforcing the notion that water is insufficient there.

Water is not scarce in St. Katherine, in fact, due to development interventions over the past 40 years, there is more water put toward production there than ever before. I asked one of the engineers involved in Nile pipeline project why the Egyptian government and European Union would go to so much trouble bringing water to a small frontier community, especially since the cost of the project equated to an average yearly wage for every one of St. Katherine's 6,000 residents. He answered: "Look around you, there is no water here! We need to bring more water, or how will the people survive? What we are pumping from the Nile to here it is not much, it is less than what evaporates off the river in a single day. Really it is not much, but it can make a difference here." 42 While the Nile might have water to spare channeling it to St. Katherine will certainly not reduce its evaporation rate. His answer embodies the incongruities at the heart of modern water discourse. Development planners match the perceived abundance of water flowing through one place to the perception of water scarcity in another. Both abundance and scarcity discourses are produced by a set of 'experts' who have the power and influence to convince people that it is so (Mitchell, 2003; Alatout, 2009). Nile water is not the only source that has come under the gaze of development planners interested in opening Katriin to further consumption. Hydrologists have studied the quantity and quality of water available in the aquifer below St. Katherine (El Sayed et. al, 2012; Khalil, 2009; Tantawi et. al, 1995), and GIS technicians have sought to "measure groundwater potentiality" for future development initiatives in the area. (Ellewa and Qaddah, 2011). But these scientific undertakings all open with talking points that assume scarcity. Water uses in St. Katherine are never questioned, and the social effects of

\footnotetext{
${ }^{42}$ Ethnographic notes: September $7^{\text {th }}, 2008$.
} 
introducing water regimes that are not adapted to the biophysical realities of the landscape are not explored by this development discourse.

I have argued that a particular way of thinking about water, as a resource that can be controlled, managed and divorced from the real and everyday effects that it has on societal change is at the root of the evolving hydro-cultures in St. Katherine. I have demonstrated that the shift toward modern water cultures is problematic for three main reasons. First, it divorces people from the knowledge of their local sources, handing water's management over to 'experts'. Secondly it reinforces existing inequalities over water as cash derived from wages becomes the basis for access. Finally it separates people from fully controlling their means of production.

"Representing water as something devoid of social content - that is, as a part of nature, a natural resource, or commodity - allows nature to be used as the explanation for water scarcity instead of, for example, the lopsided distribution of water services in cities (with poor sections being disproportionately underserviced). Given the antisocial nature of modern water, nature always takes the blame as "the principal 'cause' of water scarcity rather than the particular political economic configurations through which water becomes urbanized [or otherwise made available to people]. Recognition of water's social nature, by contrast, draws critical attention to the socio-economic circumstances that occasion every instance of water scarcity" (Linton, 2010, p.70)

I draw on such a lengthy quote by Jamie Linton to conclude this chapter because my research in St. Katherine provides a valuable case study to his theoretical frame. His work on the idea of modern water is a critical frontier in water research. For the past two hundred years a particular western, modernist and scientific way of thinking about water has undergirded the development of capitalist driven growth based economies across the world. This ideology must continue to be explored and challenged, to understand and check the vicious cycle of water scarcity production and modernist hydrological fixes to it. 


\section{Chapter 6: Summary, Discussions and Next Steps}

If you ask me what is the object of my work, the object of the work is to always reproduce the concrete in thought-not to generate another good theory, but to give a better-theorized account of concrete historical reality. This is not an antitheoretical stance. I need theory in order to do this. But the goal is to understand the situation you started out with better than before. - Stuart Hall, 1988

\section{A. Summary of Findings}

The goal of this research was to understand water's function in St. Katherine. I found that the introduction of a capitalist tourist economy there through top down and one sided development initiatives is re-ordering social relations and altering hydro-cultures. Tourist consumption of St. Katherine's sacred and historical landscape joins the production of an urban landscape to constitute a spatial fix. Water is a critical resource maintaining this fix, but the physical landscape does not provide enough local water to support the concentration of recently sedenterized Bedouin and Egyptian migrants to Katriin. A discourse on water scarcity has emerged which encourages further capital investments in physical water infrastructure. Rather than question national development goals themselves, nature is presented as a problem that must be solved through further development intervention. These plans do not take into account the viability of pre-modern water systems in support of agro-pastoralist livelihoods, well adapted to the physical landscape. Instead they introduce expensive modern water systems that can only be accessed through financial transactions, reinforcing a dependence on wage based livelihoods for the majority of Katriin residents. The government is now heavily subsidizing water for a population that cannot afford its true cost and social actors who have the financial means to do so are able to secure more water for their own business activities. Water's function in St. Katherine then supports the global status quo of growth based development initiatives.

\section{B. Recent Climactic and Political Developments.}


In January and February of this year the largest precipitation levels in 30 years brought much needed snow and rain to St. Katherine, ensuring a plentiful water supply for the months and years to come. Local residents rejoiced at the prospect of increased water tables as surface water replenishes the area's aquifer. This recent precipitation left significant destruction in its wake. The force of the floods barreling through the drainage basin where Katriin lies carried boulders, rocks and silt damaging buildings, roads and telephone cables. For nine days the town and its residents were cut off from the rest of the country until debris could be cleared to make the road passable to vehicles again. Fuel could not reach the electric power plant, food and water deliveries were halted, thus revealing the dependencies that have emerged since the urban project began in the 1970s. While damages to the town of Katriin itself were limited this time, it lies in the region's largest drainage basin and a larger flood could have disastrous consequences.

The flood is not the only event that exposed the hazards and vulnerabilities intrinsic to the production of St. Katherine's modern landscape. In early 2011 a key component of the balance maintaining the status quo there was ruptured. A political power vacuum was felt in the region during the transition between the Mubarak and Morsi regimes. Political unrest in Egypt resulted in fewer tour agents programming trips to the area. ${ }^{43}$ Global news snippets originating from the Sinai of sporadic kidnappings, rocket launches, aerial bombings and remilitarization only reinforced the idea that Katriin was a dangerous place to be. Without tourists climbing Mt. Sinai every night, the cash flowing through this place has dried up. Furthermore, Egypt as a whole, is currently experiencing a major diesel shortage because government does not have enough foreign reserves to purchase and subsidize fuel at the rates it had been for so long. ${ }^{44}$ The fuel shortage is

\footnotetext{
${ }^{43}$ http://english.ahram.org.eg/NewsContent/3/12/63596/Business/Economy/Egyptian-tourism-sector-ravaged-bypolitical-unres.aspx

${ }^{44}$ http://www.egyptindependent.com/news/diesel-shortages-continue-impact-becomes-broader
} 
making the pumps that are so crucial to maintaining St. Katherine's modern water infrastructure much more expensive to operate. Whether it be rains or politics the story of water in St. Katherine is continually evolving.

\section{New realities in context}

The paradox of these nearly synchronous climactic and political events, is that water is now readily available in St. Katherine but tourists are not. The rearticulation of the hydro-social cycle there has fully exposed the dialectic between socio-economic and hydro-cultural relations. As the inputs required to access water and the habits surrounding its daily consumption have morphed to fit a wage-based urban economy, it will be important to understand how the now abundant water available in the physical landscape actually translates to the material reality of people's everyday lives. Water must still be transported to every single home that does not have access to their own well, which is $99 \%$ of the population. This water must still be paid for in cash as must food (the largest expense for the majority of households).

As water began to serve its new function drawing in large amounts of short-term visitors to this landscape, its flow was redirected toward the urban center that services it. Most residents became completely dependent on monthly water deliveries, and disconnected from traditional sources that supported previous semi-nomadic livelihoods. Today, the significance of this transition is beginning to be revealed. Thanks to recent rains, spring is in full bloom and pasturage is readily available for sheep and goats to graze on, but as I have discussed (chapter 4), many gave up their herds to move into town. Surface streams now flow past orchards dotting the landscape, but most of these have not been tended in decades and will take time and energy to be fully 
productive again. Meanwhile many tourist guides in the rotating dour system ${ }^{45}$ now go months without access to the wages that their visiting clients provide. The decline of tourist arrivals means that Jebelaya Bedouin are at serious risk of not being able to satisfy their subsistence needs.

Recent events in Egypt, Sinai and St. Katherine in particular again clearly support David Harvey's theory of the spatial fix.

While [the] disparate meanings of "to fix" appear contradictory, they are all internally related by the idea that something (a thing, a problem, a craving) can be pinned down and secured. In my own use of the term, the contradictory meanings can be played out to reveal something important about the geographical dynamics of capitalism and the crisis tendencies that attach thereto. (Harvey, 2001, p.25)

The discursive production of water scarcity (chapter 5) has given way to the political production of tourist scarcity, a 'problem' which is proving more difficult to 'fix' than it was to create. Spatial 'fixes' depend on expensive infrastructural projects but these are almost always within the realm of possibility as long as enough capital can be channeled in support of it. The production of water scarcity, while problematic can always be 'fixed' through further investment into pipes, pumps and treatment plants. Compelling tourist arrivals to continue flowing through the St. Katherine landscape is much more difficult. Tourism as an industry is caught up in complex macro political-economic processes and it will be difficult to 'fix' the perception that St. Katherine is an unattractive or dangerous place to spend a vacation. Mobile capital has fled, devaluing the immobile capital now in place there.

The disarticulation of the tourism industry, in conjunction with the recent rains, has led some Bedouin out of urban settlements and back to the land. Some families have begun to return to the core occupations that have supported people in this area for a long time. The St. Katherine

\footnotetext{
${ }^{45}$ The dour system evolved from the daily bread rations that the monastery provided to each of the four Jebelaya clans. Every day 1 family representative was permitted to call on the monastery in turn. A semblance of this system remains in contemporary St. Katherine, but is related to providing even access guiding opportunities, especially for tourists climbing Mt. Sinai.
} 
landscape is again dotted with mobile tent settlements and small flocks of goats and sheep. It remains to be seen whether tourists will begin booking trips back to Egypt in the numbers that they did prior to the 2011 political upheavals any time soon. As Hazbun (2008) has noted, the industry has proven to be very resilient in the Middle East despite the repeated negative political press that the region receives. The World Tourism Organization continues to predict steady growth in the sector globally (WTO, 2012). But this begs the question, is the growth paradigm a good one to be reinforcing?

\section{Dissemination of the Research}

This research is of course never final. Just as I am building on the thoughts of others, I hope that some might find the analysis in this thesis helpful toward generating their own. I plan to stay connected to the St. Katherine community as much as possible. Social networking has made this a reality to a certain degree, and I remain in online conversations with a number of my friends there who have told me about the recent changes discussed above. While I do not have the financial means nor institutional backing to return to the area any time soon, I plan to work there again. I have already begun to explore the possibility for collaborative partnerships with service learning organizations to build a program which would incorporate critical development theory and practical political action in St. Katherine.

In the more immediate term, I envision making this project relevant by producing a qualitative and interactive map of St. Katherine's hydro-social cycle as a "tangible product" of my research. It will tell the story of the St. Katherine's development through water's physical and social flows there using Google Earth. The files will be shared online for anyone to download and interact with, and a video presentation that I narrate will be uploaded to discussion boards and 
travel blogs to try and help those visiting St. Katherine understand some of the impacts that their presence there is having. This qualitative map could also be used in future research projects in St. Katherine.

E. Broader impact of the research.

\section{Toward a paradigm of de-growth}

I have provided a case study framed within the wider critical development literature to reinforce the idea that the modernist tendency to promote 'progress' through economic growth is problematic. Development planners too often dismiss local knowledge and production practices that are well adapted to the limitations and abundances of bio-physical ecologies (Scott, 1995, Escobar, 1996; Rahmena and Bawtree, 1997; Peet and Hartwick, 2009). No landscape can contain endless growth and development interventions in one place are always dependent on the exploitation of people and resources in others (Swyngedouw 2004 (a); Mitchell, 1996). The current disarticulation of the tourism industry in St. Katherine, while perceived by most as a critical setback, is I believe an opportunity to understand and theorize the emerging field of dedevelopment and de-growth (Fournier, 2008; Kallis, 2011; Whitehead, 2013). Transitioning toward a development paradigm that is not based on the growth imperative of capitalist driven modes of production, one much more adapted to ecological limitations within each landscape, is paramount if we are to avoid the serious social, political and economic crises that growth economies constantly engender at multiple scales.

The Makhad Trust is an NGO working with Bedouin in South Sinai to support a transition away from dependence on tourism. Their community development initiatives are funding small scale initiatives aimed at restoring gardens and wells and preparing for the possibility of further 
political unrest or drought in the area. While there are certain tensions surrounding their work, the outcomes and possibilities of these smaller scale initiatives present an opportunity for further research. Their ideas come in stark contrast to the Nahda Project unveiled by president Morsi last year. In a speech in which he proposed that the Egyptian government invest L.E.20 billion (\$3.3 billion) into the 'reconstruction' of Sinai he said: "We realize the importance of water and minerals of Sinai, and will work on the development of all fields here." 46

A large portion of these development funds will no doubt be channeled toward massive hydro developments, reinforcing the problems that I have exposed in St. Katherine at wider scales. Most of the research on the effect of development initiatives in Katriin has focused on the marginalization of Bedouin communities due to the uneven distribution of benefits derived from economic growth and disparities in development funding distribution. (Gilbert, 2011; Sarnowski, 2010). While important in their own right, these studies fail to tackle some deeper issues. Rather than question and confront the idea of growth, their work argues that Bedouin should be allowed to participate in the growth process more fully. My thesis opens up a space for a critique of the development process in St. Katherine itself, providing unique insights into the way economic growth has produced scarcity there. Future scholars should explore the ways that Katriin residents are now adapting to capital flight, especially in light of the opportunities it presents for reorienting economies toward emerging theories on de-growth.

\section{Implications for Future Development Critique}

My work in St. Katherine could be applied to any landscape in which water's productive capacities are being put to the service of capitalist modes of production. My methodology is not limited to the Sinai, nor Egypt, North Africa or even arid regions more generally. This study could

\footnotetext{
${ }^{46}$ http://www.ikhwanweb.com/article.php?id=29937
} 
be replicated in a water rich area such as West Virginia, and I believe it should be. Morgantown, $\mathrm{WV}$, the city in which I have spent the past two years refining my understanding of hydro-social processes, would be an ideal place to explore ways in which water in this landscape has been coopted into through capitalist driven growth. Socio-economic relations have undergone significant transformations here in the past century (Gaventa, 1982). The landscape has been altered significantly, most apparently via surface mining and the mountain top removal techniques the coal industry employs. Excess rock and soil laden with mining byproducts are dumped in "valley fills". This modifies stream flows and leads to the toxification of watersheds. While the transition toward modern water that mining and other has been different and is much more complete here, hydro-cultural transformations are never final. As the natural gas industry uses vast amounts of water to break apart rock in the Marcellus shale formation, it is imbuing groundwater with a mix of chemicals that are deteriorating public water supplies. Here, as in so many places, water scarcity is being produced through unfettered 'development'.

\section{F. Concluding Thoughts}

My experience living in St. Katherine for 15 months was the impetus behind this research project. Working to further development policies planned in Cairo but incongruent with what I was witnessing on the ground, led me to question the reasoning behind large scale development interventions. The Nile pipeline project was of special interest to me, not only because it appeared grossly irrational, but also because it raised important questions about the role that water played in this landscape. As I struggled through the difficulties of learning Arabic, a large portion of my vocabulary was developed via conversations I was having with people about their everyday interactions with water. Maya was one of the first words that I learned, and as my knowledge of 
the language progressed, I learned that it had not been raining as much as before, and that people no longer used water like they used to.

My own interactions with water in Katriin were unlike anything I had previously experienced. Having been raised in societies where the transition toward modern water sourcing strategies was seemingly complete, I was confronted with very different ways of accessing and using water. I left St. Katherine in December 2008 with a completely different notion of the social dimensions of water, and a desire to explore how society and water co-constitute each other and change together. This thesis is the conclusion, but not the end of a long thought process toward that end. Theories about the world frame our thinking, and it was a privilege to spend the past two years reading through countless ideas about the social constructions and material realities that shape our perceptions and daily routines. My bibliography has opened a slew of new viewpoints and ways of thinking to be sure, but I have worked to channel all of these often disparate ideas into one that is my own. This project has transformed my own politics. 


\section{BIBLIOGRAPHY}

Alatout, Samer. 2009. Bringing Abundance into Environmental Politics: Constructing a Zionist Network of Water Abundance, Immigration, and Colonization. Social Studies of Science. Vol. 39, No.3, pp. 36-394

Ali, Dina. 1998. Case Study of Development of the Peripheral Coastal Area of South Sinai in Relation to its Bedouin Community. Master's Thesis in Urban Planning: Virginia Polytechnic Institute and State University

Allan, J. A. 2002. The Middle East Water Question: Hydropolitics and the Global Economy. London: I.B. Tauris.

Baca, Miguel. 2007. Situational Analysis of the Current Markets and Marketing Strategies for Tourism in South Sinai. P.A. Consulting Group. EuropeAID/ 122290/D/SV/EG.

Bailly, Antoine. 1987. Des images mentales de Fribourg; Trois images pour deux groupes culturels. Cahier de l'institut de géographie de Fribourg. Vol.5 pp. 99-106

Bakker, Karen. 2003. Archipelagos and networks: urbanization and water privatization in the South. The Geographical Journal. Vol. 169, No. 4, pp.328-341

2005. Neoliberalizing nature? Market environmentalism in water supply in England and Wales. Annals of the Association of American Geographers. Vol. 95, No. 3. pp. 542 565.

-------. 2007. The 'commons' versus the 'commodity': Alter-globalization, privatization, and the human right to water in the global South'. Antipode. Vol. 39, No.3, pp. $430-455$.

Baviskar, Amita. 2007. Waterscapes: The cultural politics of a natural resource. Permanent Black: Ranikhet, India.

Bellorini, T. and Hoade, E. Trans. 1948. Visit to the Holy Places of Egypt, Sinai, Palestine and Syria in 1384 by Frescobaldi, Gucci and Sigoli. Franciscan Press: Jerusalem.

Britton, Stephen. 1991. Tourism, capial and place: towards a critical geography of tourism. Environment and Planning D. Society \& space. Vol.9, No.4, pp. 451-478.

Cole, Donald. 2003. Where have the Bedouin gone. Anthropological Quarterly. Vol. 76, No. 2, pp. $237-267$.

Dames and Moore. 1985. Sinai Development Study, Phase 1, Final Report. Advisory Committee for Reconstruction: Ministry of Development: Arab Republic of Egypt.

Duncan, J.S. and Duncan, N.G. 1988. (Re)-reading the landscape. Environment and Planning D: Society and Space. Vol 6, pp. 117-126 
Ellewa, H. and Qaddah, A. 2011. Potentiality for ground water mapping in the Sinai Peninsula, Egypt, using remote sensing and GIS based modeling. Hydrogeology Journal. Vol. 19, pp. 613-628.

Escobar, Arturo. 1995. Encountering Development: The Making and Unmaking of the Third World. Princeton University Press

Escobar, Arturo. 2001. "Culture Sits in Places: Reflections on Globalism and Subaltern Strategies of Localization." Political Geography. 20: 139-74.

Essex et al. 2004. Tourism development in Mallorca: Is water supply a constraint? Journal of sustainable tourism. Vol. 12, No. 1, pp. 4-28.

Evans, M. 1988. Participant Observation: The researcher as research tool. In J. eyles and D.M. Smith, eds, Qualitative Methods in Human Geography. Cambridge: Polity Press.

Fletcher, Robert. 2009. Ecotourism discourse: Challenging the stakeholders theory. Journal of Ecotourism. Vol 8, No. 3, pp. 269-285.

-------. 2011. Sustaining tourism, sustaining capitalism? The tourism industry's role in global capitalist expansion. Tourism Geographies: An international journal of tourism space, place and environment. Vol.13, No.3, pp.443-461.

Fournier, V. 2008. Escaping from the economy: the politics of degrowth. International Journal of Sociology and Social Policy Vol. 28, No.11/12, pp. 528-545

Freundschuh, S \& Kitchin, R. 2000. Cognitive Mapping: Past, Present and Future (Frontiers of Cognotive Science). Routledge.

Gaventa, John. 1982. Power and Powerlessness: Quiescence and Rebellion in an Appalachian Valley. University of Illinois Press.

Gilbert Hillary. 2011. This is not our life; it's just a copy of other people's: Bedu and the price of 'development' in South Sinai. Nomadic Peoples. Vol 15. No.2 pp. 7-32

Glassner, Martin Ira. 1974. The Bedouin of Southern Sinai under Israeli Administration. Geographical Review, Vol. 64, No. 1, pp. 31-60

Gleick, P.H. 2011. The World's Water Vol 7: The Biennial Report on Freshwater Resources. Island Press

Grainger, John and Gilbert, Francis. 2008. Around the Sacred Mountain: the St. Katherine Protectorate in South Sinai, Egypt. Eds: Mallarach, Josep-Maria. Protected Landscapes and Cultural and Spiritual Values. IUCS, GTZ and Obra Social de Caixa Catalunya. Kasparek Verlag, Heidelberg. 
Greenwood, Ned. 1997. The Sinai: A physical geography. University of Texas Press: Austin, TX

Harvey, D. 1989. The Condition of Post-Modernity: An inquiry into the Origins of Cultural Change. Wiley- Blackwell

--------. 2001. Globalization and the Spatial Fix. Die Geographische Revue: Zeitschrift für Literatur und Diskussion. Vol. 3, No.2 pp.23-30

-------. 2003. The New Imperialism. Oxford University Press.

Hazbun, Waleed. 2004. Globalisation, Reterritorialisation and the Political Economy of Tourism Development in the Middle East. Geopolitics, Vol.9, No.2 (Summer 2004) pp.310-341

Hazbun, Waleed. 2008. Beaches, Ruins, Resorts: The Politics of Tourism in the Arab World. University of Minnesota Press.

Hesham et. al. 2003. Potential contamination of groundwater in the World Heritage Site of the St. Katherine Protectorate, Egypt. Egyptian Journal of Biology, Vol 5. pp. 1-9

Hobbs, Joseph. 1992. Sacred Space and Touristic Development At Jebel Musa (Mt Sinai), Egypt. Journal of Cultural Geography. Vol.12, No.2, pp. 99-113.

-------. 1995. Mount Sinai. University of Texas Press: Austin, TX.

-------. 1996. Speaking with People in Egypt's St. Katherine National Park. Geographical Review, Vol. 86, No.1, pp. 1-21

Hoskins, Franklin. 1909. The route over which Moses Led the Children of Israel out of Egypt. National Geographic Magazine. Vol. 20, No. 12, pp. 1011-1038

Khalaf, Sulayman. 1990. Settlement of Violence in Bedouin Society. Ethnology. Vol. 29, pp. 225242.

Kitchin, Robert. 1994. Cognitive Maps: What are they and why study them?. Journal of Environmental Psychology. Vol. 14, No.1, pp. 1-19.

Khalil, Mohammed. 2009. Hydrogeophysical Assessment of Wadi El-Sheikh Aquifer, Saint Katherine, South Sinai, Egypt.

Jacobs, Jessica. 2010. Sex, Tourism and the Postcolonial encounter: Landscapes of longing in Egypt. Ashgate.

Johnston, B.R. 2003. An introduction to the Political Ecology of Water. Capitalism, Nature, Socialism. Vol.14, No.3, pp.73-90. 
Kallis, G. 2011. In defense of degrowth. Ecological Economics. Vol. 70, No.5, pp.873-880.

Kaika, Maria. 2003. Constructing Scarcity and Sensationalizing Water Politics: 170 Days that shook Athens. Antipode. Vol.35, No.5, pp. 919-954.

Langbein,Walter B., and William G. Hoyt. 1959.Water facts for the nation's future. New York: Ronald Press.

Lavie, S., \& Young, W. C. 1984. Bedouin in limbo: Egyptian and Israeli development policies in southern Sinai. Antipode, Vol. 16, No. 2, pp. 33-44.

Linton, Jamie. 2008. Is the Hydrologic Cycle Sustainable? A Historical-Geographical Critique of a Modern Concept. Annals of the Association of American Geographers. Vol 98, No.3, pp.630-649.

------. 2010. What is Water?: The History of a Modern Abstraction. UBC Press.

------- 2012. The human right to what? Water, rights, humans and the relation of things. The Right to water: Politics, governance and social struggles. Ed. Sultana \& Loftus. Routledge: New York.

Marston, Sallie. 2000. The Social Construction of Scale. Progress in Human Geography. Vol.24,No.2, pp.219-42.

Marx, Emanuel. 1980. Wage Labor and Tribal Economy of the Bedouin in South Sinai. When Nomads Settle. Ed. Philip Salzman. pp. 111-123. New York: JF Bergin.

------.. 2008. Hashish Smuggling by Bedouin in South Sinai. Organized Crime: Culture, Markets and Policies, 29-37.

Marx, K. 1954. Capital Vol. 1. Penguin

McClure, M.L. and Feltoe, C.L., trans. 1920. The Pilgrimage of Etheria. New York: Macmillan.

Milne, S., \& Ateljevic, I. 2001. Tourism, economic development and the global-local nexus: Theory embracing complexity. Tourism Geographies: An international journal of space, place and environment. Vol.3, No.4, pp 369-393.

Mitchell, D. 1995. There is no such thing as culture: Towards a reconceptualization of the idea of culture in geography. Transactions of the Institute of British Geographers.

1996. The Lie of the Land. University of Minnesota Press.

-------. 2008. New Axioms for Reading the Landscape: Paying Attention to Political Economy and Social Justice. In: Political Economies of Landscape Change. Eds. Wescoat \& Johnston. Springer. 
Mitchell, T. 2002. The Rule of Experts: Egypt, Technopolitics, Modernity. UC Press.

PA Consulting. 2008. South Sinai Sustainable Tourism Development Plan 2007-2017. Development. London.

Peet, R. and Hartwick, E. 2009. Theories of Development: Contentions, Arguments, Alternatives. Guilford Press

Perevolotsky, A. 1981. Orchard Agriculture in the High Mountains Region of Southern Sinai. Human Ecology. Vol 9, No. 3. Pp. 331-357.

Perevolotsky, A. Perevolotsky, A. Noy-Meir, I. 1989. Environmental Adaptation and Economic Change in Pastoral Mountain Society: The case of the Jebaliyah Bedouin of the Mt. Sinai Region. Mountain Research and Development, Vol. 9, No. 2, pp. 153-164.

Pocock, D.C.D. 1979. The contribution of mental maps in perception studies. Geography. Vol.64, No.4, pp. 279-287

Rabinowitz, D. 1985. Themes in the Economy of the Bedouin of South Sinai in the Nineteenth and Twentieth Centuries. International Journal of Middle East Studies, Vol.17, No.2, pp. 211-228.

Rahnema, M. and Bawtree, V. 1997. The Post-Development Reader. Zed Books.

Sanderson et al. 2007. Participatory cartographies: Reflections from research performances in Fiji and Tanzania. Participatory Action Reserach Approaches and Methods: Connecting People, Participation and Place. Eds. Kindon, Pain \& Kesby. pp. 122-131. Routledge: London.

Sarnowski, Andrea. 2010. The role of indigenous people in National Development Processes: Participation and Marginalization of Indigenous Bedouin in South Sinai Tourism Development. Dissertation: Johannes Gutenberg-Universität, Mainz.

Schmidt, Jeremy. 2011. Scarce or Insecure? The right to water and the ethics of global water governance. The Right to water: Politics, governance and social struggles. Eds. Sultana \& Loftus. Routledge: New York.

Scott, James. 1998. Seeing like a State: How certain schemes to improve the human condition have failed. Yale University.

Schackley, M. 1998. 'A golden calf in sacred space?:The future of St. Katherine's monastery, Mount Sinai'. International Journal of Heritage Studies. Vol. 4 Nos. 3-4. pp. $124-134$.

Smith, Neil. 1990. Uneven Development: Nature, Capital and the Production of Space. Basil Blackwell: Oxford 
Sims, D. and El Miniawy, H. 2003. South Sinai Development Profile. Egyptian Environmental Affairs Agency: SEAM Programme.

Stonich, Susan. 1998. The political ecology of tourism. Annals of Tourism Research. Vol.25, No.1, pp.25-54.

Swyngedouw, Erik. 1997. Neither Global nor Local: 'Glocalization' and the politics of scale. "Spaces of Globalization: Reasserting the Power of the Local. Guilford: New York

-------. 2004(a). Scaled Geographies: Nature, Place and the Politics of Scale. Scale and Geographic Inquiry. Eds.

------2004(b). Social Power and the Urbanization of Water. Oxford University Press.

------- 2006. Circulations and Metabolisms: (Hybrid) Natures and (Cyborg) Cities. Science as Culture. Vol.15, No.2, pp. 105-122.

------. 2009. The political economy and political ecology of the Hydro-Social Cycle. Journal of Contemporary Water Research and Education. No. 142, pp. 56-60.

Smith, Neil. 2004. Scale Bending and the Fate of the National. Scale and Geographic Inquiry: Nature, Society, and Method. Blackwell: Malden, MA

Tantawi et. al, 1998. Hydrochemical and stable isotope study of groundwater in the Saint Catherine-Wadi Feiran area, south Sinai, Egypt. Journal of African Earth Sciences. Vol 26, No. 2, pp. 277-284.

Tuan, Yi-Fu. 1975. Images and mental maps. Annals of the Association of American Geographers. Vol.65, No.2, pp. 205-213.

UNHSP 2003 Water and Sanitation in the World's Cities - Local actions for global goals. Edited by (UN-HABITAT). Earthscan, London

UNWTO. 2009. Tourism Highlights: 2008 Edition (Madrid: UNWTO)

Williams, Raymond. 1977. Marxism and Literature. Oxford University Press

Whitehead, Mark. 2013. Degrowth or Regrowth? Environmental Values. Vol 22, pp. 141-145. 